\title{
Menores extranjeros no acompañados y extutelados. Propuesta de intervención psicopedagógica
}

Elsa Liras Pinto - Universidad de Granada

Recepción: 14.06.2021 | Aceptado: 16.10.2021

Correspondencia a través de ORCID: Elsa Liras

Citar: Liras, E (2021). Menores extranjeros no acom psicopedagógica. REIDOCREA, 10(30), 51-119.
(iD) $0000-0001-6466-1359$

0000-0001-6466-1359

RESUMEN: El presente artículo lleva a cabo una aproximación con los Menores Extranjeros No Acompañados y extutelados, con el fin de examinar y conocer la situación actual que viven, a través de una revisión de la literatura existente y un análisis y diagnóstico de las necesidades a través de las herramientas DAFO y CAME sobre posibles propuestas de intervención. Abordando una problemática social actual como es la delicada situación en la que se encuentran estos jóvenes cuando cumplen la mayoría de edad y comienza la transición a la vida adulta. A través de una metodología de investigación-acción, se plantea como objetivo general el diseño de una propuesta de intervención psicopedagógica dirigida a trabajar la emancipación y la autonomía a través de una mejora del autoconcepto en Menores Extranjeros no Acompañados (16-18) y en jóvenes extutelados (18-25) pertenecientes a la provincia de Granada. Se concluye con que aquellos jóvenes que han tenido una infancia marcada por problemas familiares, sociales o con carencias en sus necesidades básicas pueden ver afectado su autoconcepto e identidad personal, lo que puede condicionar las propuestas de intervención dirigidas a la formación para su autonomía.

Palabra clave: Menores Extranjeros No Acompañados

\section{Unaccompanied and extuted foreign minors. Psychopedagogical intervention proposal}

ABSTRACT: The present document carries out an approach with unaccompanied and ex-ward foreign minors, in order to examine and learn about the current situation they are living. The literature reviewed, the needs of these minors and the diagnosis is made through the DAFO and CAME tools. These tools are also used to organize future intervention proposals. The document also addresses social problems such as the situation of minors when they reach the age of majority and begin adult life. Through the research-action methodology, the design of a psychopedagogical intervention proposal is proposed. This intervention is aimed to work on the emancipation and autonomy of minors. Within this intervention, topics such as self-acceptance in unaccompanied minors (16-18) and in ex-ward youths (18-25) belonging to the province of Granada are addressed. This document ends with those young people who have had a childhood marked by family and social struggel or with deficiencies in their basic needs may see their self-concept and personal identity affected, which may condition the intervention proposals aimed for training for their autonomy.

Keyword: Unaccompanied Foreign Minors

\section{INTRODUCCIÓN}

El presente artículo pretende abordar una problemática que, en la actualidad, sigue existiendo e incrementándose en nuestro país, como es el de los menores extranjeros no acompañados, prestando especial atención al proceso de transición a la vida adulta de estos jóvenes. Las sociedades actuales viven inmersas en una crisis humanitaria de refugiados sin precedentes (Azorín, 2019). El elevado número de menores extranjeros no acompañados, MENA, que actualmente ha llegado al territorio continental europeo está desembocando en una fuerte preocupación por parte de las autoridades nacionales de los países especialmente afectados (Tassinari, 2019). Centrándonos en España, el estudio de Bravo y Santos- González (2017) corrobora que las cifras actuales de menores extranjeros no acompañados tutelados han alcanzado valores realmente alarmantes, en el año 2018 había 13.012 niños y niñas en los sistemas de protección, ello implica una gran subida respecto a los 6.414 registrados en 2017 y los 3.997 en el año 2016 (UNICEF, 2019). Aunque cabe destacar que el número exacto de MENA en España es un dato difícil de estimar dado por la falta de coordinación entre 
comunidades autónomas y la ausencia de rigor en el cálculo de estadísticas (Bravo y SantosGonzález, 2017). Según el estudio de Bravo y Santos- González (2017) este fenómeno migratorio ha supuesto el desarrollo de importantes implicaciones tanto éticas como políticas. En esta línea y como afirma Fuentes (2014), la llegada de menores extranjeros no acompañados al territorio español ha pasado de ser considerado un fenómeno puntual a convertirse en uno de los colectivos de intervención prioritario dentro del sistema de protección en España.

Los menores extranjeros que se encuentran en territorio español tienen derechos establecidos, por la normativa comunitaria y estatal, sobre la protección jurídica de menores, procedentes de países terceros. (Lázaro y Morroy, 2010). La ley de protección jurídica del menor LO/1996 de 15 de enero los define en el artículo 1 como:

Menores de 18 años, nacionales de países terceros, que llegan al territorio español sin ir acompañados de un adulto responsable de ellos, ya sea legalmente o con arreglo a los usos y costumbres, en tanto no se encuentran efectivamente bajo el cuidado de un adulto responsable (LO/1996, art.1).

Como señala Quiroga et al. (2005, citado en Santos- González, 2015), estos jóvenes se encuentran en una situación difícil y frágil, lo que les convierte en personas especialmente vulnerables. Señalando los problemas en la etapa de desarrollo en la que se encuentran y el proceder de otra cultura, además de otras cuestiones legales.

Además, la problemática se incrementa cuando cumplen la mayoría de edad, siguiendo a Ospina (2015), en España este colectivo supone una preocupación ya que los menores disponen de atención y tutelación hasta los 18 años. Una vez cumplen la mayoría de edad, existe gran cantidad de jóvenes que no han conseguido regularizar su situación en el país, incrementando exponencialmente la probabilidad de acometer actividades delictivas como pueden ser los robos entre otros. Estos jóvenes se encuentran por lo tanto en una situación desfavorecida ya que deben integrarse en el país de acogida, en muchos casos de una manera forzosa y rápida, provocando con ellos problemas emocionales y psicológicos, desembocando en conductas disruptivas y carencias afectivas (Díaz, 2017) En relación a la idea de Green y Powers (2007, citado en Santana, Alonso y García, 2016) los jóvenes tutelados se enfrentan a una edad adulta instantánea de manera brusca al salir del sistema de protección. Y dependiendo la forma en la que estos jóvenes afronten la transición al mercado laboral, de los recursos y apoyos y de sus posibilidades y expectativas sobre la transición saldrán o no de la previsible trayectoria excluyente (Parrilla, Gallego y Moriña, 2010). En España, actualmente existen dos regímenes tutelares para la mayoría de edad en Menores Extranjeros No Acompañados: El régimen de la tutela familiar y el régimen de pisos tutelados $\mathrm{O}$ asistidos.

Estos jóvenes no están lo suficientemente preparados para cubrir las necesidades materiales ni psicológicas una vez están fuera del sistema de protección (Arnau, Marzo, Jariot y Sala, 2013, citado en Santana, Alonso y García, 2016). En esta línea Wade (2011 citado en Bravo y Santos- González, 2017), describe importantes carencias en el apoyo prestado a su proceso de transición a la vida adulta, desarrollándose alguna investigación sobre la importancia de su bienestar psicosocial (Manzani y Arnoso, 2014 citado en Bravo y Santos González, 2017).

Además, en esta investigación se tiene en cuenta el autoconcepto, ya que esta constatado en la literatura el impacto emocional que genera la experiencia migratoria en estos menores, destacando en la investigación de Bravo y Santos- González (2017), las necesidades emocionales de esta población, tratándose de un aspecto escasamente abordado en las intervenciones. Resulta evidente que se trata de múltiples retos los que estos menores 
afrontan en su etapa vital (López, Santos, Bravo y del Valle, 2013), y en los cuales se debe diseñar propuestas de intervención para intentar cubrir estas necesidades.

En cuanto a programas esta investigación se centra, en la propuesta por la comunidad autónoma de Andalucía, Programa de Mayoría de Edad para jóvenes tutelados y Extutelados. y en un modelo de intervención "Intervención Socioeducativa de Acogimiento Residencial" con el Programa Umbrella de Bravo y Del Valle (2009), y el programa de Buenas prácticas en la atención a menores inmigrantes en Andalucía (Observatorio de la Infancia en Andalucía, 2012), ambos con el objetivo de facilitar la integración social y laboral en menores extranjeros no acompañados.

Se sigue por lo tanto las conclusiones del estudio de Bravo y Santos- González (2017), donde se afirma que las claves para favorecer la mejora en la intervención son la creación de programas de apoyo a la transición de estos jóvenes atendiendo al malestar emocional que sus experiencias previas han podido ocasionar, esta investigación se centra en la propuesta de una intervención psicopedagógica centrándose en mejorar el autoconcepto positivo con el fin de favorecer la etapa de tránsito a la vida adulta.

En la actualidad, como sociedad occidental, los periodos para la consecución de una autonomía personal de los jóvenes españoles se han ampliado en el tiempo, prolongando el proceso de emancipación de sus familias hasta que se tienen unos niveles suficientes de formación, madurez personal, integración social y profesional y sin dejar atrás la capacidad económica, situándose la edad media de emancipación en España se sitúa en los 29 años (Observatorio de Emancipación, 2020). Cuando los menores no acompañados llegan a la mayoría de edad, además de contar con todas estas dificultades los jóvenes se encuentran con una desprotección al riesgo de exclusión social por carecer de apoyo familiar, institucional. De esta manera los jóvenes extutelados pasan a ocupar un especial interés en la sociedad y una preocupación a la que tiene que hacer frente la intervención social.

En la presente investigación se considera necesario articular mecanismos o programas específicos que faciliten la transición de los MENA a la vida adulta de la mejor forma, además de una revisión de los programas ya existentes. Se trata por lo tanto de aportar soluciones o alternativas para facilitar y mejorar la transición de estos jóvenes a la mayoría de edad. Por lo tanto, se considera, que para lograr que estos jóvenes puedan llegar a emanciparse e integrarse social, cultural y laboralmente se debería potenciar su formación académica, profesional y entre otras, un autoconcepto positivo. De esta manera se lograría reducir el número de MENA y extutelados en las calles y con ello una mejora tanto personal como de la convivencia social.

\section{MENORES EXTRANJEROS NO ACOMPAÑADOS}

\section{MIGRACIÓN Y ESTADISTICAS}

En muchas zonas del mundo y a lo largo de la historia, se puede hablar de miles de personas que se ven diariamente en la necesidad de dejar sus ciudades natales y trasladarse a otro país, surgiendo así importantes movimientos migratorios. Por lo tanto, la migración internacional no es un fenómeno que se deba considerar novedoso, sino que ha estado presente a lo largo de toda la historia de la humanidad (Messina, 2006, citado en Ortega, 2019). Según Angrela y Sotomayor (2009, citado en Aguaded-Ramírez y Angelidou,2017), el perfil de los inmigrantes ha cambiado en los últimos años, es decir el fenómeno de las migraciones, tradicionalmente, estaba considerado algo como únicamente de adultos, mientras que en las últimas décadas además se ha identificado la presencia de nuevos actores como son los menores migrantes. 
Las y los menores migrantes son un grupo especialmente vulnerable por su desplazamiento forzado, pero no siempre se cubren todas sus necesidades, lo que puede inhibir el potencial para su integración en la sociedad de acogida. Esto plantea notables desafíos ya que la integración de este grupo vulnerado está condicionada entre otros aspectos, por su bienestar social y emocional. Siguiendo la aportación de Bravo Rodríguez (2005, citado en Ortega, 2019) el fenómeno migratorio se debe enmarcar en el contexto de cambios económicos, sociales, culturales y tecnológicos en las últimas décadas con el avance de la globalización.

Además, según Save the Children (2016) también aumenta la complejidad de estos flujos migratorios, ya que en las migraciones actuales se mezclan personas que escapan de conflictos o de violaciones de derechos humanos, con las que huyen de la pobreza y con personas que buscan mejorar sus condiciones de vida, se diluye, por lo tanto, la distinción entre personas refugiadas, migrantes y otros grupos especialmente vulnerables. A continuación, se muestra un gráfico sobre la evolución de la irregularidad de niños, niñas y adultos en España durante el periodo de 2002 al año 2019:

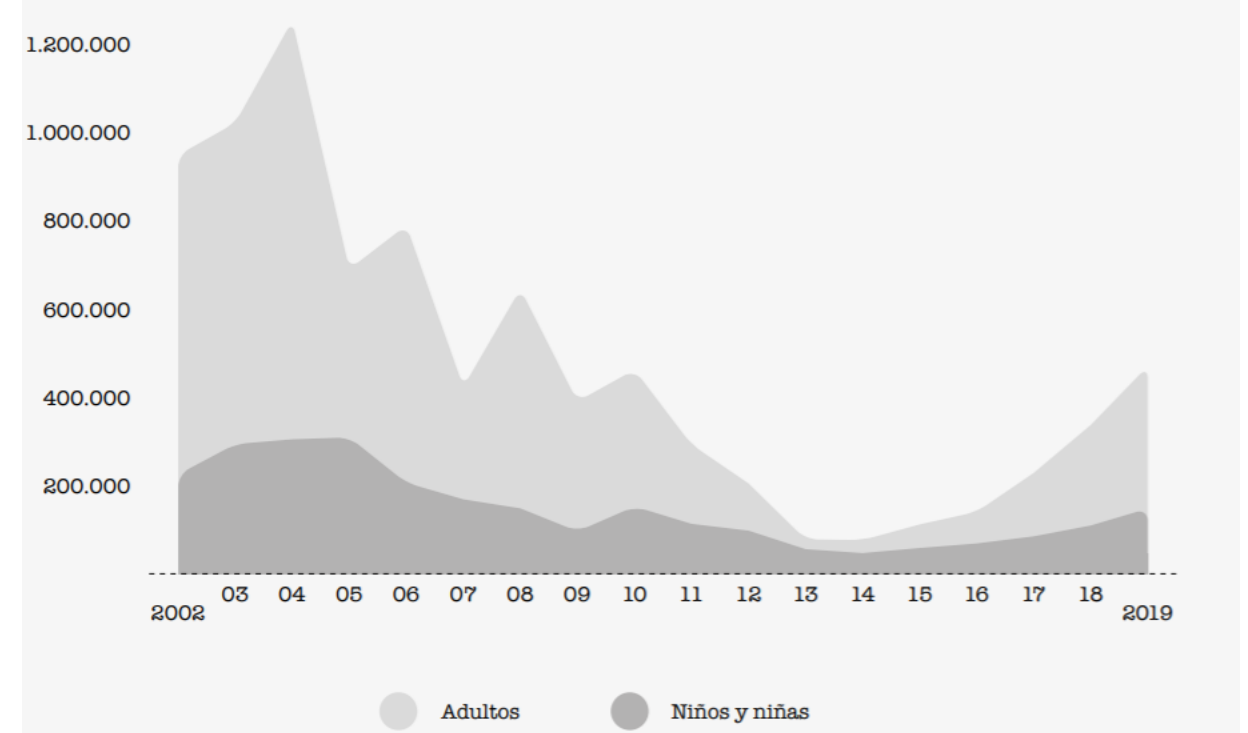

Figura 1. Evolución de la irregularidad de niños, niñas y adultos en España (Save the Children, 2021)

En el gráfico anterior, se puede comprobar como en el año 2013-2014 se llega a igualar el número de niños y niñas con el número de adultos.

En los últimos años y según expresa la OCDE, han ido en aumento las investigaciones sobre la integración de personas migrantes, pero en algunos aspectos aún es limitada, fragmentada y esta circunscrita a ciertos casos específicos. Un porcentaje significativo de menores no acompañados en muchos países de la OCDE experimentan graves dificultades no solo para obtener el acceso a la educación, sino también para recibir servicios básicos y en consecuencia pueden ser especialmente vulnerables a padecer una formación académica deficiente y bajos niveles de bienestar social, emocional y motivacional (OCDE, 2017).

Entre alguna de estas necesidades se encuentra, el aprendizaje del idioma del país de acogida, la necesidad de superar la escolaridad interrumpida, la necesidad de ajustarse al nuevo sistema educativo y según la OCDE (2017), se encuentra también la necesidad de comunicación, la necesidad de relación y sentido de pertenencia, la necesidad de una identidad personal bien desarrollada, la necesidad de sentir seguridad, la necesidad de sobrellevar la separación, perdida y/o trauma (TEPT) y todo esto lo aportan en parte los profesionales que trabajan día a día con estos menores y jóvenes. Así es que, entre los 
incalculables inmigrantes, muchos son menores extranjeros no acompañados que en la mayoría de los casos entran de forma irregular abandonando sus casas y en busca de una prosperidad en España, además muchos viajan en condiciones precarias y peligrosas las cuales posteriormente tienen consecuencias negativas en sus conductas:

Se puede señalar, que el fenómeno de la migración de menores extranjeros no acompañados ya no debe verse de forma monocolor, sino que la diversidad se ha instalado definitivamente en el sí de esta migración. Esta heterogeneidad, representada principalmente por múltiples nacionalidades y la diversidad de sexos, debe ser interpretada como la confirmación de la consolidación de este tipo de migración protagonizado por niños, niñas y jóvenes sin referentes familiares que tienen manifestaciones en otros muchos puntos del mapa (UNICEF,2010, p.28).

La sociedad actual siguiendo a Azorín (2019), vive inmersa en una crisis humanitaria de refugiados sin precedentes. En este sentido en el informe de la OCDE (2017), se manifiesta el alarmante incremento de migración internacional admitiéndose la llegada a Europa de miles de personas procedentes de países en vías de desarrollo. En muchas ocasiones, la infancia queda desprotegida y es ignorada en los acuerdos y en las políticas que se toman a diario. Más de 95.000 menores no acompañados solicitaron protección internacional en la Unión Europea en 2015, se trata de cuatro veces más que el año anterior (Save the Children,2016).

Actualmente además de que los flujos migratorios se hacen cada vez más complejos debido a las diferentes causas de migración como se ha citado anteriormente, cabe destacar que son niños y niñas cada vez más jóvenes: de 2000 a 2015, aumentó en un $41 \%$ el número de niños y niñas migrantes de 0 a 4 años y un $25 \%$ en los menores de 20 años (Save the Children,2016).

El peso relativo de los diferentes rangos de edad se deriva de la composición de los flujos migratorios a lo largo de los años, la movilidad laboral es primero una motivación individual y más adelante familiar (Save the Children, 2021). A continuación, se observa un gráfico sobre la evolución por edades de la irregularidad en España en el transito del 2002 al 2019:

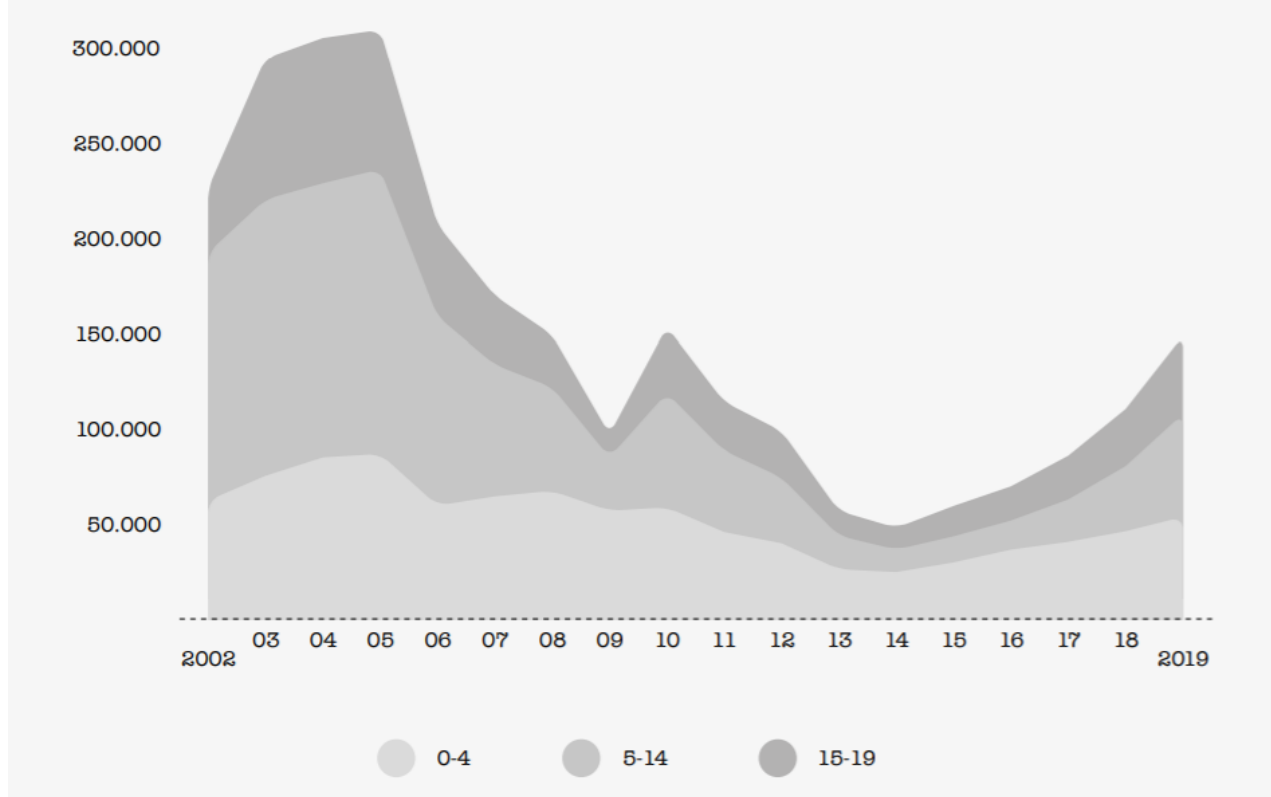

Figura 2. Evolución por edades de la irregularidad de la infancia en España (Save the Children, 2021) 
En el gráfico anterior se puede comprobar como el intervalo de edad que predomina durante todos los años del periodo es el de 15 a 19 años, aproximándose o superando en algunos casos la mayoría de edad, siguiéndole el intervalo de edad de 5 a 14 años y sin olvidar los niños y niñas de 0 a 4 años que se mantienen durante el periodo más estable, aunque con cifras elevadas.

Debido a su situación geográfica España ha recibido el flujo de migraciones de ciertos países durante años. Según Giménez y Suarez (2001), y haciendo referencia a las estadísticas, la inmigración de menores en España comienza a desarrollarse con gran fuerza a partir de la segunda mitad de la década de los 90 y es a partir de 1995, cuando se originan las primeras entradas de Menores Extranjeros No Acompañados en el territorio, y así en los próximos años se generaliza en el estado español.

Aunque resulta complicado saber la cifra exacta de MENA en España dada la falta de coordinación intracomunitaria, parece que la cantidad alcanzó en 2004 las 9.177 personas, número que descendió notablemente con el comienzo de una crisis económica en el país, habiendo en los años sucesivos un total de 3.261 menores (Bravo y Santos- González, 2017). En el año 2013 llegan al territorio español, un total de 2.841 menores extranjeros no acompañados, un año después aumenta la cifra hasta unos 3.660, estando bajo la tutela del estado, y aumentando un 30\% más que el año anterior (Save the Children, 2016). Fue a partir de 2017 cuando el número de MENA en España comenzó a crecer de manera exponencial. De acuerdo a los datos de Save the Children (2018), en 2017 fueron 2.500 MENA en España, de los cuales 2.177 llegaron en patera. A mediados de 2018, el número de MENA en España había llegado a 6.414 personas que estaban bajo la tutela de las Administraciones Públicas, siendo Andalucía la comunidad autónoma con más menores tutelados de España con 2.209 niños y niñas. En este contexto, los menores no acompañados han experimentado un preocupante incremento, según UNICEF (2019). En cuestión tan solo de seis meses, en diciembre de 2018, el número de MENA aumento con un total de 12.437, en específico Andalucía paso a dar residencia y tutela a casi 6.3000 MENA (Europa Press, 2018). En el Registro de Menores Extranjeros No Acompañados, a fecha de 31 de diciembre 2019 figuraban inscritos un total de 12.417 menores bajo la tutela o acogimiento de los servicios de protección. De ellos 11.329 son niños y 1.088 niñas. Se ha producido un descenso del 17,88 \% respecto de los 13.796 inscritos en el año 2018. Según los datos del Registro Andalucía acoge a 4.617 menores (Fiscalía General del Estado, 2019). A continuación, se expone una gráfica de la evolución de estas llegadas, en el periodo de años de 2013 hasta el 2020:

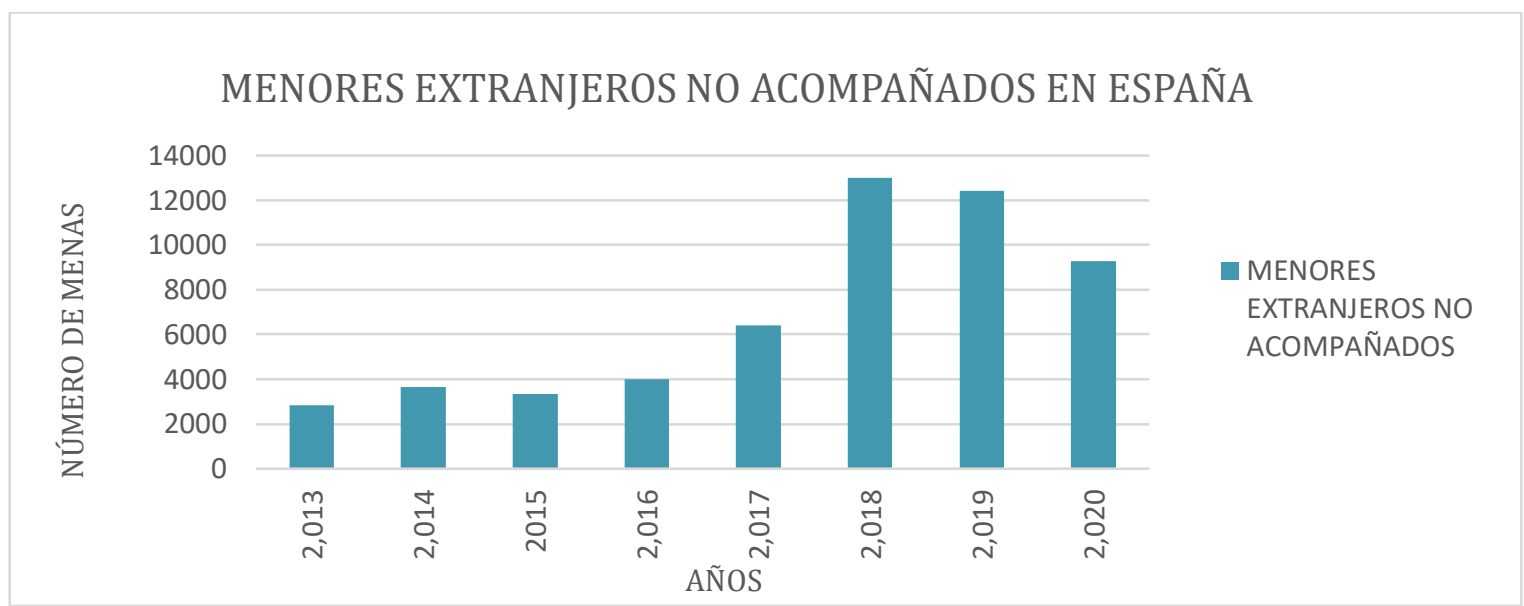

Figura 3. Número de Menos Extranjeros No Acompañados llegados a España en los últimos años. (UNICEF, 2019; Fiscalía General del Estado, 2019) 
Según la Memoria de la Fiscalía:

Siendo conscientes de las múltiples aristas que presenta este problema, los datos nos asoman a una realidad que requiere de una actuación conjunta y coordinada de las autoridades gubernativas, de los servicios educativos, sociales y sanitarios, y de las entidades encargadas específicamente de la protección de menores, para abordar el tratamiento singularizado que merecen quienes, de forma voluntaria o no, han asumido el riesgo de alcanzar nuestras costas en busca de un futuro mejor (Fiscalía General del Estado, 2019, p. 41).

Según Vargas (2019), existe un factor como es el sexo determinante, ya que de casi 13.000 MENA que se encontraban en España en 2019, solamente 971 chicas fueron registradas según los datos oficiales del Gobierno, estos datos se podrían atribuir al arraigo de sociedades patriarcales en los países de origen, que denotan como las oportunidades migratorias dentro de las familias quedan atribuidas generalmente a los varones:

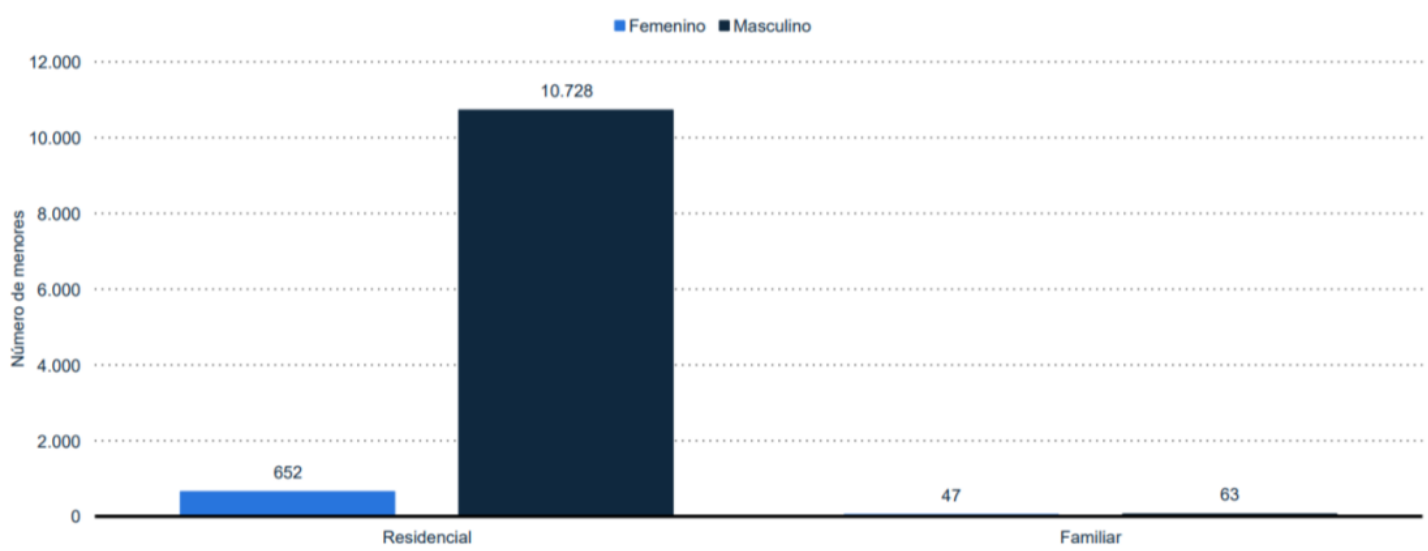

Figura 4. Menores extranjeros no acompañados acogidos en España en 2019, por género y tipo de acogida (Fernández, 2021b).

\section{TÉRMINO “MENA” COMO MENOR EXTRANJERO NO ACOMPAÑADO}

A lo largo de la historia se han utilizado múltiples terminologías para catalogar a estos menores, llegando a las siglas MENA que son las que actualmente manejan las propias instituciones gubernamentales del Estado. Para comenzar, se considera necesario indagar en el propio término, para así evitar sufrir posibles confusiones conceptuales. El término de Menor Extranjero No Acompañado- MENA- está recogido y definido por el Consejo de la Unión Europea y por el Comité sobre los Derechos del Niño de las Naciones Unidas entre otros, y aunque no exista una unificación de los diferentes términos, en la presente investigación se ha elegido la definición desarrollada por UNICEF:

Menor Extranjero No Acompañado es el menor nacional de un Estado no miembro de la Unión Europea o el apátrida menor de 18 años, que, al entrar al territorio español, no va acompañado de un adulto. También será Menor Extranjero No Acompañado cualquier menor al que se deje solo tras su entrada en el territorio de un Estado miembro de la Unión Europea, en este caso en el territorio español. La responsabilidad que recae sobre el adulto puede ser de hecho o de derecho, o sea haber sido asumida por ley o con arreglo a costumbre. El adulto declina su responsabilidad una vez que el menor ha entrado en el territorio. (UNICEF, 2009, p.27). 
La ley de protección jurídica del menor LO 1/1996 de 15 de enero los define en su artículo 1 como:
...menores de 18 años, nacionales de países terceros, que llegan al territorio español sin ir acompañados de un adulto responsable de ellos, ya sea legalmente o con arreglo a los usos y costumbres, en tanto no se encuentran efectivamente bajo el cuidado de un adulto responsable (LO 1/1996, artículo 1).

Se puede ampliar el concepto de MENA con la definición que aporta El Alto Comisionado de Naciones Unidas para los Refugiados (1997, citado en ACNUR, 2004):

\begin{abstract}
Los menores no acompañados pueden haber solicitado asilo por miedo a la persecución, a la falta de protección ante violaciones de derechos humanos, conflictos armados y/o graves disturbios en su país de origen. Algunos de ellos pueden haber viajado a Europa huyendo de situaciones de pobreza. Muchos de estos menores han vivido experiencias terribles y han sobrevivido a circunstancias de extrema dureza (ACNUR, 2004, p.2).
\end{abstract}

Según la investigación de Martínez (2011), existe una falta de consenso en la delimitación del fenómeno y en consecuencia una falta de acuerdo en el tratamiento del mismo. Pero, Goenechea (2016, citado en Ortega, 2019), señala que todas estas definiciones tienen en común el hecho de que se trata de niños, niñas y adolescentes menores de 18 años en proceso migratorio, solos o acompañados, fuera de su país de origen, separados de las personas que por ley o por costumbre les tienen a su cargo y que han accedido al país de destino a través de una solicitud de asilo o en muchas ocasiones de forma irregular.

Tras una revisión de la literatura, se ha podido comprobar como muchas investigaciones se deciden finalmente por utilizar otros términos para referirse a los menores extranjeros no acompañados. Como es, por ejemplo, la investigación de Belattar (2014) se refiere al colectivo utilizando las siglas MMMs, haciendo referencia a "Menores Migrantes No Acompañados". Este cambio de terminología se debe a que el término "migrante" es un término libre de prejuicios y discriminaciones, algo que no pasa con el término MENAS, ya que socialmente se le ha atribuido un sentido peyorativo que lleva a etiquetar al migrante como una persona diferente, extraña y perjudicial. Esto no se debe a que sea un término con la propia raíz peyorativa, sino que es la sociedad quienes ensuciamos el termino haciendo un mal uso del mismo. Un estigma y criminalización del término, otorgándoseles unas connotaciones de deshumanización, descriminalización, negatividad, rechazo y que hace que la sociedad olvide la vulnerabilidad de estos menores, etiquetados muchas veces como "delincuentes" o "vándalos". No se puede diseñar políticas, ni llevar a cabo acciones hacia un colectivo si en el propio término se acentúa la diferencia de un colectivo (Belattar,2014).

Frente a esta nueva situación, ACNUR y Save The Children plantean la necesidad de redefinir el concepto:

El alcance semántico de Menor No Acompañado se intenta superar con la introducción del término de Menor Separado. Ambas organizaciones defienden que este término refleja con mayor exactitud la realidad de estos menores ya que están "separados" de su familia, pero también de sus orígenes o de su cultura y pueden estar acompañados por una familia extensa en el país de origen (Unicef, 2010, p. 20).

Para concluir este apartado, se considera que nos estamos enfrentando cada vez más al estigma y criminalización que sufren estos menores migrantes no acompañados, y aunque sea cierto que la palabra MENA "cosifica" y "deshumaniza", utilizando un término que en muchas ocasiones intenta aislar, no es suficiente centrarnos únicamente en la terminología. 
Por lo que es fundamental conocer su realidad y las posibles respuestas que podemos ofrecer como sociedad a estos niños y niñas tan vulnerables (Save the Children, 2021).

\section{PERFIL, CARACTERÍSTICAS Y MOTIVOS DE LA MIGRACIÓN}

Ahora bien, tanto la transición como la trayectoria posterior de un joven tutelado no puede entenderse de forma independiente a su experiencia antes y durante su intervención protectora (Wade y Dixon, 2006). Llevan a cabo sus proyectos de migración solos, llegando a escondidas a una nueva sociedad y nueva cultura, donde las expectativas se alejan bastante de la realidad que con posterioridad van a experimentar. De este modo se encuentran en una situación de triple vulnerabilidad dado que son menores, inmigrantes e indocumentados (Bicocchi y Levoy, 2008).

El estado debe proteger a estos niños y niñas extremadamente vulnerables, pero para ello hacen falta recursos, y sobre todo voluntad política para cumplir con las obligaciones, legales y morales, que exigen tomar todas las medidas necesarias para garantizar su protección y los derechos, y tratarlos como lo que son, niños y niñas (Save the Children, 2016).

Según Save the Children (2018), existe un flujo de factores que interceden en la migración de este colectivo, como son factores personales, puesto que los menores tienen finalidades, incertidumbre y ambiciones en sus nuevas vidas que en sus países natales no pueden alcanzar; factores familiares, ya que muchos menores abandonan el núcleo familiar por problemas de maltrato o abuso a los que le someten, $u$ otros que repelen el estilo de vida que se lleva a cabo por parte de su familiar; sin olvidar, el factor de la situación socioeconómica a la que se enfrentan y de la que escapan para poder apoyar de forma económica a sus familiares, o para poder reencontrarse con estos si ya residen en alguno de los países de destino.

En esta línea, la decisión de estos jóvenes de emigrar puede ser bien individual, familiar o social, y según cita Monterde (2013), aunque sus expectativas son diferentes a la realidad que se encuentran, no quieren regresar a sus países, además, este autor nombra en su investigación que los menores extranjeros no acompañados tienen una doble condición, por una parte, de menores ya que tienen menos de 18 años y hay que protegerlos; y, por otra parte, como extranjeros que hay que controlar y a veces expulsarlos. $Y$ así en muchas ocasiones se puede olvidar que se trata de un menor y que su situación como inmigrante debería considerarse para poder entender mejor su situación personal. Es necesario llegados a este punto citar la Convención de Naciones Unidas sobre los Derechos del Niño, de 20 de noviembre de 1989 donde se aclara que todos los niños tienen que tener la misma consideración y merecen, por lo tanto, los mismos derechos, independientemente de su nacionalidad u otra característica (Save the Children, 2011).

Hay que garantizar las ventajas de la migración protegiéndoles de los riesgos, y debemos ser capaces de mejorar sus vidas, limitando el número de niños y niñas que se vean obligados a migrar, al tiempo que creamos sistemas y mecanismos transnacionales que permitan encontrarlos rápido, garantizar sus derechos y protegerlos una vez han salido de casa. Para ello se coincide con Save the Children (2016) en que es fundamental que conozcamos qué está pasando con estos niños y niñas, las causas por las que migran, sus necesidades de protección, sus redes de apoyo y sus rutas, elementos todos ellos que se suelen desconocer, cuando no ignorar. Como se cita en la investigación de Ramírez y Angelidou (2017), existen abundantes y diferentes maneras que son utilizadas por estos menores para llegar al territorio español pero todas ellas se asemejan en el gran peligro que suponen para ellos mismos, para su salud y para su vida. Respecto al país de procedencia de estos menores, se trata de Marruecos, Argelia, Mali, Nigeria y Republica de Guinea los principales países de origen de 
los jóvenes que llegan a España (Save the Children, 2016). Al igual que en 2018, en 2019 Marruecos seguía siendo el principal país de nacionalidad de los Menores Extranjeros No Acompañados que llegaron a costas españolas. Concretamente, un $60 \%$ sobre el total de los mismos provenía de este país del norte de África, la segunda posición del ranking era para Argelia, con un $12,28 \%$.

A continuación, se muestra una gráfica de la distribución porcentual de los países de origen de los menores extranjeros no acompañados:

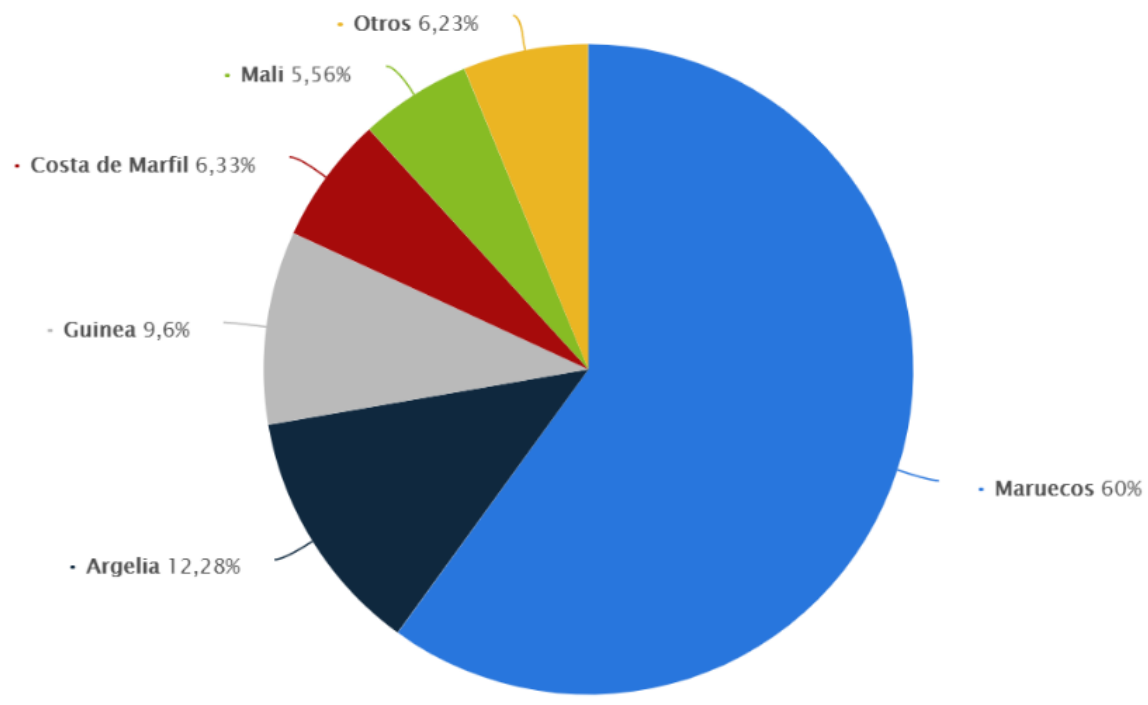

Figura 5. Menores extranjeros no acompañados (MENA) registrados en España en el año 2019, por país de origen (Fernández, 2021a).

Estas personas se encuentran en una situación desfavorecida, ya que deben integrarse en el país en el que se encuentran generalmente de manera forzosa y rápida, provocando problemas emocionales y psicológicos derivados de una posible exclusión por parte del resto de personas que rodean a estos migrantes, desembocando en conductas disruptivas y carencias afectivas al estar lejos del nexo familiar (Díaz, 2017). Estos menores tienen una serie de limitaciones, que actúan de barrera a la hora de pasar por estos estados emocionales derivados de su historia de vida, como puede ser la lengua y los prejuicios de la sociedad a la que llegan.

Según Save the Children (2016), la infancia migra por diferentes razones, idealmente debería ser de forma voluntaria, pero también hay que ser conscientes de que muchos niños y niñas abandonan su casa forzados por sus circunstancias en las que viven. Viajan dentro de sus países o entre países, acompañados de sus padres o solos, y las oportunidades que les abre un mundo nuevo vienen acompañadas por riesgos, entre ellos: riesgo de ser explotados sexual o económicamente, riesgo de sufrir abuso, abandono o violencia, o un cuidado inadecuado que vulnere sus derechos. Pero no hay que quedarse únicamente con los riesgos ya que las oportunidades de la migración pueden ser inmensas como salvar la propia vida, evitar caer en la esclavitud o en un matrimonio forzado, conseguir una vida digna, una educación... Por lo tanto, centrar el debate siempre en los riesgos de estas migraciones nos puede llevar a esforzarnos únicamente en controlar el tráfico de personas, olvidándonos de la voluntad, el deseo y los derechos de niños y niñas que migran. Según Díaz (2017), desde una perspectiva social y educativa, tanto las instituciones como los profesionales de la 
educación tienen que promover acciones que conlleven una materialización de la inclusión de todas las personas, sean cual sean sus características y procedencia, fomentando así la equidad tan deseada.

En definitiva, en la presente investigación se sigue con la idea de Ruiz, Palma y Vives (2019), coincidiendo en la idea de que la protección hacia estos menores tiene el compromiso de evitar que al cumplir la mayoría de edad experimenten una regresión en sus proyectos. En esta línea, Mendoza y Morgade (2019), destacan la importancia de la relación con los familiares que mantienen los MENA durante el proceso de migración y una vez asentados en su país de destino.

Consta por lo tanto que las razones por las que estos menores abandonan sus países son muy variadas, tan diversas como numerosas, pero detrás de estas razones se encuentran multitud de menores que, en el momento de su llegada se enfrentan a una triple vulnerabilidad: su condición de menores, migrantes y no acompañados, estas circunstancias los acompañan hasta sus 18 años, edad en la que inician una nueva etapa de un triple riesgo en el camino hacia una exclusión social, y que esta vez se caracteriza por: ser jóvenes, extutelados y extranjeros (Ruiz, Palma y Vives, 2019).

Para intentar abordar esta cuestión, mediante una reforma de ley se autoriza a las comunidades autónomas a cesar la tutela cuando el menor supere los seis meses fuera del centro y se encuentre en paradero desconocido. Esta medida supone que la comunidad autónoma, que debe hacerse cargo y cuidar del niño o niña, pueda "darle de baja" sin exponerse a reclamaciones y exigencias de responsabilidad, y sin tan siquiera tener que demostrar que ha hecho lo posible por encontrarle (Save the Children, 2016). En 2014, 896 menores edad abandonaron los centros de protección de manera voluntaria, mostrándose en la siguiente gráfica la evolución en el periodo de 2015 a 2019:

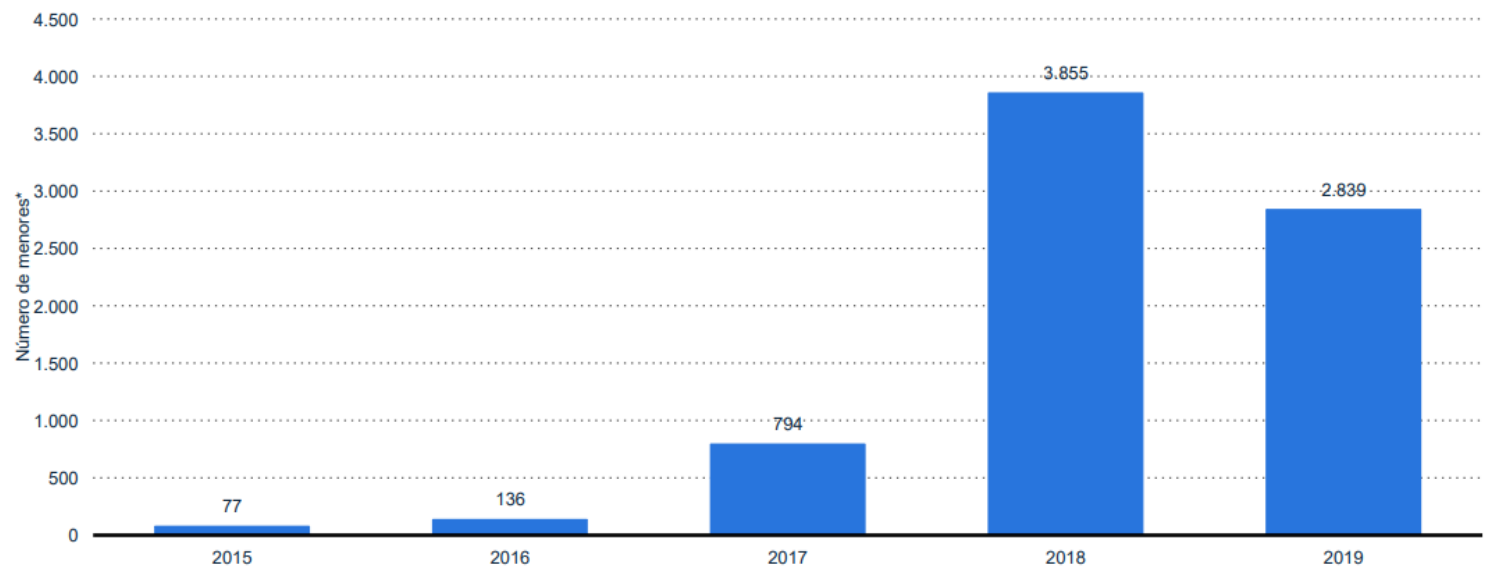

Figura 6. Número de menores extranjeros no acompañados (MENA) fugados de centros de acogida en España entre 2015 y 2019 (Centro Nacional de Desaparecidos, 2020; Fernández, 2021d).

En la estadística anterior se muestra la evolución del número de menores extranjeros no acompañados fugados de centros de acogida en España en el periodo de 2015 a 2019. Se observa como en 2018, la cifra de fugas se disparó, llegando a quintuplicarse con respecto al año anterior, en el año 2019 se experimentó una notable mejoría, siguiendo aun así manteniéndose por encima de los 2.800 casos. 
En referencia a esto el Centro Nacional de Desaparecidos cita lo siguiente:

En 2019, a efectos estadísticos, se ha introducido un nuevo estado denominado "cesadolatente", en el que se han introducido todas las denuncias de menores extranjeros fugados voluntariamente de centros de protección o asistencia, y que, bien han cumplido la mayoría de edad, o ha transcurrido el plazo establecido en el Código Civil para el cese de la tutela legal (Centro Nacional de Desaparecidos,2020, p. 17).

Así, el Código Civil establece que: la tutela de los menores que se encuentran en situación de desamparo corresponderá por ministerio de la Ley a la Entidad Pública (Ley 26/2015, artículo 239). Sin embargo, en los artículos 172, 276 y 277 indica una serie de circunstancias por las que la entidad Pública, cesará en la tutela que ostente sobre los menores declarados cuando haya transcurrido el plazo de seis meses desde el abandono voluntario del centro, o bien que el menor se haya trasladado voluntariamente a otro país, o bien alcanzado la mayoría de edad, entre otros.

Cabe destacar que en estos porcentajes que se presentan a continuación existen variables como el territorio y el número de habitantes de cada comunidad autónoma, lo que sumándose a la situación geográfica inciden en el número de registros de menores extranjeros acompañados por cada comunidad autónoma:

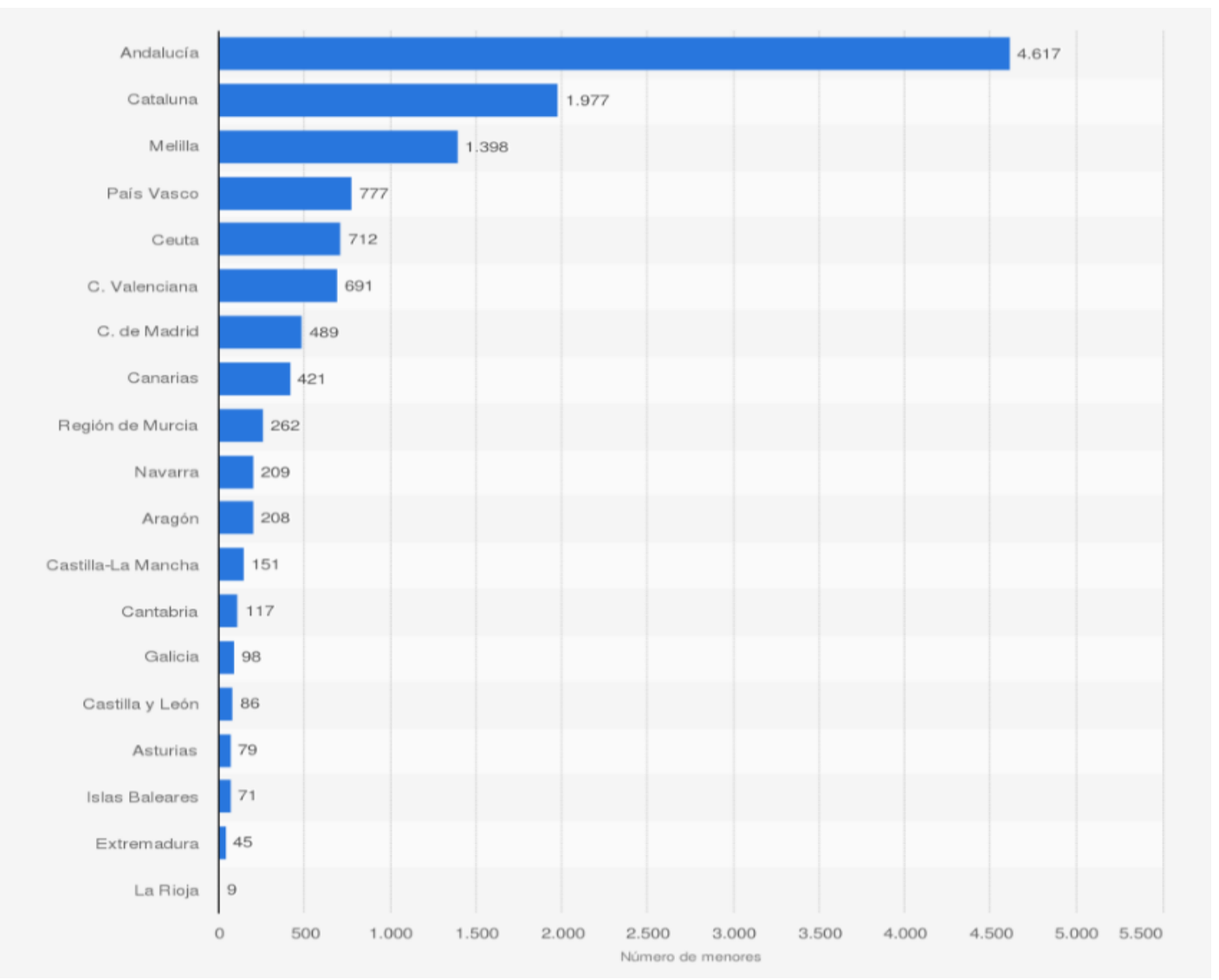

Figura 7. Menores migrantes inscritos en el Registro de Menores Extranjeros no Acompañados de España en diciembre de 2019, por comunidad autónoma (Fernández, 2021c).

Por lo tanto, si hacemos referencia a las comunidades autónomas de España, en la siguiente tabla se pueden apreciar que la comunidad con más menores migrantes no acompañados inscritos en el año 2019 en el Registro de Menores es la Comunidad de Andalucía con un 
total de 4.617 menores bajo la tutela o acogimiento de protección en España, lo que en parte se debe a la situación estratégica de esta comunidad próxima a las fronteras, siguiéndola Cataluña y melilla, con 1.977 y 1.398 respectivamente, mientras que la comunidad autónoma con menos menores registrados es La Rioja con un total de 9 MENA inscritos en la comunidad autónoma. Haciendo referencia a la figura 3, donde se observa los MENA registrados en España en el año 2019 tratándose de un total de 12.414 aproximadamente, nos encontramos con que la comunidad de Andalucía tiene registrados a el $37,18 \%$ de estos menores respecto a la totalidad de España, mientras que la Rioja tiene el 0,07\% respecto de la totalidad.

Además, González (2007, citado en Uceda, 2019), estableció algunas características que tienden a presentar los menores extranjeros no acompañados que llegan a España, entre las que se encuentran, principalmente que se trata de varones, como se ha comentado anteriormente proceden en su mayoría de Marruecos, la edad media es de unos 16 años, tienen una madurez mayor a la que presentaría cualquier joven de su edad, entre sus propósitos tiende a mejorar su situación personal y familiar, rechazan el sistema de protección en favor de opciones con menor control, no suelen haber acabado la escolarización obligatoria en su país y le dan más importancia a las actividades formativas para el empleo que a su educación reglada.

\section{NECESIDADES DE LOS MENORES EXTRANJEROS NO ACOMPAÑADOS}

Cabe destacar que cuando hablamos de MENA y para el diseño de una propuesta de intervención, debemos tener en cuenta que es necesario analizar sus necesidades específicas. Algunas de éstas son satisfechas a la llegada al centro, pero otras, sin embargo, persisten hasta que alcanzan la mayoría de edad (Bravo et al., 2010), estas necesidades están divididas en diferentes áreas, somo son, su formación educativa, formación ocupacional, inserción laboral, idioma, conocimiento cultural, habilidades sociales y de autonomía, problemas psicológicos, problemas referidos al consumo, gestión de su documentación e integración social en la comunidad.

Quiroga et al. (2005, citado en Santos-González, 2015), afirman que es evidente que estos jóvenes se encuentran en una situación muy difícil y frágil, lo que les convierte en personas especialmente vulnerables. Puesto que además de tener problemas en la etapa de desarrollo en la que se encuentran, se les añade el hecho de proceder de otra cultura lo que esto conlleva a otra forma de comunicación en cuanto al idioma, edades que no son verificadas como ciertas, así como también no se deben olvidar las cuestiones legales que les amparan.

En definitiva, son necesarias actuaciones para estos jóvenes en diferentes niveles, así, la importancia de intervenir de manera educativa y preventiva, antes de la mayoría de edad, con una intervención que se ajuste a sus características personales y así se les prepare para la autonomía a nivel emocional, formativo y económico que les sea útil y garantice el proceso de emancipación una vez cumplidos los dieciocho (FEPA, 2014).

\section{DE LA TUTELA A LA VIDA ADULTA}

En este apartado cabe destacar como López, Santos, Bravo y del Valle (2013), entienden la transición a la vida independiente y adulta como un proceso en el cual un adolescente asume nuevos roles y tareas relacionadas con un nuevo nivel de autonomía necesario, de manera progresiva hasta que pasan a ser similares a los adultos que tienen como referencia. Generalmente este proceso se da por concluido cuando existe la finalización de los estudios, la consecución de un puesto laboral y la capacidad de mantener relaciones maduras para establecer un hogar propio. La fase de mayor intensidad en este proceso se produce a partir de la mayoría de edad es decir en España una vez cumplidos los 18 años. 


\section{JÓVENES EXTUTELADOS, CARACTERÍSTICAS Y NECESIDADES}

La legislación nacional la cual se desarrolla más adelante establece que cuando un menor extranjero llega a España y se determina su minoría de edad, el Estado debe asumir su tutela y poner a su disposición una serie de recursos. Sin embargo, esta protección cesa cuando estos menores cumplen la mayoría de edad, existiendo así el grave riesgo de que se vean inmersos en un circuito de marginación y exclusión social si no continúan percibiendo apoyo (Rodríguez, 2006).

El proceso de emancipación cuando se habla de jóvenes extutelados se define desde la Federación de Entidades con Proyectos y Pisos Asistidos:

La transición de una situación de protección a una situación de autonomía, momento en el que entran en juego el despliegue de las diferentes competencias alcanzadas y se ponen de manifiesto las dificultades y las carencias personales. Se trata de un camino único y personal en que factores como la familia, el origen, los recursos disponibles y las propias capacidades juegan un papel decisivo. Es a la vez un proceso dinámico, que evoluciona a lo largo de la vida de la persona y que puede mejorar mediante un plan de acción. (FEPA, 2015, p. 13).

Para los menores extranjeros no acompañados que han estado bajo la tutela de las Administraciones Públicas, la vida independiente se presenta de manera abrupta y forzada el día que cumplen los 18 años y son expulsados del Centro de Menores donde se encontraban. Es entonces cuando se plantean dos posibilidades, la primera, aspiran a conseguir una de las limitadas plazas para acceder a los diferentes programas que existen en Comunidades Autónomas, centrándonos en Andalucía Programa Mayoría de Edad, en los que durante un periodo de tiempo disfrutan de un proyecto que intenta favorecer su autonomía personal, incluyendo un lugar en donde vivir. La segunda opción, implica vivir de forma totalmente autónoma, haciéndose cargo por si mismos de todas las necesidades que implica la vida independiente en cuestión tan solo de unas horas. Las dos opciones dan lugar a situaciones problemáticas con una gran complejidad, en las que se necesitan propuestas de intervención.

En esta línea, Melendro (2015), acuña el término "jóvenes adultos" para referirse a aquellos jóvenes que se encuentran en tránsito a la vida adulta y que están rodeados de factores de vulnerabilidad social, asociados a la falta de independencia laboral, económica, familiar y social que les hace imposible vivir de manera autónoma además de estar en una constante incertidumbre vital. De esta manera, los jóvenes extutelados en este proceso sufrirán las causas de esta transición, las específicas para grupos de vulnerabilidad social y además las que afectan a las personas migrantes siendo más específicos en los prejuicios sociales contra los Menores Extranjeros No Acompañados.

Siguiendo la línea de la investigación de Bhabha (2011), indica como la creciente heterogeneidad de orígenes, objetivos y estrategias dificultan y tensionan la regulación institucional de este flujo migratorio. El desplazamiento de estos menores no es un hecho aislado en el territorio español, la desigualdad que existe en la actualidad entre los diferentes países sitúa a estos menores como uno de los sectores de la población más vulnerable en cuanto a violación de los derechos humanos fundamentales, que más tarde se refleja con su mayoría de edad.

Por lo tanto y siguiendo esta línea, la preparación para la vida adulta debe realizarse a partir de una verdadera valoración de sus necesidades, tanto de las percibidas como de las reales. Para ello se deben establecer estrategias útiles y necesarias para que los menores se doten de unos vínculos adecuados a partir de apoyo social y de motivación para que de esta manera continúen formándose. La preparación para la vida adulta ha de estar unido a la propia 
planificación que se les ofrece a los menores durante su desarrollo personal y social (Stein, 2006).

Uno de los tantos problemas que existen en lo que respecta a este colectivo es por lo tanto la transacción a la vida adulta, estos jóvenes se ven forzados a la tesitura de alcanzar su autonomía a una edad muy temprana, partiendo de situaciones de mayor desventaja, se puede mostrar una elevada complejidad en la que han de enfrentarse a unas numerosas barreras, las cuales dificultan su participación en la sociedad (Tezanos, 2009). La literatura revisada pone en alza el debate en el que se encuentra actualmente este problema, se centra en las preocupaciones sociales en torno a la experiencia vivida por estos menores, su desarrollo psicológico y emocional, su protección, su cuidado, la intervención que se lleva a cabo y la repercusión que están teniendo los servicios sociales. Sin embargo, esta misma revisión nos lleva a la conclusión de que existe un vacío en cuanto a investigación de la transición a la vida adulta, cuando estos menores llegan a la mayoría de edad y ven limitados los derechos que anteriormente tenían por ser menores de edad (Ruiz, Palma y Vives, 2019).

Estos jóvenes se convierten después de la extinción de la tutela en jóvenes extranjeros extutelados, los cuales siguen estando no acompañados y con menos apoyo, tanto por parte de las administraciones como por parte de la propia sociedad en la cual se tienen que incorporar. Cuando estos menores cumplen los 18 años (mayoría de edad para el estado español) la tutela deja de ser efectiva y comienza para el joven un nuevo y complejo proceso de transición hacia una vida adulta. Es el momento donde pierden derechos sociales, económicos y educativos, que sin los permisos adecuados y en una situación de total de desamparo, estos menores pierden la capacidad de continuar en una educación reglada y acceder en las mismas condiciones que un autóctono a las posibilidades formativas que les puedan aportar mayores cualidades para una correcta inserción en el mundo sociolaboral (Uceda, 2019). Estos menores se convierten en adultos de un día para el otro de una manera forzosa, aunque su situación sea exactamente igual e incluso peor a la que tenían horas atrás cuando aún eran menores (Ruiz, Palma y Vives, 2019).

Entre algunas de las necesidades que podemos encontrar en este colectivo López Sánchez (1995, citado en Santana, Alonso y García, 2016), elaboró una taxonomía de necesidades de los jóvenes tutelados por la Administración, dividiéndolas en fisio-biológicas: alimentación, higiene, juego y deporte, las cognitivas como estimulación sensorial, adquisición de un sistema de valores y normas y por ultimo las emocionales y sociales como seguridad emocional, identidad personal y autonomía progresiva entre otras. Se pone de manifestó por lo tanto que los jóvenes tutelados no están suficientemente preparados para cubrir sus necesidades tanto materiales como psicológicas fuera del sistema de protección (Arnau, Marzo, Jairot y Sala, 2013, citado en Santana, Alonso y García, 2016).

Por lo tanto, se considera que es de imperioso valor el estudio y trabajo en profundidad para así intentar evitar que las desigualdades sociales que les caracterizan por encontrarse en el tránsito hacia la vida adulta, estar fuera de su país, sin apoyo ni familiar ni institucional, les sitúen de forma directa en el camino hacia la exclusión social (Ruiz, Palma y Vives, 2019).

\section{PROCESO DE TRANSICIÓN A LA VIDA ADULTA}

Los jóvenes en riesgo de exclusión social experimentan una situación vital muy compleja y viven la transición a la vida adulta como una etapa complicada al tener que hacer frente a una serie de barreras que se presentan como obstáculos para su participación en la sociedad (Bendit y Hahn-Bleibtreu, 2008; Tezanos, 2009). 
Los jóvenes que abandonan el sistema de protección cuando cumplen la mayoría de edad, suelen presentar también problemas relacionados con la salud mental y física, conductas sexuales de riesgo, consumo de estupefacientes, tabaco y alcohol, el desempleo, la falta de una vivienda, las actividades delictivas y la ausencia de una red de apoyo adecuada no hacen sino incrementar los problemas de esta transición. A todos estos, se suma el desconocimiento de todos los trámites burocráticos y administrativos que deben realizar y las situaciones a las que se enfrentan de irregularidad jurídica y administrativa. (Santana, Alonso y García, 2018).

Esta transición a la vida adulta ya es de por si complicada para todos los jóvenes independientemente de su nacionalidad, pero en el caso de los que fueron MENA, la tarea se presenta aun con más dificultades. Algunas de las barreras que dificultan aún más el proceso de transición son la barrera lingüística, la falta de establecimiento de límites y normas, de habilidades sociales, de habilidades para la vida independiente, las deficiencias educativas y formativas y los problemas emocionales y de conducta que pueden presentarse (López, Santos, Bravo y Del Valle, 2013). Según Green y Powers (2007, citado en Santana, Alonso y García, 2016), los jóvenes tutelados se enfrentan a una "edad adulta instantánea" de manera brusca al salir del sistema de protección.

Con el fin de que este proceso de transición sea fructífero va a depender tanto del sistema de protección como de la labor socioeducativo que se ejerce con estos jóvenes tanto en el centro de acogida como en las ayudas posteriores a la mayoría de edad. El caso de los MENA, por lo tanto, añade nuevas características al perfil de los niños y niñas en situación de desamparo, por lo tanto, necesita de intervenciones personalizadas y diferenciadas del resto. Estas diferencias son debidas como ya se ha expuesto, a su origen, su cultura, su idioma y su situación familiar, a las que por supuesto s eles suma las diferencias individuales y personales. Por lo que el primer paso ideal sería desarrollar una evaluación inicial de cada caso para desarrollar estos planes de intervención individualizados y que este proceso de emancipación en la mayoría de edad deje de percibirse como algo estandarizado (Bravo y Del Valle, 2009).

En concreto, en cuanto a lo referido a educación los jóvenes tutelados y extutelados tienen niveles educativos más bajos que los jóvenes no tutelados, además de más dificultades para obtener el diploma de educación secundaria obligatoria (Montserrat, Casas, Malo y Bertrán, 2011). En el momento de tránsito a la vida adulta de estos jóvenes que han estado anteriormente bajo la tutela de las administraciones públicas se produce un salto al vacío, no solo por las circunstancias sociales, laborales y económicas a las que deben hacer frente sino a la falta de información y evaluación que se ofrece sobre tanto los programas como actuaciones que están previstos para ellos (Ruiz, Palma y Vives, 2019).

Cuando pueden solicitar el permiso de residencia y de trabajo para introducirse en el mercado laboral como se les solicita, la realidad acaba demostrando como esta transición teórica llevada a la práctica es imposible. En la actualidad, en Andalucía, como en otras comunidades autónomas, acceder y mantenerse en el mercado laboral resulta una ardua tarea para personas jóvenes contando una buena y extensa formación académica y con apoyo familiar, convirtiéndose este tránsito en un escenario de gran adversidad para la empleabilidad de jóvenes y si se trata de jóvenes extutelados estas cifras empeoran (Ruiz, Palma y Vives, 2019). Estos jóvenes solo pueden transitar a la vida adulta a través de su incorporación al mercado laboral, por lo que cuando esto no sucede y no pueden tener un contrato laboral de un año a jornada completa, vuelven a ser extranjeros en situación irregular, lo que supone un proceso de regresión en sus experiencias (Senovilla, 2007), algo que no favorece nada a su proceso de su nueva vida independiente. 
Por lo que representa un fenómeno de grandes y urgentes dimensiones, ante el cual se siguen produciendo situaciones de vulnerabilidad de los derechos individuales y sociales de los menores, derechos que son reconocidos a nivel internacional (Ruiz, Palma y Vives, 2019).

Dependiendo de la forma en que los jóvenes afronten la transición al mercado del trabajo, de sus recursos/apoyos y de sus posibilidades/expectativas que tengan sobre esa transición saldrán o no de la previsible trayectoria excluyente (Parrilla, Gallego y Morriña, 2010). En la comunidad autónoma de Andalucía y según el informe en abril de 2021 constaban 137.378 personas extranjeras demandantes de empleo de las cuales 88.115 estaban en paro, representando estos el $64,14 \%$ del total, en lo que respecta a contratos existen 2.914 que se trata de contratos indefinidos y 46.653 contratos definidos. Además, cabe destacar como de ese total de 137. 378 personas extranjeras demandantes de empleo son 8.111 las que estaban en el rango de 20 a 24 años (Observatorio Argos, 2021).

Siguiendo a Orteux (2008, citado en Santana, Alonso y García, 2016), la inserción laboral da la oportunidad de vincularse con el mundo del trabajo, a través entre otras de la adquisición de competencias aplicadas a entornos laborales y el aprendizaje de conocimientos de carácter pre-laboral.

\section{PROGRAMAS DESTINADOS A LA INTEGRACIÓN SOCIO-LABORAL}

Es necesario revisar una serie de programas y propuestas de intervención, que comparten el objetivo de facilitar la integración social y laboral a menores extranjeros no acompañados.

La Ley 1/1998 de 22 de Abril de los Derechos y la Atención al Menor, establece que: al menos, durante el año siguiente a la salida de los menores de un centro de protección, la Administración de la Junta de Andalucía efectuará un seguimiento de aquéllos al objeto de comprobar que su integración socio-laboral sea correcta, aplicando la ayuda técnica necesaria ( Ley 1/1998, artículo 37.2) , y que: se potenciará el desarrollo de programas de formación profesional e inserción laboral de los menores sometidos a medidas de protección, con el fin de facilitar su plena autonomía e integración social al llegar a su mayoría de edad (Ley 1/1998, artículo 19.1.f).

Sobre los programas que se desarrollan en un centro de protección de menores la Junta de Andalucía y siguiendo la Orden de 13 de julio de 2005, por la que se aprueba el Proyecto Educativo Marco para los centros de protección de menores en el ámbito de la Comunidad Autónoma de Andalucía, los programas residenciales son instrumentos técnicos para orientar la acción de los centros, de acuerdo al perfil de menores en ellos atendidos en cada momento y variarán de acuerdo a la necesidad de adaptación constante a los cambios en dichos perfiles, teniendo en cuenta a los jóvenes extutelados:

- Programas de Acogida Inmediata

- Programas dedicados a la Atención Residencial Básica

- Programas Específicos de Atención a la Diversidad

- Programas Complementarios o de apoyo al acogimiento residencial

- El programa +18 , la atención ante la mayoría de edad

Por un lado, existen los Centros de Orientación e Integración Laboral -COIL- destinados al colectivo de menores, entre 16 y 18 años, que se encuentran en Centros de Protección en los que se trabajan habilidades y actitudes necesarias para que estos menores puedan encarar la vida en un futuro de forma independiente con el mayor éxito posible cuando llegue su edad de emancipación, y, por otra parte, el Programa de Mayoría de Edad, P+18. 
Conscientes de esta necesidad y de las dificultades que supone este tránsito, la Comunidad Autónoma de Andalucía, crea en 1997 un Programa de Mayoría de Edad para jóvenes tutelados y extutelados, $P+18$. Se trato de un programa pionero en España que nació de la necesidad de proporcionar a este colectivo unas herramientas personales, sociales y laborales y así poder evitar situaciones de exclusión social. Este programa contaba en el año 2010 con 16 entidades colaboradoras, y 18 años después no existen datos de que este programa ofrezca cobertura a la totalidad de los jóvenes que salen de los sistemas de protección. Cabe preguntarnos entonces, ¿Se trata de un sector de población invisible? (Ruiz, Palma y Vives, 2019).

En Andalucía según la consejería para la Igualdad y Bienestar Social de la Junta de Andalucía existen dos modalidades de recursos para el Programa +18 :

- Recursos de Alta Intensidad, lo constituyen pisos de autonomía, en los que se proporciona una atención integral atendiendo a las necesidades de los jóvenes que han tenido que abandonar los centros de menores y carecen de cualquier posibilidad para vivir de forma autónoma cuando cumplen los 18 años.

- Recursos de Media Intensidad, compuestos por una red de centros de día, donde se realizan todas las actuaciones programadas con un seguimiento constante y con formaciones para lograr su interacción social y laboral.

Este programa se desarrolla a través de Entidades Colaboradoras, en virtud de Convenios de Colaboración con la Consejería de Igualdad, Salud y Políticas Sociales. Con ello se pretende que el programa se realice mediante una intervención de profesionales con experiencia en el área educativa y en la orientación sociolaboral, disminuyendo el riesgo de exclusión social y fomentando habilidades en este colectivo. Este apoyo se lleva a cabo mediante numerosas acciones, entre las que destacan el acompañamiento en su proceso de autonomía plena, la formación integral no formal y becas para su formación y alquiler de una vivienda (Ley 1/1998 de 22 de abril, de los Derechos y Atención al menor).

La intervención socioeducativa de acogimiento residencial (Bravo y Del Valle, 2009) donde se recoge el Programa Umbrella como una propuesta de trabajo para la vida independiente, con el diseño de actividades individuales diseñadas para aumentar la autonomía. También se hace referencia a las buenas prácticas en la Atención a Menores Inmigrantes de Andalucía (Observatorio de la Infancia de Andalucía, 2012), abarcando a todos y todas las menores inmigrantes con el objetivo de favorecer la integración, educación y promoción a la vida laboral.

Tras una revisión de la literatura cabe destacar que las intervenciones que existen hacia este colectivo son referidas a la inserción laboral, y como se cita en Ruiz, Palma y Vives (2019), para estos jóvenes extutelados el empleo adquiere una posición central ya que favorecerá su autonomía y su desarrollo social personal y social. Teniendo en cuenta que estos (su gran mayoría) son dependientes de su entorno familiar y social para subsistir por carecer de empleo que le permita el desarrollo total de su autonomía. Esta situación, por lo tanto, explica y representa la desigualdad social en el transito acelerado hacia la vida adulta de los jóvenes extutelados que se ha comentado en el punto anterior.

Cuando cumplen los 18 años los poderes públicos dejan de lado las acciones que iban dirigidas hacia la prioridad del interés de estos jóvenes y relegan a la capacidad limitada de recursos la responsabilidad hasta entonces asumida de garantizarles un nivel de vida adecuado, que permita su desarrollo físico, mental, espiritual y moral (Convención de Derechos del Niño, 1989 citado en Ruiz, Palma y Vives, 2019). 
Los jóvenes extranjeros extutelados se vuelven invisibles, se les pierde la pista (Unicef, 2009). La responsabilidad social hacia este colectivo por lo tanto no debe acabar en el momento que cumple los 18 años, en la actualidad y siguiendo en la línea de Ruiz, Palma y Vives (2019), existe una falta de claridad en las normativas, programas insuficientes y meramente asistencialistas, no existe un sistema generalizado de prestaciones de salida del sistema de protección.

A los menores extranjeros no acompañados el Estado tiene la obligación de protegerles, ser su tutor legal y garantizar su educación y desarrollo. No obstante, se les facilita una educación deficiente y no pueden trabajar en las mismas condiciones que los niños españoles mayores de 16 años. Al cumplir los 18 años se les abandona a su suerte sin apoyos y en muchas ocasiones sin haber recibido la documentación a la que tienen derecho (Save the Children,2016).

La integración a largo plazo de estos menores en la sociedad del país de acogida es una obligación de los poderes públicos que está siendo desatendida. Esto debido, por un lado, a que las respuestas que se les da no tienen en cuenta sus deseos ni buscan ofrecer a cada uno de estos chicos un proyecto de vida y, por otro lado, prima su condición de migrantes sobre la de ser menores de edad. Un ejemplo de esto es que para poder trabajar no les basta con cumplir los 16 años como cualquier chico español, sino que tienen que, además, cumplir con una serie de requisitos adicionales. Aunque a todos los menores de edad que se encuentran en territorio español se les reconoce los derechos establecidos en la Convención sobre los Derechos del Niño en igualdad de condiciones respecto a un niño o niña español, el acceso a estos derechos se ve condicionado, en primer lugar, por su situación administrativa (Save the Children, 2016).

Así es que el obstáculo definitivo para la integración es el acceso al mercado laboral, que además supone una discriminación con respecto a los niños y niñas españoles. Los MENA en edad laboral necesitan cumplir determinados requisitos para poder trabajar, mientras que los menores nacionales pueden hacerlo desde el momento en el que cumplen 16 años. Y no poder trabajar marca de forma importante su futuro, ya que a los 18 años no van a tener de qué vivir y el no haber trabajado antes limita sus opciones para solicitar, una vez adultos, la autorización de residencia y trabajo (Save the Children, 2016).

Save the Children (2016) considera esta transición forzada como una "patada en el trasero" de la mayoría de edad el mismo día que los MENA cumplen 18 años y se acaba la tutela, hay un punto de inflexión en sus vidas. En la mayoría de los casos, pasan de un día para otro de la protección a estar solos e indefensos. Estos jóvenes extutelados tienen un tiempo limitado para lograr la documentación que les permite quedarse en España. Se trata de la comunidad autónoma la que tutela al menor de edad la que tiene que tramitar su autorización de residencia, sin embargo, no siempre lo hace a tiempo, dejando que muchos alcancen la mayoría de edad al interpretarse los plazos legales en perjuicio del niño. Cumplidos los 18 años sin autorización de residencia, obtenerla dependerá de la recomendación de la entidad que le ha tutelado, de la acreditación de medios económicos para subsistir y de una oferta en firme de trabajo. En definitiva, el paso a la mayoría de edad de estos niños y niñas muestra que la protección concedida hasta este momento de sus vidas olvida la obligación de velar por su pleno desarrollo y garantizar su autonomía para desenvolverse en el mundo de los adultos cuando dejen de ser legalmente niños y niñas. No se trabaja para su integración y se les expulsa inmediatamente cuando cumplen los 18 años. Por ello resulta frecuente que, a medida que se aproximan a la mayoría de edad, estos niños abandonen los centros de protección para buscar formas de ganarse la vida al margen de las instituciones públicas. 
Se coincide con la idea de Save the Children (2018), en la necesidad de elaboración de un plan individualizado de seguimiento y acompañamiento durante el tiempo necesario para alcanzar los objetivos identificados con el menor y hasta como mínimo los 25 años.

\section{EI AUTOCONCEPTO COMO FACTOR PSICOSOCIAL}

\section{DEFINICIÓN DE AUTOCONCEPTO}

A través de una revisión de la literatura, el presente capitulo se sustenta en un conjunto de teorías, potencialmente explicativas del fenómeno que se presente abordar. Se muestra como el autoconcepto tiene múltiples definiciones y diversidad de opiniones sobre las dimensiones que lo conforman, y sobre su estabilidad a lo largo del tiempo. Buscar una definición consensuada y aceptada en el mundo académico ha sido un trabajo arduo y lleno de discrepancias, principalmente por la esencia subyacente al concepto en sí (GalindoDomínguez, 2019). No obstante, parece ser que actualmente en general se acepta considerar el autoconcepto como un constructo jerárquico y multidisciplinar (Cazalla- Luna y Molero, 2013).

Este constructo es definido ya en la década de los 70 como:

La percepción que una persona tiene sobre sí misma, formada a partir de las experiencias y relaciones con el medio, donde juegan un papel importante los refuerzos ambientales y los otros significativos (Shavelson, Hubner y Stanton, 1976, p.411).

Rosenberg (1979) lo define como la totalidad de los pensamientos y sentimientos que hacen referencia al sí mismo como objeto. Es a partir de Harter (1990), cuando se desarrolla el modelo multidimensional, el cual está explicado más adelante, este modelo es utilizado frecuentemente para evaluar el autoconcepto. Para Burns (1990), es un conjunto organizado de actitudes que el individuo tiene hacia sí mismo y ya distinguía tres componentes, el componente cognoscitivo, el afectivo y el evaluativo y un componente comportamental o tendencia conductual. Kimmel y Weiner (1998, citado en Schmidt, 2010) sostuvieron que, el autoconcepto es la opinión que uno tiene de su persona y es un conjunto de ideas y sentimientos que uno tiene de sí mismo.

Rabazo (1999) propuso la siguiente definición compleja de autoconcepto:

Un sistema complejo y continuamente activo y susceptible de cambio, constituido por un conjunto de creencias acerca de la propia existencia cuya función principal serie la de interpretar la información autorreferente entrante, guiar la conducta y capacitar al individuo para asumir y desempeñar ciertos roles en su desarrollo vital en función de criterios y de las más variadas situaciones (Rabazo, 1999, p.101).

La definición más sustantiva es la propuesta por Byrne y Baron (2005, citado en PalaciosGaray y Coveñas-Lalupú, 2019), afirman que el autoconcepto es la opinión que se tiene de sí mismo, las actitudes, las emociones y el conocimiento con relación a las capacidades y aceptación social de que disponga cada individuo.

\section{CARACTERÍSTICAS DEL AUTOCONCEPTO}

La presente investigación se apoya en el modelo jerárquico y multifacético de Shavelson, Hubner y Stanton (1976). Estos autores conciben el autoconcepto como la percepción que el individuo tiene de sí mismo, la cual se basa directamente en sus experiencias en relación a 
los demás y en las atribuciones que él mismo hace de su propia conducta. Estos autores definen siete características básicas del autoconcepto:

- Esta organizado, el individuo adopta un sistema de categorización particular que da significado y organiza las experiencias de la persona; las categorías representan una forma de organizar las experiencias propias y así atribuirles un significado. En consecuencia, el autoconcepto está estructurado.

- Es multifacético, el sistema de categorización parece incluir las áreas tales como la escuela, la aceptación social, el atractivo físico y las habilidades sociales y físicas.

- Su estructura puede ser jerárquica. Sus dimensiones tienen significados e importancia diferente en función de los valores y de la edad de las personas.

- El autoconcepto global es relativamente estable, su variabilidad depende de su ubicación en la jerarquía, de manera que las posiciones inferiores son más variables. Esta característica se desarrolla más adelante.

- Es experimental, se va construyendo y diferenciando a lo largo del ciclo vital del individuo.

- Tiene un carácter evaluativo, la dimensión evaluativa varía en importancia y significado dependiendo de los individuos y las situaciones. Esta valoración diferencial depende, probablemente, de la experiencia pasada del individuo en una cultura y sociedad particular, en una familia, etc.

- Es diferenciable de otros constructos con los cuales esta teóricamente relacionado.

A partir de este modelo, otros investigadores han estudiado el factor multidimensional diferente en forma, pero no en contenidos, además este modelo de Shavelson ha sido ampliamente investigado y validado (Musitu, García y Gutiérrez, 1991, citado en García, y Musitu, 2001).

Una de las características más relevantes del autoconcepto, es que tiene la capacidad de permanecer cambiante y estable al mismo tiempo, es estable en sus aspectos más nucleares y profundos, a la vez que variable en sus aspectos más dependientes del contexto (García y Musitu, 2001; Guido, Mújica y Gutiérrez, 2011). En numerosas investigaciones se constata que los seres humanos buscan denodadamente la consistencia y la estabilidad y se resisten activamente a cualquier información que desafíe o amenace su autoconcepto. Sin embargo, a pesar de esta importante resistencia al cambio, también existen numerosas evidencias empíricas que muestran la ocurrencia de cambios temporales, así como modificaciones permanentes en el autoconcepto (García y Musitu, 2014).

Sobre todo, es imprescindible citar como el contexto inmediato provoca ciertos cambios temporales en el autoconcepto que la persona tiene de sí misma en un momento determinado. Por lo tanto, desde un enfoque sociológico se ha prestado una mayor atención a la naturaleza dinámica y adaptativa del autoconcepto (Musitu y García, 2014). En esta línea, se considera interesante como Williams James al referirse a la naturaleza variable del autoconcepto, afirmaba que el individuo tiene tantos selfs sociales diferentes como grupos distintos de personas cuyas opiniones le importen, ya que se trataba de considerar el autoconcepto como un producto social (Musitu y García, 2014).

La diferencia entre autoconcepto y autoestima, según D'Ágata (2011) es una cuestión de debate. Es cierto que ambos términos están estrechamente relacionados, y por ello han suscitado confusión conceptual en muchos estudios del autoconcepto (Gorostequi y Dorr, 2005; Fleming y Courtney, 1984, citado en Sosa et al; 2016). Hay autores que abogan por la no diferenciación, por ejemplo, las teorías de investigadores ya citadas como Shavelson, Hubner y Stanton (1976), Fernández (2014), también señala que no hay una distinción clara entre ambos conceptos y afirma que los dos términos son dos dimensiones de la misma 
realidad, uno el aspecto afectivo y otro el cognitivo. Al contrario de esta idea, existen otros autores que afirman que ambos conceptos se pueden diferenciar de forma clara como son Watkins y Dhawan (1989 citado en Sosa et al. 2016). Esta última teoría ha sido apoyada posteriormente por la mayoría de los investigadores, entre ellos Rodríguez (2010). A pesar de estas discrepancias, se puede concluir, con que todos los autores coinciden en que el término autoconcepto incluye auto descripciones abstractas que se pueden diferenciar (Musitu y García, 2014). Desde esta perspectiva, el término del autoconcepto hace referencia exclusiva a los aspectos puramente cognitivos, mientras que la autoestima en cambio alude a variables afectivas y/o evaluativas de uno mismo (Garaigordobil, Dura y Pérez, 2005; Vera, Rosselló y Toro-Alfonso, 2010).

En el estudio del autoconcepto, Alarcón (2012) señala que existen dos perspectivas en la forma de abordar este constructo, la perspectiva unidimensional y otra multidisciplinar. Este es uno de los aspectos más conflictivos y polémicos respecto al autoconcepto. En cuanto a la tendencia a plantear una dimensión única donde se hace hincapié en los aspectos más globales (Coopersmith, 1967, Marx y Yonne,1978, citado en Sosa et al. 2016). Esta concepción unidimensional se fue transformando a lo largo de la historia y es a partir de los años setenta cuando se empieza a considerar como una estructura compuesta por varias dimensiones dispuestas jerárquicamente (Byrne y Shavelson, 1986, Epstein, 1974; Marsh y Shalveson, 1985, citados en Rodríguez, 2010). Así en los últimos años los distintos estudios se han apoyado en esta aproximación empírica, este estudio se centra en García y Musitu (2001), los cuales han señalado que el autoconcepto está formado por las siguientes dimensiones: emocional, física, social, académico y familiar. Esta multidimensionalidad explica las diferentes autoconcepciones que la persona manifiesta en los diferentes ámbitos (Alarcón, 2012).

A continuación, se definen las 5 dimensiones del instrumento Autoconcepto Forma 5, según García y Musitu, (2014):

- $\quad$ Autoconcepto académico, se refiere a la percepción que el individuo tiene de la calidad del desempeño de su rol, como estudiante o como trabajador. La dimensión gira en torno a dos ejes, al sentimiento que el estudiante tiene de su rol y a las cualidades específicas valoradas.

Autoconcepto social, se refiere a la percepción que tiene la persona de su desempeño en las relaciones sociales. Dos ejes definen en esta dimensión, el primero hace referencia a la red social del individuo y a su facilidad o dificultad para mantenerla y ampliarla; el segundo eje se refiere a algunas cualidades importantes en las relaciones interpersonales.

- Autoconcepto emocional, hace referencia a la percepción de la persona de su estado emocional y de sus respuestas a situaciones específicas, con cierto grado de compromiso e implicación en su vida cotidiana. El factor tiene dos fuentes de significado, la primera se refiere a la percepción general de su estado emocional y la segunda a situaciones más específicas, donde la otra persona implicada es de un rango superior.

- Autoconcepto familiar, se refiere a la percepción que tiene la persona de su implicación, participación e integración en el medio familiar. El significado de este factor se articula en torno a dos ejes. El primero se refiere específicamente a los padres en dos dominios importantes de las relaciones familiares como son la confianza y el afecto. El segundo eje hace referencia a la familia y al hogar.

- Autoconcepto físico, este factor hace referencia a la percepción que tiene la persona de su aspecto físico y de su condición física. El factor gira en torno a dos ejes que son complementarios en su significado. El primero alude a la práctica deportiva en su vertiente social. El segundo hace referencia al aspecto físico. 


\title{
LA ADOLESCENCIA EN RELACIÓN CON EL AUTOCONCEPTO
}

Palacios (2000, citado en Sosa et al., 2016), afirma que existen variaciones en el autoconcepto del sujeto a lo largo de la vida, así como en el modo de valorarse a sí mismo. Uno de los periodos de la vida que se caracteriza precisamente por el cambio, así como por ser un momento de consolidación de la identidad, es la adolescencia (Bakhurst y Sypnowich, 1995; Palmonari, 1991, citado en García y Musitu, 2014). Debido en gran parte por las nuevas sensaciones que experimentan los adolescentes como son; la autonomía, la pertenencia al grupo de iguales, los cambios físicos o las nuevas formas de relacionarse con la autoridad, las cuales influyen en la percepción que cada uno de ellos tiene de sí mismo (Parra, Oliva y Sanchez-Queija, 2004).

Estudios realizados los últimos años confirman esta idea, añadiendo que la adolescencia es una etapa en la que se resiente tanto el autoconcepto general como el autoconcepto en todas sus dimensiones (Fernández-Zabala y Sarasa, 2015, citado en Fernández., Goñi, Camino y Zubeldia, 2018). En esta línea, existen investigaciones que confirman que el ajuste escolar y el rendimiento académico disminuyen en la adolescencia media (Ibabe, 2016). En esta línea Fuentes et al. (2015), afirman que la conducta disruptiva aumenta en los adolescentes durante la educación secundaria. Así, estudios como el de Coelho, Marchante y Jimerson (2017) avalan la importancia de prestar atención a los cambios de etapa y centro educativo, ya que las intervenciones educativas pueden prevenir y disminuir el impacto negativo que tiene la caída del autoconcepto durante la educación secundaria.

De una manera paulatina se van integrando, rechazando o aceptando parcialmente la información proveniente de nuevas experiencias para el adolescente (Musitu y García, 2014). La experiencia de ser reconocido y aceptado por otros, sobre todo por personas que son significativas en su vida, le conducirá a autoconcepto positivo o negativo de sí mismo y a la afirmación de su identidad como persona (Iñiguez, 2016).

Afirmando que las percepciones de cada persona tienen un valor, ya sea positivo o negativo, se debe entender que tienen una importancia determinada, según los intereses, necesidades, situación o motivos del sujeto. Cuanto más positivo sea el autoconcepto del sujeto, más preparados estaremos para afrontar adversidades, resistir las frustraciones y más satisfacción encontraremos por el simple hecho de vivir (Iñiguez, 2016).

\section{INTERVENCIÓN PSICOPEDAGÓGICA RESPECTO AL AUTOCONCEPTO}

\section{Según Esnaola, Goñi y Madariaga:}

\begin{abstract}
Una posible intervención educativa a través del autoconcepto va a permitir acercar en la medida de lo posible las visiones del mundo actual del adolescente a las del adulto educador, lo cual comporta que este conozca mejor y valore los grupos sociales significativos del contexto de los adolescentes, al mismo tiempo que registra sus valores para poder trabajar de manera más educativa. Naturalmente esto requiere de un conocimiento más profundo de la forma de entender la vida por parte de los adolescentes y sus consiguientes actitudes y motivaciones vitales (Esnaola, Goñi y Madariaga, 2008, p 82).
\end{abstract}

Este hecho despierta la atención y preocupación desde un punto de vista pedagógico desarrollando diferentes estudios que intenten comprender el proceso de emancipación. Para asegurar que los adolescentes tengan un buen ajuste psicosocial y psicopedagógico evitando futuros problemas, una de las intervenciones habituales son los programas dirigidos a producir cambios en la autoestima o autoconcepto de adolescentes. En relación con este tipo de intervenciones hay que tener en cuenta que las intervenciones que no se centran directamente en la mejora de la autoestima muestran eficacia en la mejora del autoconcepto 
adolescente. Se trata de intervenciones dirigidas a la mejora de la comunicación, entrenamiento en habilidades sociales, autobservación y reestructuración cognitiva, expresión y comprensión de emociones, resolución de conflictos. Además, hay que tener en cuenta, que debería trabajar en la mejora del autoconcepto en estas edades desde las instituciones educativas. Las intervenciones para mejorar la autoestima en edades tempranas parecen resultar más eficientes cuando se llevan a cabo en el ámbito escolar.

El hecho de que los adolescentes de edades tempranas se caractericen por sufrir grandes cambios y confusión en torno a sí mismos parece contribuir también a que la autoestima sea particularmente influenciable en estas edades por lo que los programas escolares puede resultar especialmente útil en poblaciones que se encuentran aún en la adolescencia temprana o en periodos previos, dado que en la adolescencia tardía ya suelen haberse consolidado las pérdidas de autoestima que experimentan muchos jóvenes.

\section{MARCO LEGISLATIVO}

En este apartado se pretende exponer y analizar las principales normativas que hacen referencia al termino MENA y a los jóvenes extutelados, comenzando por el ámbito internacional (Europa), pasando por el estatal (España) y finalizando en el ámbito autonómico de la Comunidad Autónoma de Andalucía. Así se pretende entender tanto las dificultades y posibilidades con las que cuentan, como la situación socioeconómica y jurídica a la que se tienen que enfrentar una vez cumplen la mayoría de edad.

\section{INTERNACIONAL}

Refiriéndonos a la primera norma internacional que encontramos se trata de la Convención sobre los Derechos del Niño -CDN- que entró en vigor en España en 1991. La Convención sobre los Derechos del Niño se trata de un tratado internacional que recoge los derechos de la infancia y que, por primera vez, reconoce a los niños como titulares de derechos que son exigibles jurídicamente (Save the Children, 2016). Este tratado entiende en su primer artículo que un niño es cualquier persona que sea menor de dieciocho años o de la edad aplicable según cada ley. De acuerdo con el artículo tercero, el bienestar de cada niño y niña siempre será el fin primordial de todas las autoridades, órganos e instituciones. Es el artículo octavo el que está relacionado directamente con los Menores Extranjeros No Acompañados, pues los Estados miembro deben estar comprometidos a preservar su identidad, nacionalidad, nombre y relaciones familiares de acuerdo con la ley, y, en el caso de que se le sea privado alguna de estas características de forma ilegal, son los Estados miembro los encargados de restablecerlo prestando asistencia y protección apropiadas para restablecer su identidad. Así el artículo veinte, establece la necesidad de los Estados a tener que ocuparse de su cuidado, protección, asistencia, prestando particularmente atención a la conveniencia de que haya continuidad en la educación del niño tanto como a su origen étnico, religioso, cultural y lingüístico (Convención sobre los Derechos del Niño, 1990).

En el ámbito europeo, es la Resolución 97/C 221/03 del Consejo de Europa de 26 de junio de 1997 la relativa a los Menores No Acompañados nacionales de países terceros, es entonces cuando se empieza a tomar en consideración la situación de estos jóvenes que llegan a los países de la Unión Europea, prestando especial atención a su situación de vulnerabilidad y la atención atendiendo a sus necesidades específicas. En su artículo número tres, el cual trata sobre garantías mínimas para todos los menores extranjeros no acompañados, se decreta que independientemente de su situación jurídica los menores no acompañados deberán tener derecho a la protección necesaria y a los cuidados básicos con arreglo a las disposiciones de la legislación nacional. También se establecen artículos 
relativos a la tramitación de peticiones de asilo y repatriación en caso de que se considere oportuno y/ o necesario.

Pese a todo, la legislación europea deja en manos de la propia ley de los Estados el trato hacia estos menores, por lo que no se asegura el cumplimiento de estos principios. Por ello, en el siguiente apartado se hace referencia a la legislación estatal de España, ya que estos anteriores se pueden llegar a considerar demasiado globales.

\section{ESTATAL}

Respecto a la primera ley que hace referencia a estos menores en España es parte de la Constitución Española de 1978, la infancia está presente a lo largo de todo el texto constitucional ya que, como ciudadanos, se les hace extensible los derechos fundamentales. Son destacables algunos artículos, la cual garantiza la infancia a través del artículo 39 que los niños deben gozar de la protección prevista de los acuerdos internacionales que velan por sus derechos, lo cual incluye a cualquier menor en territorio español sin tener en cuenta su origen. El artículo 10 aboga por la dignidad de la persona, sus derechos y deberes. Derechos y libertades fundamentales que están recogidos en la Constitución Española en función de la Declaración Universal de Derechos Humanos y los demás tratados internacionales ratificados por España. Además, el marco jurídico español incluye algunas normas sobre integración a nivel nacional. En la Constitución española, sin ir más lejos, el artículo 13.1, el que asegura que los extranjeros gozarán en España de las libertades públicas que garantiza el presente título en los términos que establezcan los tratados. El artículo 20 se refiere a la limitación de la libertad de expresión como medio protector de la infancia. Referido a la mayoría de edad, en la Constitución Española se recoge mediante el Real Decreto-Ley 33/1978, de 16 de noviembre, en su artículo 1ํㅡㄹ la mayoría de edad empieza para todos los españoles a los 18 años recién cumplidos.

Haciendo referencia a Ley Orgánica 1/1996, de 15 de enero, de Protección Jurídica del Menor, de modificación parcial del Código Civil y de la Ley de Enjuiciamiento Civil. El Título I comienza enunciando un reconocimiento general de derechos contenidos en los Tratados Internacionales de los que España es parte, y además deben ser utilizados como mecanismo de interpretación de las distintas normas de aplicación a las personas menores de edad. Por otra parte, del conjunto de derechos de los menores, se ha observado la necesidad de matizar algunos de ellos, combinando, por una parte, la posibilidad de su ejercicio con la necesaria protección que, por razón de la edad, los menores merecen. Entre algunos criterios del capítulo I, se destaca la preparación del tránsito a la edad adulta e independiente, de acuerdo con sus capacidades y circunstancias personales. En el capítulo II "Derechos del menor" haciendo referencia a su artículo 3, referencia a Instrumentos Internacionales, los menores gozarán de los derechos que les reconoce la Constitución y los Tratados Internacionales de los que España sea parte, especialmente la Convención de Derechos del Niño de Naciones Unidas y la Convención de Derechos de las Personas con Discapacidad, y de los demás derechos garantizados en el ordenamiento jurídico, sin discriminación alguna por razón de nacimiento, nacionalidad, raza, sexo, discapacidad o enfermedad, religión, lengua, cultura, opinión o cualquier otra circunstancia personal, familiar o social. La presente ley, sus normas de desarrollo y demás disposiciones legales relativas a las personas menores de edad, se interpretarán de conformidad con los Tratados Internacionales de los que España sea parte y, especialmente, de acuerdo con la Convención de los Derechos del Niño de Naciones Unidas y la Convención de Derechos de las Personas con Discapacidad. Los poderes públicos deberán garantizarán el respeto de los derechos de los menores y adecuarán sus actuaciones a la presente ley y a la mencionada normativa internacional. En el artículo 22 bis, programas de preparación para la vida independiente, se decreta que las Entidades Públicas ofrecerán programas de preparación para la vida independiente dirigidos a los jóvenes que 
estén bajo una medida de protección, particularmente en acogimiento residencial o en situación de especial vulnerabilidad, desde dos años antes de su mayoría de edad, una vez cumplida esta, siempre que lo necesiten, con el compromiso de participación activa y aprovechamiento por parte de los mismos. Los programas deberán propiciar seguimiento socioeducativo, alojamiento, inserción socio-laboral, apoyo psicológico y ayudas económicas.

Haciendo referencia ahora a la llamada "Ley de Extranjería", la Ley Orgánica 4/2000 del 11 de enero, sobre derechos y libertades de los extranjeros en España y su integración social. Se trata de la principal normativa a nivel estatal relacionada con las personas migrantes, considerando como extranjero a toda persona que carezca de nacionalidad española. Es en el artículo 35 donde se centra en el caso de los menores extranjeros no acompañados estableciendo unas líneas generales de actuación frente a estos menores. En caso de tratarse de un menor, se deriva a las autoridades competentes de protección de menores de cada comunidad autónoma en cuestión, la cual se deberá encargar de elaborar un informe sobre las circunstancias familiares y decidir si se procede a la repatriación o es su defecto, la permanencia en España. Estos últimos, que residan tutelados por la Administración Pública u otra entidad pública que tenga convenio para ejercer la tutela de los mismos tendrán una autorización de residencia, lo que les otorga un estatus regularizado. Esta ley también contempla, la posibilidad de que estos menores con autorización de residencia, una vez alcanzada la mayoría de edad, si desean renovarla o acceder a una autorización de residencia y / o trabajo, se deberán tener en cuenta todos los informes que puedan aportar las administraciones en referencia al esfuerzo de integración, formación o mercado laboral. Queda reflejado que es responsabilidad de las Comunidades Autónomas establecer proyectos para facilitar la inserción sociolaboral de estos menores una vez cumplan la mayoría de edad.

La mayoría de edad es un tema muy debatido con estos menores, es por ello que se aprobó el protocolo en 2014 para completar el proceso especificado en la ley anteriormente comentada Ley Orgánica 4/2000, de 11 de enero, sobre derechos y libertades de los extranjeros en España y su integración social, con el objetivo de coordinar la intervención con los menores a realizar desde su identificación hasta su puesta en disposición del Sistema de Protección de Menores. Se puede cuestionar la aplicación de la ley a la hora de diagnosticar la edad de estos jóvenes, poniendo en duda las intenciones del Gobierno con este interés por determinar la mayoría de edad en estas personas migrantes, sin tener en cuenta que, en caso de duda sobre la minoría o mayoría de edad, siempre deberá resolverse a favor del menor.

La ordenación del sistema educativo, junto con las leyes de protección jurídica y social del menor, aparecen como el desarrollo legislativo básico que da cobertura a los principios reguladores anteriormente citados. Además de las normativas referidas anteriormente, a nivel estatal se regulan otras que, con carácter específico, tratan determinados aspectos relacionados con los menores. Entre estas normativas destacamos: el Código Civil, la Ley de Enjuiciamiento Civil, la Ley Orgánica de protección jurídica del menor, etc.

Sin embargo, cabe destacar llegados a este punto, como es la obligación de integrar a los migrantes la que recae directamente sobre las comunidades autónomas, siendo el resultado de esto una descentralización de 17 planes de integración completamente diferentes, que siguen líneas dispares y funcionan de manera irregular. En el siguiente apartado se trata por lo tanto la legislación de la Comunidad Autónoma de Andalucía.

\section{COMUNIDAD AUTONÓMICA DE ANDALUCÍA}

Por otra parte, y dado que las competencias en materia de servicios sociales se encuentran transferidas a las comunidades autónomas españolas, será desde ellas desde donde se 
regule la normativa específica de ordenamiento y funcionamiento de los servicios que se presten a las familias y menores en cada comunidad.

El estatuto de autonomía de la comunidad de Andalucía, de acuerdo con la Ley Orgánica 2/2007 para su reforma, establece en el artículo 3.10. 17ํㅡ como uno de sus objetivos básicos la integración social, económica, laboral y cultural de los inmigrantes de Andalucía.

La Comunidad Autonómica se encarga de gestionar la protección de los Menores Extranjeros no Acompañados, siendo derivados a Centros de Menores de Protección. Es entonces, cuando de acuerdo con el Decreto 355/2003, están destinados a acoger de manera residencial a todos los menores sobre los que se apliquen dichas medidas de tutela, ofreciendo no solo un lugar de acogida, si no un espacio de convivencia y desarrollo educativo de las distintas capacidades que se requieren para todos estos menores.

En esta línea, se ha de citar la Ley 1/1998 de 22 de abril, de los Derechos y Atención al menor, la cual establece que, una vez cumplida la mayoría de edad de estos jóvenes, la Junta de Andalucía es la encargada de realizar un seguimiento del joven para confirmar que su inserción sociolaboral sea adecuada y también el establecimiento de programas de formación los cuales deben facilitar este proceso. Cabe citar, llegados a este punto, el anteriormente mencionado Programa Mayoría de Edad para jóvenes que han sido o son tutelados y el cual se debe desarrollar en función de las necesidades del grupo objeto, orientándoles hacia una vida autónoma de las personas, llegando a poder extenderse hasta los 25 años de edad. Dicho programa es desarrollado por las Entidades Colaboradoras, según los Convenios de Colaboración junto con la Consejería de Igualdad, Salud y Políticas Sociales. En el caso de los menores extranjeros no acompañados, este programa dispone de recursos para potenciar la integración, la atención a la diversidad, las necesidades lingüísticas, culturales, de relación u otras que puedan presentar estos jóvenes. Los pilares base de este programa son entre otros:

- La madurez y el desarrollo personal y social

- La orientación vocacional y formación laboral

- La consecución de recursos básicos, principalmente la vivienda y el acceso a un empleo

En referencia a la Comunidad Autonómica de Andalucía, debemos revisar el Decreto 124/2014, de 2 de septiembre, por el que se aprueba el III Plan Integral de Inmigración en Andalucía Horizonte de 2016, donde se hace mención al caso específico de estos menores, especificando programas de integración sociolaboral antes de cumplir la mayoría de edad y la incorporación al plan de menores que han sido tutelados previamente de los menores inmigrantes, haciendo especial hincapié en la idea de desarrollar programas educativos y de inserción laboral en el caso de que permanezcan en la comunidad de Andalucía.

Por lo tanto y siguiendo la línea de la presente investigación la legislación que rige a un Menor Extranjero No Acompañado al cumplir la mayoría de edad queda reflejado entre otras por la Ley Orgánica 4/2000, la cual decreta que un menor extranjero no acompañado necesita renovar su autorización de residencia una vez alcance la mayoría de edad y para ello son necesarios los informes positivos por parte de la administración pública autonómica que atienda a sus características para una inserción sociolaboral, como se ha comentado anteriormente.

Según Pardilla (2017) y haciendo referencia al Real Decreto 557/2011, cuando el menor ha tenido una autorización de residencia, esta conserva la antigüedad, pueden darse dos supuestos: 
- Si ha residido en España por más de cinco años, le permite tener una estancia indefinida bajo las mismas condiciones que el resto de los ciudadanos españoles. Cabe destacar que se trata de una situación poco probable ya que la mayoría de MENA no llegan a residir 5 años en el Centro de Menores.

- El otro caso cuando no han cumplido estos 5 años de residencia, es que se les otorga una "residencia temporal", la cual puede renovarse por dos años si se acreditan medios económicos mensuales del 100\% del Indicador Público de Renta de Efectos Múltiples y en función de los informes positivos mencionados anteriormente (de acuerdo con los Presupuestos Generales del Estado de 2018, este requisito representaría 6.454,03 euros anuales). Posteriormente, pueden solicitar una modificación para obtener la autorización de residencia y trabajo.

Por lo que, los jóvenes extutelados se encuentran en una encrucijada, donde tienen la obligación de buscar puestos de trabajo precarios muchas veces dentro de la propia economía sumergida no solo para demostrar el tiempo que se les solicita sino para poder subsistir. Estos factores dificultan aún más el tránsito a la vida adulta, la cual no se realiza de forma progresiva. Por lo tanto, la situación de estos jóvenes mayores de edad debe hacer frente a una legislación que pretende que demuestren poseer la cantidad de 537,84 euros al mes, los cuales evidentemente deben conseguir trabajando, pero a su vez a no poder acceder a un permiso para trabajar legalmente si no cumplen los requisitos previamente. Por lo tanto, existe la opción como he mencionado de trabajar de manera ilegal, cuando no encuentran un puesto de trabajo con un contrato prolongado en el tiempo de un año para poder conseguir los requisitos que se les impone legalmente. Existe, por lo tanto, una lucha continua contra las administraciones por prologar su estancia y una situación de desmotivación y muchas veces de desesperación por no saber que será en un futuro de ellos/as. No existen ni tiempo ni recursos suficientes para poder preparar a estos "jóvenes adultos extranjeros" para vivir de una forma autónoma y legal en España, por lo que posibles intervenciones por parte de profesionales son una de las herramientas fundamentales para poder mejorar esta situación (Uceda, 2019).

\section{OBJETIVOS}

Entre los objetivos que recoge esta investigación existe un objetivo general y dos objetivos específicos. Según Buendía, Colás y Hernández (1998) la delimitación de los objetivos a trabajar debe responder a la detección de determinados síntomas como son los problemas de exclusión social. A continuación, se presentan los objetivos que se trabajaran para el diseño de la propuesta de intervención psicopedagógica.

\section{Objetivo general:}

- Trabajar la emancipación y la autonomía en Menores Extranjeros no Acompañados (16-18) y en jóvenes extutelados (18-25) en su proceso de transición a la vida adulta, a través de un a propuesta de intervención psicopedagógica.

Objetivos específicos:

- Analizar la situación de desprotección y los problemas con los que se encuentran los menores extranjeros no acompañados a partir del día que cumplen 18 años de edad, y forman parte de otro colectivo.

- Mejorar el autoconcepto de menores (16-18) y extutelados (18-25), fomentando actividades de intervención psicopedagógica para mejorar la fase de transición a la vida adulta de los jóvenes y prevenir posibles conductas disruptivas. 


\section{METODOLOGÍA}

El presente artículo se trata de una propuesta de intervención psicopedagógica a través metodología de investigación-acción. Cabe destacar que no existe una unanimidad sobre el concepto de investigación-acción, y por lo tanto en sus prácticas de investigación. La investigación-acción es definida como una forma de indagación introspectiva, colectiva emprendida por los participantes en situaciones sociales, con objeto de mejorar la racionalidad y la justicia de las prácticas sociales o educativas, así como su comprensión de esas prácticas y de las situaciones en que estas tienen lugar. Se trata de un método muy aplicado en los procesos de transformación actuales, para estudiar, controlar y alcanzar las modificaciones deseadas en un entorno social de aplicación (Vidal y Rivera, 2007). Actualmente la investigación es impensable desvincularla del contexto social en el que se encuentra. El contexto social afecta por lo tanto a la creación científica de múltiples formas y crea un espacio propio de reflexión intelectual (Colás, 1998). La reivindicación de la diversidad lleva a considerar la identidad individual, social y cultural como contenido clave de la investigación. Por lo tanto, la investigación- acción es una forma de investigación que permite vincular el estudio de los problemas en un contexto determinado con programas de acción social, de manera que se logren de forma simultánea conocimientos y cambios sociales (Vidal y Rivera, 2007). Se trata por lo tanto de una investigación que constituye una imperiosa necesidad social. En esta investigación-acción se seguirán una serie de pasos a seguir según esta metodología, en primer lugar, se debe identificar un área de mejora como es la autonomía y emancipación de los Menores Extranjeros No Acompañados al cumplir la mayoría de edad, realizando una revisión en la literatura para encontrar posibles propuestas de actuación. Siguiendo con la metodología, el siguiente paso es implementar la propuesta de intervención con el fin de una mejora. Esta propuesta debe ser diseñada con una evaluación especifica tanto a corto como a largo plazo, para un futuro seguimiento a la hora de la práctica. Finalmente, debe realizarse un análisis de los datos recogidos para efectuar cambios y reflexionar sobre los mismo, haciendo si es posible nuevas propuestas de mejora en el área identificada que serían aplicadas en el siguiente ciclo de la metodología.

\section{PARTICIPANTES}

Los participantes de esta investigación-acción se trata de dos colectivos, como son los menores extranjeros no acompañados de 16 a 18 años y los jóvenes extutelados o tutelados por el estado de 18 a 25 años. Concretamente esta propuesta está dirigida a jóvenes entre 16 y 25 años bajo la protección de la tutela de la comunidad autónoma de Andalucía ya sea en centros de menores o en residentes de viviendas tuteladas.

\section{INSTRUMENTO}

Se realiza una propuesta de intervención psicopedagógica dirigida a los participantes expresados con anterioridad a través de un análisis DAFO y un análisis CAME de las necesidades detectadas de programas y propuestas de intervención realizados a partir de la revisión de la literatura.

\section{ANÁLISIS DE NECESIDADES}

Para comprender mejor las necesidades a las que hay que hacer frente y mejorar la situación de estos menores extranjeros no acompañados se ha realizado un análisis DAFO y CAME. La finalidad que se quiere conseguir con estos análisis es analizar y obtener información acerca de las necesidades de los menores extranjeros no acompañados y extutelados para poder abordarlas desde una propuesta de intervención psicopedagógica, facilitando la 
integración social y laboral. Para completar el análisis DAFO, se lleva a cabo también un análisis CAME que resulta de un esfuerzo por dar respuesta a aquello que se puede cambiar.

\section{ANÁLISIS DAFO}

En primer lugar, con respecto al análisis de la presente investigación, se ha utilizado la técnica $\mathrm{DAFO}$, que es una herramienta que facilita el análisis de los factores estratégicos críticos, con el propósito de poder programar y así crear una estrategia para la toma de decisiones. Presenta cuatro métodos para la localización de necesidades: debilidades, amenazas, fortalezas y oportunidades. Se presenta, el análisis DAFO en las dos secciones que incluyen el análisis interno (debilidades y fortalezas) y el análisis externo (amenazas y oportunidades).

Se trata de realizar una reflexión sobre qué aspectos son los que más y mejor pueden potenciar la transformación del problema analizado en esta investigación. Se visualizan los aspectos positivos y negativos, tanto desde dentro como desde el exterior, siendo al tiempo conscientes de cuáles son los que han de estar más potenciados y sobre cuáles hay que prestar más atención para que no desarticulen las acciones posteriores a la hora de su implantación. A continuación, se presenta el análisis tanto de limitaciones como de potencialidades que presenta la propuesta de intervención frente a la situación de estos colectivos:

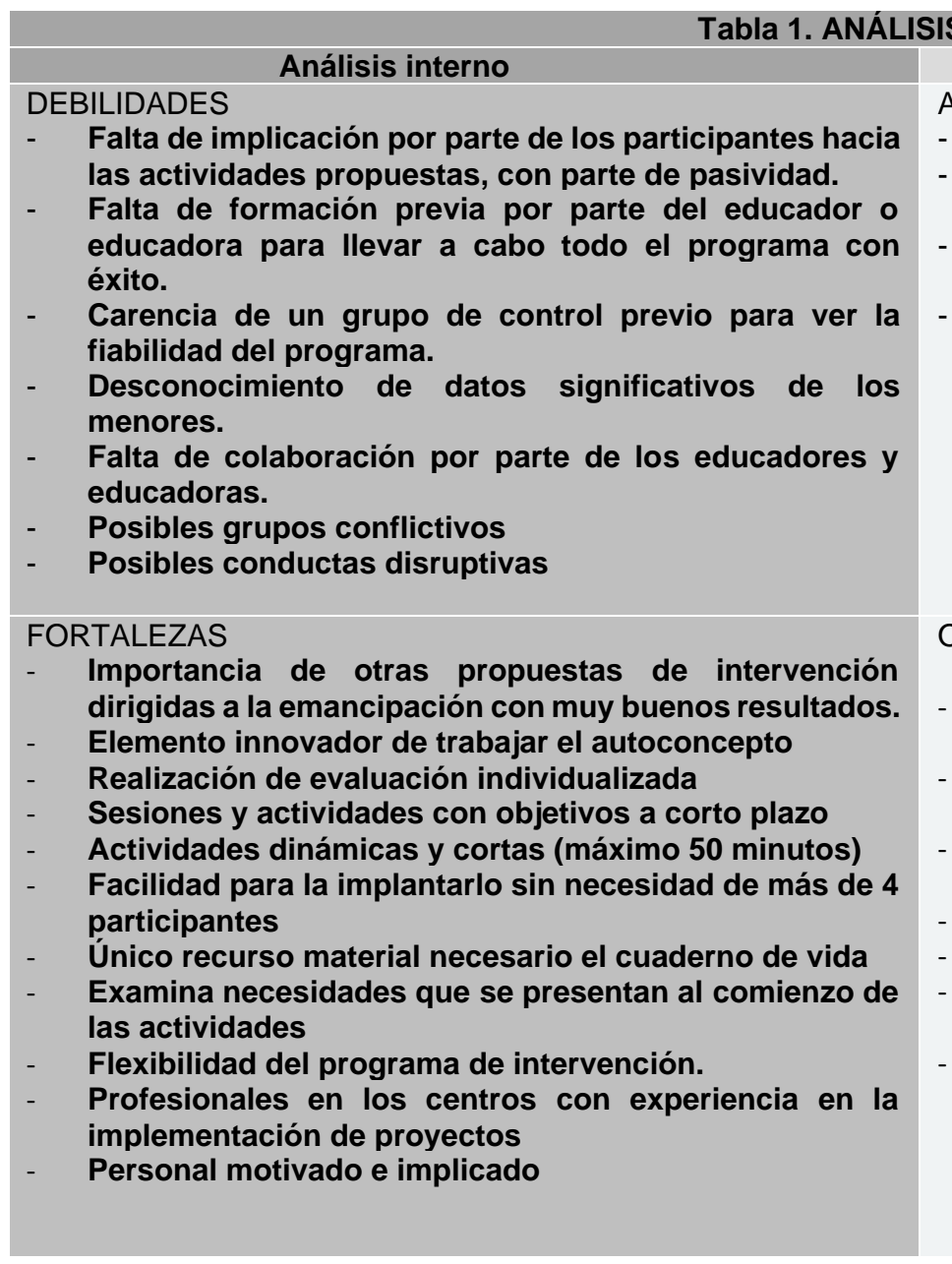

\section{OPORTUNIDADES}

Habilidades sociales y contenidos aprendidos se pueden poner en práctica en su entorno inmediato.

Programa +18 de la Junta de Andalucía para el colectivo de 18 a 25 años

Gran cantidad de centros de menores en la ciudad de Granada

Posible adaptación de las actividades a otros contextos.

Existencia de Historia de vida de los participantes en el centro. Posibilidad de adaptarse al desarrollo evolutivo de ambos grupos

Competencias a desarrollar relacionadas con la LOMCE 


\begin{abstract}
ANÁLISIS CAME
Por otra parte, posteriormente se realiza un análisis CAME como ampliación de la matriz DAFO, dividido en cuatro partes, corregir, afrontar, mantener y explotar, con la intención de dar posibles respuestas a las dificultades encontradas en el anterior análisis DAFO. A partir del análisis CAME se comienza a diseñar una serie de estrategias y planificación para la definición del proyecto de intervención, para complementar las ideas analizadas del programa con el análisis DAFO. De esta manera en función de las debilidades, fortalezas, amenazas y oportunidades se realiza el siguiente análisis: Corregir las debilidades o hacer que desaparezcan o que no afecten negativamente, Afrontar las amenazas y evitar que se conviertan en debilidades, Mantener las fortalezas y tomar medidas para evitar perderlas, Explorar y explotar las oportunidades creando estrategias y planificando acciones para que se conviertan en futuras fortalezas.
\end{abstract}

\title{
Tabla 2. ANALISIS CAME
}

\section{CORREGIR DEBILIDADES}

Realización de actividades dinámicas en el módulo I para captar el interés

El programa cuenta con una formación previa, con los objetivos y competencias a conseguir en cada actividad, desarrollado de manera específica Existen programas de inserción laboral los cuales han cumplido sus objetivos

El centro/piso ofrece cualquier tipo de información necesaria sobre cada menor con la posibilidad de entrevistas individuales

En el programa se contempla la posibilidad de evaluar a un grupo de control previamente y que cumpla con unas características similares a los otros grupos que realizarán el programa.

Se trata de un programa planificado de trabajo colaborativo con el máximo de actores profesionales para su implementación

Propuestas metodológicas para evitar las conductas disruptivas

\section{MANTENER FORTALEZAS}

Se siguen los puntos fuertes de otras programaciones realizadas hacia la emancipación de los jóvenes Analizar y comparar los resultados con un programa donde no se trabaje el autoconcepto

Realizar cada sesión autoevaluaciones o coevaluaciones cortas

Ofrecer cierta flexibilidad temporal a la hora de implementar el programa

Actividades con modalidad individuales o por parejas Realización de materiales o recursos, con posibles modificaciones

Realización de Pre- test y análisis de estos para comprobar sus necesidades y objetivos específicos, para poder adaptar el programa en caso de que sea necesario

Implicar a los profesionales mejor preparados para el desarrollo de la propuesta de intervención

\section{AFRONTAR AMENAZAS}

Existe la posibilidad de realizarlo al aire libre Se propone la posibilidad de acortar las 5 últimas actividades de cada módulo

En caso de discontinuidad del proceso debería repetirse a modo de repaso en una sesión.

\section{EXPLOTAR OPORTUNIDADES}

Ofrece las competencias y objetivos que se va a pedir en los participantes para hacerles partícipes del programa

Pisos de tutela donde se puede llevar a cabo el programa de intervención

Proponer a todos los centros la implementación y los objetivos del programa

Adaptación del programa, implementación por parte de los profesionales del centro, personalizada y grupal Desarrollo de una Historia de Vida de cada menor, que le acompañe hasta los 25 años.

Programa realizado para un rango de edades muy amplio

Necesidad de revisar todos los años posibles cambios en la legislación 


\section{DISEÑO DE LA PROPUESTA DE INTERVENCIÓN PSICOPEDAGÓGICA}

En este apartado se procede a explicar la propuesta de intervención que va a llevarse a cabo para mejorar el autoconcepto y la autonomía para la emancipación de ambos colectivos, para favorecer una correcta integración social como laboral. Se especificarán los destinatarios y el contexto, además de fijar sus correspondientes objetivos, a partir de los cuales y basándonos en la revisión de la literatura y los análisis realizados, se desarrollan actividades para satisfacer las necesidades detectadas. Todo esto, tendrá una temporalización general a través de un cronograma y una evaluación general de la propuesta.

\section{CONTEXTUALIZACIÓN}

La propuesta de intervención desarrollada se centra en la Comunidad Autónoma de Andalucía, dado que la población de menores extranjeros ha ido incrementándose en todas las provincias andaluzas a lo largo de los últimos años (Observatorio de la Infancia en Andalucía, 2012). La propuesta se desarrollará tanto en centros de menores como en pisos tutelados, basado en lo que rigen las leyes de esta comunidad autónoma y en los programas desarrollados por esta. Para los menores extranjeros no acompañados a los que va dirigido la propuesta de intervención y según el Decreto 355/2003, de 16 de diciembre de Acogimiento Residencial de Menores los Centros de Protección son establecimientos destinados al acogimiento residencial de menores sobre quienes se asuma u ostente previamente alguna de las medidas de tutela o guarda, sin prejuicio de la atención inmediata que se les preste cuando se encuentren transitoriamente en una supuesta situación de desprotección. Los Centros de Protección, constituyen espacios donde se atiende las menores, promoviendo el desarrollo integral de las diversas dimensiones como personas, combinando la calidad técnica y la calidez humana. Se trata por lo tanto de un entorno convivencial y formativo en el que se garantiza, una serie de recursos profesionales y materiales adecuados y por otro, una calidez que posibilite relaciones afectivas.

Respecto a los jóvenes extutelados de la comunidad de Andalucía y refiriéndonos a la Ley 1/1998 de 22 de Abril de los Derechos y la Atención al Menor, establece en un artículo que: al menos, durante el año siguiente a la salida de los menores de un centro de protección, la Administración de la Junta de Andalucía efectuará un seguimiento de aquéllos al objeto de comprobar que su integración socio-laboral sea correcta, aplicando la ayuda técnica necesaria (Ley 1/1998, art.37.2) y en además: se potenciará el desarrollo de programas de formación profesional e inserción laboral de los menores sometidos a medidas de protección, con el fin de facilitar su plena autonomía e integración social al llegar a su mayoría de edad (Ley 1/1998, art.19.1f).

Como se ha comentado anteriormente el Decreto 355/2003, de 16 de diciembre de Acogimiento Residencial de Menores los Centros de Protección son establecimientos destinados al acogimiento residencial de menores sobre quienes se asuma u ostente previamente alguna de las medidas de tutela o guarda, sin perjuicio de la atención inmediata que se les preste cuando se encuentren transitoriamente en una supuesta situación de desprotección. Con este propósito se desarrolla el Programa de Mayoría de Edad para jóvenes que son o han sido tutelados o tuteladas, $P+18$, el cual se inicia desde las necesidades detectadas en este grupo de personas, que, al cumplir la mayoría de edad son considerados por la legislación vigente como personas que ya han alcanzado la madurez, con plena capacidad para vivir de forma autónoma. Así se trata de permitirles enfrentarse a su nueva situación de autonomía e independencia con unas mínimas garantías para llegar a su plena integración sociolaboral. Mediante este programa se promueve la integración de jóvenes desde una perspectiva integral, desde cuatro pilares: La maduración y el desarrollo personal y social, La orientación vocacional y la formación para el empleo, La consecución 
de recursos básicos, especialmente la vivienda y el Acceso al empleo, para lo que se promueve la Formación Ocupacional o Inserción Laboral para jóvenes que han sido tutelados o tuteladas por la Junta de Andalucía

Por lo tanto, y en base a este contexto se trata de la elaboración de una propuesta de intervención que de facilidades a la hora de integrarse el mercado laboral y en la propia sociedad, mejorando en todo momento su autoconcepto como el factor psicosocial principal para evitar posibles conductas disruptivas y favorecer su autonomía sociolaboral y la emancipación en su mayoría de edad.

\section{DESTINATARIOS}

El perfil de los destinatarios de esta propuesta de intervención va dirigido a un rango de edad de jóvenes de 16 a 25 años:

- Menores Extranjeros No Acompañados a partir de los 16 hasta los 18 años en los centros de menores, aproximándose a la edad de emancipación con el fin de prepararse para ello.

- Jóvenes extutelados y tutelados por las administraciones en los pisos tutelados de los 18 a los 25 años, los cuales ya han comenzado su emancipación.

\section{OBJETIVOS}

A través de esta propuesta de intervención, basándose en los objetivos propuestos para el Programa +18 y teniendo en cuenta que en los centros de protección orientan a estas personas para la vida autónoma, iniciando acciones antes de alcanzar la mayoría de edad, las cuales se pueden extender, en algunos casos, hasta los 25 años, se diseñan los objetivos de dicha propuesta de intervención.

El objetivo general de esta intervención está relacionado con el análisis DAFO y CAME realizado anteriormente teniendo de base la revisión de la literatura que existe sobre este tema. Se trata de la elaboración de una propuesta de intervención para favorecer el autoconcepto positivo de estos jóvenes y así facilitar su integración social y laboral a través de actividades y dinámicas.

Dentro de este objetivo general podemos distinguir dos específicos:

- Favorecer el autoconcepto positivo

- Dotar de habilidades sociales y conocimientos para fomentar su autonomía personal con el fin de llegar a una plena integración social y laboral

\section{METODOLOGÍA}

La propuesta se realiza a través de una metodología activa, práctica y participativa, con explicaciones breves y directas, siendo dinámicas con el fin de conseguir una mayor atención y motivación. La metodología utilizada permite que se ofrezca un tiempo final en cada actividad a la reflexión en grupo e individual con el objetivo de que se posibilite un aprendizaje significativo de los contenidos o temas tratados, con el objetivo de que los y las participantes perciban la utilidad de sus aprendizajes, refiriéndonos a la competencia de aprender a aprender. Para facilitar esta tarea en la propuesta se ofrece la herramienta del cuaderno de vida, un tipo de porfolio realizado por cada participante en el transcurso de la propuesta. Será participativa, para así crear un clima de confianza en el que los participantes puedan expresar libremente sus opiniones y vivencias. Por lo tanto, se pedirá confidencialidad a todas los/las 
participantes del programa. También será de importancia la asistencia regular y el compromiso. Aunque no será obligatorio que participen si no se ven cómodos/as con el tema tratado en alguna sesión. Se dejará expresarse, opinar, manifestar sus inquietudes y valoraciones de forma abierta y tolerante a todo el mundo. Puesto que las experiencias de cada participante le pueden ayudar a otro, y así ver que no son las únicos/as que han vivido o están viviendo estas situaciones, consiguiendo así estrechar lazos entre todos/as. Esta propuesta debe ser entendida como un esfuerzo de innovación y mejoramiento de la práctica social, la que deberá ser sometida permanentemente a condiciones de análisis, evaluación y reflexión.

Las sesiones de esta propuesta de intervención se desarrollan la mayoría en grupos de trabajo, favoreciendo así las relaciones interpersonales entre los propios compañeros/as y con los educadores/as. Para la realización de la propuesta de intervención, se debe utilizar un lenguaje claro, procurando que todos/as los participantes de la propuesta participen en el programa con independencia de las posibles barreras de idioma. Además, en todo momento es necesario que se refuercen positivamente los éxitos, aumentando así de forma transversal el autoconcepto de los participantes y el esfuerzo por mejorar.

Es necesario propiciar un entorno seguro que permita a estos jóvenes adquirir las habilidades y conocimientos necesarios para su desarrollo afectivo, psicológico e intelectual, conociendo no solo los factores de migración general de este colectivo sino tener en cuenta los costes del viaje que cada joven ha vivido. Esta parte es necesaria para entender las pautas de conducta a nivel individual y así poder llevar la propuesta de forma efectiva (Fuentes, 2014).

\section{TEMPORALIZACIÓN}

La propuesta de intervención psicopedagógica tendrá una duración de 2 meses y una semana, considerando que es el tiempo necesario para realizar todas las actividades inclusive de la evaluación inicial y final, dedicando 8 semanas a la intervención directa de las actividades. Se aconseja los meses de enero, febrero y marzo, para no coincidir con periodos vacacionales y así poder trabajarlo de manera continua. En el primer mes se llevará a cabo una evaluación inicial recogiendo los datos e información necesaria a cerca de los participantes, además de una observación directa llevada a cabo previamente a la intervención.

Seguidamente a esta fase, las actividades se dividirán por módulos referidos a los objetivos específicos anteriormente previstos.

- Pre- módulo: Cuaderno de vida

- Módulo I: Mejorar del autoconcepto positivo

- Módulo II: Fomentar la emancipación y autonomía sociolaboral

Cada módulo consta de una duración de 9 sesiones, con una duración máxima de 50 minutos cada una y repartidas por dos sesiones cada semana con una duración aproximada de dos meses y medio. Cada actividad cuenta con unos objetivos, competencias, destinatarios, temporalización, modalidad, desarrollo de la actividad, materiales y su propia evaluación procesual. Aunque finalmente sea en la última semana de la propuesta donde se lleve a cabo la evaluación final del programa de intervención. Es imprescindible por parte de los profesionales estructurar el tiempo de las actividades para que la repetición diaria de las rutinas les de seguridad e interioricen las nociones temporales para lo que sucederá después. 
Toda esta información queda plasmada siguiendo la organización general del siguiente cronograma:

Tabla 1. Cronograma de la propuesta de intervención

\begin{tabular}{|c|c|c|c|c|c|c|c|c|c|c|c|c|c|c|c|c|c|c|}
\hline MESES & \multicolumn{8}{|c|}{$1^{\circ}$} & \multicolumn{8}{|c|}{$2^{0}$} & \multirow{2}{*}{\multicolumn{2}{|c|}{$\begin{array}{l}3^{0} \\
9^{a}\end{array}$}} \\
\hline SEMANAS & \multicolumn{2}{|c|}{$1^{\underline{a}}$} & \multicolumn{2}{|c|}{$2^{\underline{a}}$} & \multicolumn{2}{|c|}{$3^{\mathrm{a}}$} & \multicolumn{2}{|c|}{$4^{\mathrm{a}}$} & \multicolumn{2}{|c|}{$5^{a}$} & \multicolumn{2}{|c|}{$6^{\underline{a}}$} & \multicolumn{2}{|c|}{$7^{\mathrm{a}} \mathrm{a}$} & \multicolumn{2}{|c|}{$8^{\underline{a}}$} & & \\
\hline & 1 & 2 & 3 & 4 & 5 & 6 & 7 & 8 & 9 & 10 & 11 & 12 & 13 & 14 & 15 & 16 & 17 & 18 \\
\hline ACTIVIDADES & & & & & & & & & & & & & & & & & & \\
\hline $\begin{array}{l}\text { EVALUACIÓN } \\
\text { INICIAL }\end{array}$ & & & & & & & & & & & & & & & & & & \\
\hline $\begin{array}{l}\text { REGISTRO POF } \\
\text { HROAS }\end{array}$ & & & & & & & & & & & & & & & & & & \\
\hline $\begin{array}{c}\text { CUADERNO DE } \\
\text { VIDA }\end{array}$ & & & & & & & & & & & & & & & & & & \\
\hline MODULO I & & & & & & & & & & & & & & & & & & \\
\hline ACTIVIDAD 1 & & & & & & & & & & & & & & & & & & \\
\hline ACTIVIDAD 2 & & & & & & & & & & & & & & & & & & \\
\hline ACTIVIDAD 3 & & & & & & & & & & & & & & & & & & \\
\hline ACTIVIDAD 4 & & & & & & & & & & & & & & & & & & \\
\hline ACTIVIDAD 5 & & & & & & & & & & & & & & & & & & \\
\hline ACTIVIDAD 6 & & & & & & & & & & & & & & & & & & \\
\hline ACTIVIDAD 7 & & & & & & & & & & & & & & & & & & \\
\hline ACTIVIDAD 8 & & & & & & & & & & & & & & & & & & \\
\hline ACTIVIDAD 9 & & & & & & & & & & & & & & & & & & \\
\hline MODULO II & & & & & & & & & & & & & & & & & & \\
\hline ACTIVIDAD 1 & & & & & & & & & & & & & & & & & & \\
\hline ACTIVIDAD 2 & & & & & & & & & & & & & & & & & & \\
\hline ACTIVIDAD 3 & & & & & & & & & & & & & & & & & & \\
\hline ACTIVIDAD 4 & & & & & & & & & & & & & & & & & & \\
\hline ACTIVIDAD 5 & & & & & & & & & & & & & & & & & & \\
\hline ACTIVIDAD 6 & & & & & & & & & & & & & & & & & & \\
\hline ACTIVIDAD 7 & & & & & & & & & & & & & & & & & & \\
\hline ACTIVIDAD 8 & & & & & & & & & & & & & & & & & & \\
\hline ACTIVIDAD 9 & & & & & & & & & & & & & & & & & & \\
\hline $\begin{array}{l}\text { EVALUACIÓN } \\
\text { PROCESUAL }\end{array}$ & & & & & & & & & & & & & & & & & & \\
\hline $\begin{array}{l}\text { EVALUACIÓN } \\
\text { FINAL }\end{array}$ & & & & & & & & & & & & & & & & & & \\
\hline
\end{tabular}




\section{ACTIVIDADES}

La propuesta de intervención psicopedagógica realizada se dividirá en 2 módulos, con 9 actividades en cada uno de ellos. Estos módulos están divididos según los objetivos que persiguen y secuenciados por la manera de trabajar principalmente para un buen autoconcepto y en segundo lugar para la emancipación, a través de fomentar habilidades sociales. Para alcanzar los objetivos de esta intervención se deberá contar con la participación activa de ambos grupos a los que va destinado el programa de intervención. Para la realización de este programa se debe dejar claro unos aspectos previos antes de trabajar:

Es necesario tener una actitud de respeto hacia los compañeros, compañeras y profesionales, respetado sus características y cualidades para comenzar a valorarlas, eliminando cualquier actitud de discriminación en relación con el sexo, raza o cualquier rasgo diferenciador. Conseguir una imagen ajustada y positiva de sí mismo/a, llegando a identificar sus características y cualidades más personales, para poder realizar el Módulo II.

Para una buena realización de las actividades de ambos módulos es imprescindible que desde la primera sesión se creen unas expectativas lo suficientemente grandes como para poder captar el interés y la atención de los jóvenes, así como su motivación y participación.

Al comenzar el programa en cada centro o piso tutelado, se les dará la bienvenida. A continuación, se presentará el cronograma de las actividades que se irán desarrollando. A partir de estas actividades y a lo largo del programa se irán trabajando el autoconcepto y la emancipación a través de sus propios intereses ya que se realizará una pre evaluación, no solo para ver los resultados del programa una vez se realice sino para la posible adaptación de alguna actividad a los intereses personales.

Es conveniente que se realicen unas presentaciones en el caso de que no se conozcan los participantes, con la finalidad de establecer relación e integración con el resto de los compañeros y los profesionales que lleven a cabo dicho programa. Además, es de vital importancia presentar a los participantes el cronograma que aparece al comienzo de este apartado para que sean conscientes y organicen su tiempo en función de las actividades que se van a realizar. Finalmente se desarrollarán tanto a modo individual como grupal, las actividades tanto para mejorar su autoconcepto como para desarrollar en el participante un posible proyecto de vida y autonomía para su emancipación. Para una atención a la diversidad, se debe poner atención en las personas más tímidas, con menor motivación o con más dificultad para relacionarse. Para esta actividad es imprescindible contar con un buen clima de confianza y un alto grado de auto motivación grupal. La persona dinamizadora ha de impulsar con su actitud todo el proceso.

Propuestas de control para el manejo de la interacción en el aula:

- Efectuar gestos y miradas que indiquen la conducta deseada

- Realizar indicaciones centradas en las actividades

- No otorgar atención a las conductas de disrupción leve

- Silencio del educador/a ante la dispersión del aula

- Invadir territorio, acercamiento a la zona o alumno/a disruptivo

- Utilizar el humor, no el sarcasmo

- Explicitar de forma breve las consecuencias derivadas de la conducta inadecuada 
A continuación, se desarrollan todas las actividades en diferentes tablas para su mejor compresión:

\section{Pre test y post test}

Pre test, relacionado con los intereses del participante para una posible adaptación de las actividades y con la finalidad de poder evaluar el programa una vez desarrollado, comparando los resultados con el post- test al finalizar la propuesta.

\section{Registro por horas}

Se cuenta con una herramienta muy útil llamada registro por horas que deberán realizar la primera semana y la última de la programación, con la finalidad de ver donde se debe incidir más y en algún caso si es necesario derivar a otros profesionales, deberán apuntar lo más exacto posible las horas de clase, estudio y ocio, y lo que hacen en esas horas. De esta forma se estructurará las rutinas diarias para poder adaptarse a las necesidades y capacidades de los participantes, favoreciendo el orden y organización de la vida cotidiana para que adquieran la capacidad de prever situaciones, aunque siempre permitiendo la suficiente flexibilidad.

\section{Autoevaluación}

Se trata de un breve cuestionario que se realizará de forma individual por los participantes al final de cada sesión, a modo de evaluación procesual y comprobar si se están desarrollando los objetivos establecidos para cada actividad.

\section{- PRE-MÓDULO: CUADERNO DE VIDA}

Basándonos en desarrollar la competencia marcada como clave por la LOMCE de, Aprender a aprender, que se trata de una de las principales competencias, donde se desarrolla la capacidad para iniciar un aprendizaje y persistir en él, organizar las tareas y el tiempo y trabajar de manera individual o colaborativa con el fin de conseguir un objetivo. Es imprescindible que, al finalizar cada actividad de las propuestas en el actual programa de intervención, se cree un ambiente relajado y de reflexión, donde cada uno haga autocritica de lo que ha aportado la actividad o de lo que haya podido aprender., se trata al fin y al cabo de una reflexión acerca de lo vivido hasta el momento con el programa. Para ello es necesario crear un ambiente de respeto y cordialidad. Entre algunas preguntas que se deben hacer a la hora de la reflexión son:

- ¿Cómo os habéis sentido?

- ¿Qué tema se ha trabajado?

- ¿Qué crees que se podría mejorar? 


\section{Actividad previa: Cuaderno de vida}

Esta actividad se realizará de forma continua durante todo el programa, trata de un registro personal y material donde se deben ir incluyendo cronológicamente los elementos más significativos de su pasado, presente y futuro. Todas las ideas que le puedan aparecer por la cabeza en cada momento de la propuesta y las reflexiones personales de cada actividad, además ideas respectivas que puedan surgir a cada sesión. Para ello completaran un libro que se ha desarrollado específicamente para este programa, con la finalidad de que puedan revivir los sentimientos e ideas que este programa les proporciona.

En este se incluyen:

- Las diferentes actividades tanto del módulo I como del módulo II con el fin de que los participantes sepan en cada sesión que es lo que se pretende lograr con el desarrollo de la actividad y a continuación una parte de reflexión individual

- Algunas herramientas necesarias para completar algunas de las actividades

- Camino de experiencias, como una representación gráfica donde se plantean los posibles trayectos que pueda seguir la vida del menor o el joven fuera de este programa

- Hojas destinadas a un "Mural anónimo" donde podrán dibujar, pintar o expresar las ideas que tengan para dejarlas reflejadas

- Flujograma, que consiste en elaborar un diagrama de flujo donde se van colocando cuadros en cuyo interior se pueden escribir los acontecimientos vitales más significativos en el orden temporal que ocurrieron

\section{Objetivos}

- Comprender acontecimientos significativos de su pasado

- Afrontar posibles sentimientos derivados de esos acontecimientos

- Sentirse implicados en la planificación de sus vidas

$\begin{array}{ll}\text { Competencias } & \text { - Aprendizaje autónomo } \\ & - \text { Aplicación de estrategias cognitivas en la construcción del conocimiento } \\ & - \text { Aplicación de estrategias metacognitivas de reflexión, autocontrol, } \\ & \text { autorregulación y autoevaluación } \\ - & \text { Automotivación y persistencia en el trabajo } \\ - & \text { Organización y planificación del trabajo } \\ - & \text { Expresión oral y escrita. } \\ - & \text { Habilidades interpersonales } \\ - & \text { Gestión del propio aprendizaje y gestión de los éxitos y fracasos. } \\ - & \text { Confianza en sí mismo } \\ - & \text { Toma de decisiones }\end{array}$

\section{Destinatarios}

- Menores Extranjeros No Acompañados (16 a 18)

- Jóvenes extutelados (18-25)

Temporalización

- La realización de esta actividad será aproximadamente durante los últimos 10 minutos de todas las sesiones 
Desarrollo Este tipo de intervención trata de evitar rupturas dramáticas en el relato personal de los participantes y se fundamenta en acompañarlos en la activa elaboración de un cuaderno donde existan una secuencia de acontecimientos que hayan tenido sentido personalmente. Se trata de plasmar en un inicio las vivencias, los hitos, experiencias, sentimientos a partir ya sea de escritos, dibujos o canciones. Aportando siempre por el educador o educadora una escucha activa, de comprensión y aceptación hacia sus sentimientos, aunque se deban corregir algunas conductas. En este cuaderno se reflejarán todas las reflexiones sobre las actividades realizadas en la intervención. Además, los debates en grupo pueden ayudar para elaborar una reflexión en sus cuadernos sobre temas que les hayan llamado la atención. Deben tener claro que es un cuaderno personal a modo de diario, el cual nadie tendrá acceso y podrán plasmar con total libertad sus reflexiones. Además, este cuaderno consta de las evaluaciones de cada actividad.

\begin{tabular}{lll}
\hline Materiales & - & Cuaderno de vida \\
\hline Evaluación & - & Observación directa \\
& - & Autoevaluación
\end{tabular}

- MÓDULO I: ACTIVIDADES DIRIGIDAS A MEJORAR EL AUTOCONCEPTO

Las actividades propuestas para este primer módulo están dirigidas a mejorar el autoconcepto de los menores extranjeros no acompañados y los jóvenes extutelados. Basándonos en las competencias clave a desarrollar por la LOMCE, las competencias que se desarrollan en este módulo están relacionadas con las "competencias sociales y cívicas" que hacen referencia a las capacidades para relacionarse con las personas y participar de manera activa, participativa y democrática tanto en la vida social como en la cívica. Para todas las actividades se necesita crear una atmosfera de respeto y de libertad, sin prejuzgar ninguna situación. Cabe destacar además que todas las actividades aquí propuestas son para realizar a través de una modalidad presencial.

\section{Actividad 1: Mi caja}

La primera actividad, se trata a modo de presentación de lo que se va a llevar a cabo y como una autopresentación hacia los participantes, para conseguir una buena realización del programa.

\section{Objetivos}

Trabajar el autoconcepto positivo y la introspección

Reflexionar y respetar los sentimientos de los demás, potenciando la capacidad de la empatía

- Generar lazos y reforzar las relaciones interpersonales

\section{Competencias}

\author{
Capacidad reflexiva \\ Expresión oral \\ Pensamiento critico
}




Destinatarios $\quad$ - $\quad$ Menores Extranjeros No Acompañados (16 a 18)

Jóvenes extutelados (18-25)

Temporalización $\quad-\quad 50$ minutos

\begin{tabular}{ll}
\hline Modalidad & $-\quad$ Grupos máximo de 15 personas con el fin de favorecer un contexto de \\
& confianza donde se sientan seguros
\end{tabular}

Desarrollo Para comenzar esta actividad, se pasará a cada participante la ficha de la evaluación de la propuesta para que la rellenen durante 10 minutos de forma individual.

En esta actividad, a modo de presentación se les ofrece una caja de zapatos a cada uno/a, con unas instrucciones muy claras, deben guardar dentro 4 cosas materiales u objetos que consideren que son imprescindibles en su vida, que consideren importantes o que les traigan buenos recuerdos y dejar por fuera de la caja 2 cosas que consideren que son importantes, pero podrían prescindir de ellas. Se trata de que la llenen de cosas que sean importantes para ellos y cosas que identifiquen aspectos importantes de sus vidas: valores, experiencias, hobbies.

Una vez se encuentren en el aula con todas las cajas sobre la mesa, cada participante irá sacando los elementos de su caja y compartiendo con el grupo todo lo que quieran compartir respecto a la "historia" de cada uno de esos elementos. Se dispondrán cuartillas de papel blanco para que todos los presentes puedan escribir comentarios respecto a cada caja, en la que irán depositando los mismos.

Cuando todos/as hayan presentado sus cajas, estas se tapan y cada uno de forma individual leerá los comentarios que haya recibido de sus compañeros. Finalmente se dará un tiempo para un debate grupal, y para que plasmen todas sus reflexiones en el cuaderno de vida.

Propuesta de continuidad para la actividad: Las cajas de los participantes se utilizarán a modo de cofre de tesoro después de haber compartido en esta actividad lo que hay en el interior y el significado que tiene para cada participante. Para ello se guardarán las cajas en el aula a la vista de todos, teniendo la posibilidad de añadir objetos a lo largo de las sesiones, e ir decorándolas a su gusto. El objetivo es que, con el tiempo, la caja convertida en un cofre vaya adquiriendo más significado para el participante, llegando a convertirse en un recipiente para sus sentimientos, experiencias y recuerdos tanto recientes como antiguos. Es una forma de afianzar los recuerdos y las relaciones positivas a lo largo de la propuesta, de manera que la caja y el contenido de esta se convierta en un símbolo de aspectos positivos y valiosos de sí mismo.

\begin{tabular}{lll}
\hline Materiales & - & Cajas de cartón \\
& - & Bolígrafos y rotuladores \\
& - & Cuaderno de vida
\end{tabular}




\section{Actividad 2: ¿Qué llevas en tu maleta?}

Trabajar la imaginación al fin y al cabo sirve como herramienta para buscar posibles soluciones a los problemas y así enfrentarnos a diferentes situaciones que se presentan a lo largo de la vida.

\section{Objetivos}

Trabajar la comprensión a través de la imaginación

Fomentar la comunicación

\section{Competencias}

Aprender a escuchar

- $\quad$ Comunicación de ideas y elaboración de conclusiones

\begin{tabular}{lll}
\hline Destinatarios & - & Menores Extranjeros No Acompañados (16-18) \\
& - & Jóvenes extutelados (18-25)
\end{tabular}

Temporalización $\quad-\quad 50$ minutos

Modalidad $\quad$ - $\quad$ Se desarrolla de manera grupal con un máximo de 20 participantes.

Desarrollo

En esta actividad, los participantes se colocan en un círculo ya sea de pie o sentados. Se trata de una dinámica donde el coordinador de la actividad deberá explicar de forma muy sencilla como se va a trabajar. Comienza un participante con un ovillo de lana y cuenta "En mi maleta llevo..." y dice el objeto, la persona o el momento que él o ella decida, una vez lo diga se lo lanza a otro compañero el cual deberá continuar la frase "En mi maleta llevo...+ lo que haya dicho su compañero/a y añadir algo suyo" así sucesivamente, hasta que se equivoquen o se acabe el ovillo de lana, donde al final podrán observar como con ayuda de todos y todas se ha construido una historia enlazada por las cuerdas del ovillo.

Finalmente se desarrolla un debate grupal sobre la dinámica, y los objetivos que se han conseguido a través de ella y se deja un tiempo para una reflexión individual en el cuaderno de vida del participante.

\begin{tabular}{lll}
\hline Materiales & - & Un ovillo de lana \\
& - & Cuaderno de vida
\end{tabular}

Evaluación $\quad-\quad$ Observación directa Autoevaluación 


\section{Actividad 3: El reflejo}

En esta actividad se deben hacer ver todos los aspectos positivos del participante, haciendo además que llegue a valorarlos, para así mejorar su autoconcepto, como las actitudes y comportamientos que forman la concepción que tenemos acerca de nosotros mismos.

Objetivos $\quad-\quad$ Fomentar la introspección, promoviendo el reconocimiento de uno mismo en sentido de su situación vital.

Mejorar el autoconcepto

- $\quad$ Fomentar la comunicación y el respeto

- $\quad$ Advertir y conocer cuál es la imagen que tiene cada uno sobre sí mismo, para trabajar los aspectos más relevantes

Competencias

- Comprensión de códigos de conducta aceptables en diferentes sociedades y entornos

Destinatarios

Menores Extranjeros No Acompañados (16-18)

Jóvenes extutelados (18-25)

Temporalización

50 minutos

Modalidad

Se desarrolla por grupos de máximo 4 o 5 participantes

Desarrollo

Se trata de una dinámica grupal, donde es importante realizar previamente una serie de preguntas para obtener información: información previa a su

- ¿ ¿Cuándo te miras en el espejo te ves guapo/a?

- ¿ ¿Piensas que tienes cosas buenas que aportar a los demás? ¿Cuáles?

- $\quad ¿ C r e e s$ que les gustas a tus amigos y compañeros tal y como eres?

- ¿Qué cambiarias de tu apariencia?

- ¿ ¿Cuándo te sientes y te ves bien, te sientes más seguro de ti mismo?

Una vez realizadas las preguntas de forma oral, de uno en uno acercaremos el espejo dejándolo en un sitio que, de seguridad al participante, y entonces comenzaremos a preguntar:

- ¿QQué ves en el espejo?

- ¿ ¿Cómo es la persona que te mira desde el espejo?

- ¿Lo conoces?

- ¿Qué cosas buenas tiene esa persona?

- ¿Qué cosas malas tiene quien te mira desde el espejo?

- ¿ ¿Qué es lo que más te gusta de esa persona?

- ¿Cambiarías algo de la persona del espejo?

Se trata de hacerle ver todos los aspectos positivos que tiene, y no tanto los negativos para que así pueda valorarlos. Así cada uno expresará las características personales que considera que tiene, considerando además como se juzgan a ellos mismos. Una vez hayan finalizado, serán los compañeros del 
grupo los que apoyarán la dinámica nombrando y realizando un intercambio de información sobre aspectos buenos denominando cosas que no se hayan dicho, dejando un tiempo final para plasmar las reflexiones en el cuaderno de vida.

Materiales - $\quad$ Un espejo grande

- $\quad$ Cuaderno de vida

Evaluación

Observación directa

Autoevaluación

\title{
Actividad 4: Collage
}

Al realizar un collage se propone incentivar entre todos los participantes, una producción artística que favorezca entre otras cosas la expresión del pensamiento, de las percepciones y si es posible de los sentimientos y emociones

\begin{tabular}{lll}
\hline Objetivos & - & Presentar al grupo de manera informal y fomentar la confianza grupal \\
& - & Desarrollar una comunicación y respeto grupal \\
- & Fomentar el autoconcepto positivo \\
- & Fomentar la libertad de expresión
\end{tabular}

\begin{tabular}{lll}
\hline Competencias & - & Responsabilidad personal y grupal \\
& - & Iniciativa \\
- & Toma de decisiones \\
- & Planificación y organización del trabajo
\end{tabular}

\begin{tabular}{lll}
\hline Destinatarios & - & Menores Extranjeros No Acompañados (16 a 18) \\
& - & Jóvenes extutelados (18-25)
\end{tabular}

Temporalización - 50 minutos

Modalidad $\quad$ - $\quad$ En grupos de 4 o 5 participantes

\section{Desarrollo}

\begin{abstract}
Esta actividad se trata de realizar una creación personal del retrato de cada persona a través de características propias. Para ello se divide a los participantes en grupos de 4 o 5, y a cada grupo se les entregan unas revistas, tijeras, pegamento y cartulinas. Los integrantes de cada grupo deberán compartir algunas características personales favorables que les puedan ayudar a fomentar su autoimagen positiva.

El educador o educadora, deberá distribuir las revistas por las diferentes mesas de los grupos, pidiéndoles que después de observarlas deberán elegir un máximo de 8 cada uno. Para esta selección deberán identificar en las diferentes imágenes, características que representen algunas de sus virtudes y en otras algunos de sus defectos.
\end{abstract}


Se pueden apoyar en algunas preguntas que realice el educador/a como:

- ¿Cuáles consideras que son tus defectos?

- ¿Cuáles consideras que son tus virtudes?

- ¿Qué es lo que más te gusta de ti? ¿Y lo que menos?

Dispondrán de 20 minutos para realizar el cartel, y debatir en su pequeño grupo que imágenes y cuales no le pegan más a uno u a otro. Generando un mural entre el grupo donde se complementen todas las virtudes y defectos de los compañeros. Así por ejemplo si uno se considera muy impaciente, su compañero o compañera puede que se considere lo contrario, y mientras unos lo consideran una virtud otros lo pueden considerar un defecto.

Finalmente, se expondrá la cartulina delante del gran grupo y se explicara porque se han considerado esas las más características más importantes y por qué, cada uno en su cartulina podrá realizar los dibujos de aquellas aptitudes que no ha conseguido encontrar entre las imágenes, o que tenían sus compañeros, incluyendo la posibilidad de datos personales, exponiendo así la cartulina final.

Por último, se realizará un debate grupal de la actividad, ofreciendo un tiempo para plasmar las reflexiones individuales en el cuaderno de vida.

\begin{tabular}{lll}
\hline Materiales & - & Cartulinas (tantas como grupos haya) \\
& - & Tijeras \\
- & Bolígrafos y rotuladores \\
- & Cuaderno de vida
\end{tabular}

\section{Actividad 5: Fija tus objetivos}

El alcanzar logros personales ya sean académicos, deportivos, sociales o mismamente personales ayuda a mejorar la percepción que tenemos sobre nosotros/as mismos, y mejorar por lo tanto el autoconcepto. Para ello es importante acercarse a los objetivos propios de cada uno/a y pensar cómo podemos lograrlos y mejorar, además de poder analizar los obstáculos que nos impiden llegar a nuestros objetivos para poder avanzar.

\section{Objetivos}

Considerar la importancia de poner metas

Identificar como las expectativas influyen en los objetivos y metas que establecemos personal

Analizar como una meta realista puede convertirse en un desafío

Analizar como las metas influyen en los resultados obtenidos

\section{Competencias}

Habilidades personales para el ejercicio personal autónomo 
Destinatarios $\quad$ - Menores Extranjeros No Acompañados (16 a 18)

Jóvenes extutelados (18-25)

Temporalización

50 minutos

Modalidad $\quad-\quad$ Individual

Desarrollo Esta actividad debe desarrollarse en un espacio amplio que ofrezca a los participantes la posibilidad de saltar libremente. Se trata de una actividad física donde se deben juntar unas colchonetas.

En el suelo se marca con tiza una línea para el salto y otra línea que cada participante hará hasta donde cree que va a llegar su salto. Se les indica a continuación que deben tomar carrerilla y al llegar a la línea saltar lo más lejos posible. El punto de llegada será donde los pies toquen el suelo por primera vez una vez se haya saltado. Se le dará 5 oportunidades a cada participante, y deberán apuntar si han conseguido llegar al punto prefijado previamente al salto y en qué oportunidad, si lo han superado o si no han llegado a alcanzarlo.

Una vez hayan concluido con la actividad, se desarrollará un debate o reflexión realizando un análisis individual de cada participante, hasta donde quería llegar con el salto y hasta donde ha llegado, sin olvidar en que oportunidad lo ha conseguido o no en el caso que no lo haya conseguido.

Se trata de reflexionar en grupo sobre qué resultados eran los esperados y cuales se han conseguido, debatiendo así la importancia de poner metas y objetivos personales para alcanzarlos, las emociones y sentimientos que se tienen al alcanzarlos o por el contrario la motivación que se refleja el querer conseguirlo y el esfuerzo que supone con los intentos que se realicen.

Algunas de las preguntas que se pueden realizar para comenzar el debate son:

- ¿QQué expectativas tenemos de nosotros mismos?

- ¿Por qué algunas veces nos ponemos metas inalcanzables, y por el contrario porque otras son muy fáciles de alcanzar?

- ¿Cómo construimos esa autoimagen de hasta donde somos capaces de llegar?

- ¿Lo que pensamos o creemos de nosotros mismo, nos limita a la hora de conseguir resultados o por el contrario se trata de un desafío para mejorar?

Se pueden dar unos minutos para reflexionar acerca de cada pregunta. Finalizando con una conclusión sobre como deberían ser las metas, es decir, alcanzables para que no se dejen por el camino por imposibles, pero con algo de dificultad para crear así motivación por el esfuerzo, reflejando las reflexiones individuales en el cuaderno de vida.

Materiales Espacio grande

Colchonetas

Tiza

Cuaderno de vida 


\section{Actividad 6: Logros compartidos}

Cuando tenemos cerca a una persona que acaba de lograr una meta ya sea de forma extraordinaria o no tan extraordinaria debemos de felicitar a la persona, sentir alegría y orgullo, contagiándonos de esa sinergia para seguir avanzando y así crear una sinergia que sume tu causa a la de alguien más.
Objetivos
- $\quad$ Concienciar personalmente sobre los logros más transcendentales
- $\quad$ Compartir los logros alcanzados con los compañeros y compañeras
- $\quad$ Fomentar el sentimiento de satisfacción personal que produce el alcanzar metas.
- Desarrollar la empatía
- Mejorar la autoestima reconociendo las metas alcanzadas y realizar una crítica constructiva sobre las no alcanzadas.
- $\quad$ Identificar momentos vitales del pasado y saber porque los recordamos
- Reflexionar sobre cómo nos comportamos y actuamos ante diferentes situaciones y contextos
identifican

Competencias _ $\quad$ - Responsabilidad individual y grupal

\begin{tabular}{lll}
\hline Destinatarios & - & Menores Extranjeros No Acompañados (16 a 18) \\
& - & Jóvenes extutelados (18-25)
\end{tabular}

Temporalización $\quad-\quad 50$ minutos

Modalidad $\quad-\quad$ Individual y en grupo

Desarrollo

En esta actividad el educador o educadora pedirá a los participantes que se distribuyan de tal forma que realicen un gran circulo sentados. Entonces se pasará un folio y un sobre a cada uno/a. En este folio deberán escribir de forma anónima los logros que han alcanzado a lo largo de su vida, o los que se han fijado, pero no han alcanzado, desarrollando en dos líneas por cada uno como se sintieron en ese momento, y si se sienten orgullosos/as de haberlo alcanzado. No hay máximo, pero si un mínimo de 3 logros o metas que se hayan propuesto alguna vez.

Se les da aproximadamente 20 minutos para la realización de esta tarea, y se les indica que una vez lo hayan realizado deberán doblar el folio y guardarlo en el sobre que se les ha proporcionado.

El educador o educadora juntará todos los sobres de los participantes, las revolverá y de forma aleatoria se repartirá un sobre a cada participante. En este momento se explica que habido un problema y todos los logros se han duplicado por lo cual cada uno debe hacer propios los logros del compañero o compañera de forma anónima. Cada uno /una debe hacer propia toda la información de esa hoja. 
Una vez leídas, deberán leer con orgullo los logros que están en la hoja como si fuesen suyos y sintiese ese orgullo por haberlos realizado o por el contrario si no se han llegado a alcanzar poder realizar una crítica constructiva de cómo se podría llegar a alcanzar o porque se cree que no se ha alcanzado. Se trata de que se crean esos logros como suyos y puedan expresarse libremente para dar su punto de vista, sin saber de quién son. Algunos incluso, pueden ser escritos por el educador/a.

De esta forma cada vez que se comente un logro alcanzado todo el grupo deberá aplaudir y cuando no se llegue a desarrollar proponer diferentes metas en relación a esa, o posibles relaciones o historias vividas por los compañeros y compañeras.

Una vez finalizado se recogen los sobres, y se realizan unas preguntas en el aire:

- $\quad$ - ¿Me ha resultado difícil reconocer mis logros? ¿Por qué?

- $\quad$ - ¿Cómo me he sentido al escuchar mis logros en otra persona?

- $\quad$ - ¿Considero que lo he valorado más cuando lo he visto como otro compañero los contaba?

- $\quad$ - ¿Debo estar orgulloso de haber conseguido alcanzar mis logros?

- $\quad$ - ¿Reconozco lo que soy capaz de hacer?

- - ¿Por qué considero que los éxitos muchas veces son dados por la casualidad y los fracasos se deben a aspectos internos?

Además, como es una de las ultimas actividades de este módulo, se puede reflejar logros en las propias actividades del programa, es decir hacer un balance y reconocimiento de todos los logros que han sido capaces de conseguir, independientemente de la importancia de cada uno. Con la finalidad de que recuerden todo lo posible, tratándose tanto de logros académicos como personales, dejando un tiempo para plasmarlo de forma individual en el cuaderno de vida.

\begin{tabular}{lll}
\hline Materiales & - & Folios \\
& - & Sobres \\
& - & Bolígrafos \\
& - & Cuaderno de vida
\end{tabular}

Evaluación

Observación directa

Autoevaluación

Actividad 7: Cambiamos las manos

El funcionamiento y desarrollo del propio grupo dependen de la importancia de una comunicación grupal, donde serán imprescindibles procesos de grupo como la toma de decisiones y la resolución de conflictos. 
Objetivos

Fomentar la comunicación de grupo

Aumentar la autopercepción

\section{Competencias}

Habilidades de escucha, respeto y dialogo

\begin{tabular}{lll}
\hline Destinatarios & - & Menores Extranjeros No Acompañados (16 a 18) \\
& - & Jóvenes extutelados (18-25)
\end{tabular}

Temporalización - $\quad 50$ minutos

Modalidad $\quad$ - Individual y en grupos

Desarrollo En esta actividad la finalidad es fomentar la comunicación en el grupo y favorecer el conocimiento mutuo de los menores. En el desarrollo de la actividad los participantes deberán responder a cinco preguntas, relacionadas con los cinco dedos de la mano:

- $\quad$ - Edad $\rightarrow$ dedo pulgar

- $\quad$ - Sueño por cumplir $\rightarrow$ dedo índice

- $\quad$ - Mayor defecto $\rightarrow$ dedo corazón

- $\quad$ - Mayor virtud $\rightarrow$ dedo anular

- $\quad$ - Mayor miedo $\rightarrow$ dedo meñique

Así dibujando en una hoja la silueta de su mano, cada pregunta corresponderá a un dedo. A continuación, se pondrá en común con todos los participantes. Los educadores o educadoras guardaran en la bolsa todas las manos y posteriormente se repartirá de forma aleatoria de uno en uno, tratando de averiguar a quien corresponde la mano que le ha tocado, cuando lo averigüe se lo devolverá al compañero.

Finalmente se realizará una reflexión sobre la actividad tanto de forma individual en el cuaderno de vida como en grupo, comentando lo que les ha aportado la realización de la dinámica

\begin{tabular}{lll}
\hline Materiales & - & Folios \\
& - & Bolígrafos \\
& - & Saco/caja \\
& - & Cuaderno de vida
\end{tabular}


Actividad 8: En otros ojos

Reconocer los pequeños logros cotidianos es una de las tareas que debemos involucrar en las sesiones para poder mejorar el autoconcepto.

\section{Objetivos}

Fomentar el autoconocimiento que cada uno/una tiene de sí mismo/a Identificar las diferencias de cómo me percibo y como me perciben

\section{Competencias}

Habilidades de escuchar, respetar las ideas de otros y dialogar

Destinatarios

Menores Extranjeros No Acompañados (16 a 18)

Jóvenes extutelados (18-25)

Temporalización $\quad-\quad 50$ minutos

Modalidad

Desarrollo
Individual y en grupos

La finalidad de la siguiente actividad es que cada persona pueda identificar la diferencia que existe en cómo me creo que soy y como me perciben los demás. Así es necesario contrastar tres puntos de vista con tres folios diferentes:

- Folios amarillos: Como soy

- Folios verdes: Como creo que me perciben

- Folios rosas: Como me perciben

Se reparten primero los folios amarillos, y se da 10 minutos para que lo describan, pueden ser palabras, dibujos... debe haber al menos 10 características, una vez rellenado deben doblar el papel y dejarlo encima de la mesa.

Después se les reparte los folios verdes, y deben reflejar 10 características al menos de como creo que me consideran mis amigos o mis compañeros.

La tercera hoja llevara el nombre de cada participante, repartiéndolas aleatoriamente., deberán ser completada por un compañero o compañera de forma aleatoria. En esta deberán escribir 10 características del dueño o dueña de la hoja. Una vez las hayan rellenado el educador/a recogerá los folios y se las entregara al dueño/a. Así cuando termine la dinámica cada participante deberá tener en su mesa los tres folios completados.

En este momento e individualmente deben comparar el folio verde con el folio rosa, comparando, así como creo que me perciben y como me percibe mi compañero/a. Finalmente, se desdoblara el primer folio que se había dejado en la mesa y se compararan las características que yo considero con las que consideran sus compañeros/as. Realizando un debate final a modo de reflexión con posibles preguntas guía, reflejándolo posteriormente en el cuaderno de vida: 


\section{diferencias?}

- ¿Me perciben como realmente me considero yo, o, por el contrario, hay

- $\quad$ - En caso de que haya diferencias ¿Por qué creo que las hay?

- Puede que la mirada de los demás sea parcial porque no nos conocen mucho, pero ¿Qué opinan según el espacio y el tiempo en el que estamos?

- $\quad$ - ¿Considero que las características que me han puesto son porque no me conocen bien, o porque nunca me había parado a pensarlo?

\begin{tabular}{lll}
\hline Materiales & - & Folios de colores \\
& - & Bolígrafos \\
& - & Cuaderno de vida \\
\hline Evaluación & - & $\begin{array}{l}\text { Observación directa } \\
\text { Autoevaluación }\end{array}$ \\
\hline
\end{tabular}

\section{Actividad 9: Lo mejor de mi}

Es necesario hacer llegar a los participantes nuestros propios sentimientos, y así ayudarles que tanto individual como personalmente sean capaces de descubrir por sí mismos que son queridos, aceptados y que ante todo son admirados tanto por los educadores/as como por sus compañeros/as, de esta forma tendrán confianza en ellos/as mismos/as para afrontar y conseguir nuevos retos. Por lo que se recomienda participar en esta actividad a los y las profesionales que lleven a cabo esta actividad.
Objetivos
Reforzar el autoconcepto positivo

Competencias $\quad$ - $\quad$ Aprender a aprender

\begin{tabular}{lll}
\hline Destinatarios & - & Menores Extranjeros No Acompañados (16 a 18) \\
& - & Jóvenes extutelados (18-25)
\end{tabular}

Temporalización - $\quad 50$ minutos

Modalidad $\quad$ - Individual

Desarrollo Cada persona dibuja en un folio su silueta con su nombre. Posteriormente, dejarán los folios en el centro de la sala Los demás participantes tendrán que escribirles cosas positivas a todos/as, pasando por todas las siluetas.

A continuación, cada una recogerá su folio con su silueta y todas las cosas positivas que habrá recibido de sus compañeros/as, una vez leído se pegarán todos los folios en cartulinas con el título de "páginas amarillas" y se expondrán en un lugar que este a la vista.

Finalmente, se realizará una reflexión tanto en grupo como individual, reflejándolo en el cuaderno de vida de los participantes. 
Bolígrafos

Cuaderno de vida

Evaluación

Observación directa

Autoevaluación

\section{Actividad 10: ¡Ey! Sígueme la corriente}

Evitar achacar los problemas a los aspectos personales, e intentar evitar el pensamiento de que los errores son parte de algo interno y los aciertos de la casualidad o la suerte.

\section{Objetivos}

- $\quad$ Profundizar en las motivaciones e intereses personales y como se proyectan en las acciones

- $\quad$ Fomentar la capacidad creativa

\section{Competencias}

Aprender a hacer

\begin{tabular}{lll}
\hline Destinatarios & - & Menores Extranjeros No Acompañados (16 a 18) \\
& - & Jóvenes extutelados (18-25)
\end{tabular}

Temporalización $\quad-\quad 40$ minutos

Modalidad $\quad$ - $\quad$ Grupos de 3 a 5 participantes

\section{Desarrollo}

\begin{abstract}
Para comenzar el educador o educadora explicara el desarrollo de la dinámica. Se les debe explicar que se les va a ofrecer un tema para que realicen una historia. Cada grupo deberá elegir a un representante del equipo y deberá pasar un folio que se ira rotando entre los grupos. Cada folio tiene un tema de una historia, y tendrán 5 minutos por grupo para comenzar o continuar la historia. Después pasara a otro integrante del equipo, el cual en otro párrafo continuara la historia o contara otra totalmente diferente. Se repetirá este proceso hasta que haya pasado por todos los integrantes del grupo. Teniendo el ultimo integrante la posibilidad de redactar el desenlace de la historia. Algo que hay que dejar claro es que cada integrante debe escribir al menos 5 oraciones o se les descalificara. A continuación, el educador/a pide al representante del primer grupo que coloque el folio enfrente suyo. Así se escribe en el folio el Tema de la Historia, con 3 minutos cada integrante, el educador/a dirá en voz alta "Tiempo" y deberán pasárselo a otro compañero o compañera del grupo.
\end{abstract}

Finalmente, levantaran las manos cuando se haya acabado el tiempo y doblaran el folio. Aleatoriamente se pasará el folio a otro grupo, donde el representante deberá leer en voz alta la historia que le ha tocado. 
En ese momento se darán cuenta que todos los grupos tenían la misma historia pero que casualmente unas no tienen nada que ver con otras. Una vez se hayan leído todas las historias, se realizará un pequeño debate con todos los grupos. Se deberá reflexionar sobre las razones por las cuales cada grupo ha redactado una historia totalmente diferente con un mismo tema y más en concreto como cada integrante del grupo llevo la historia por el camino que el eligió, reflejando sus características y sus ideas, intentando de esta manera extrapolarlo y ver cómo se puede aplicar lo aprendido en el día a día.

\begin{tabular}{lll}
\hline Materiales & - & Hojas de folios \\
& - & Bolígrafos y rotuladores \\
& - & Cuaderno de vida
\end{tabular}

\begin{tabular}{lll}
\hline Evaluación & - & Observación directa \\
& - & Autoevaluación
\end{tabular}

\section{- MÓDULO II: ACTIVIDADES DIRIGIDAS A MEJORAR LA EMANCIPACIÓN Y AUTONOMÍA}

Las actividades propuestas para el segundo módulo están dirigidas como en el Módulo I, a menores extranjeros no acompañados y a los jóvenes extutelados. Todas las actividades y dinámicas han sido realizadas con el fin de preparar la emancipación en los menores y jóvenes, así como trabajar las expectativas y la autonomía personal necesarias para una integración social y laboral plena, basándose en algunas de las competencias clave a desarrollar por la LOMCE como son:

Sentido de iniciativa y espíritu emprendedor, que implica actividades necesarias para convertir cualquier idea en un acto, desarrollando la creatividad o las capacidades relacionadas con asumir riesgos, planificar y gestionar proyectos.

- $\quad$ La competencia en comunicación lingüística, que se refiere a la habilidad tanto para utilizar la lengua como expresar ideas e interactuar con otras personas de manera oral $u$ escrita.

\section{Actividad 11: Una experiencia personal}

Escuchar experiencias de personas que han estado en tu mismo lugar puede ser una forma de incentivar y fomentar el interés por realizar de forma correcta las actividades propuestas.

\section{Objetivos}

Fomentar la empatía

Fomentar la motivación en los participantes 


\section{Competencias}

Sentido de iniciativa y espíritu emprendedor

\begin{tabular}{lll}
\hline Destinatarios & - & $\begin{array}{l}\text { Menores Extranjeros No Acompañados (16 a 18) } \\
\text { Jóvenes extutelados (18-25) }\end{array}$ \\
\hline Temporalización & - & 50 minutos \\
\hline Modalidad & - & Individual \\
& & \\
\hline Desarrollo & $\begin{array}{l}\text { Esta actividad se llevará a cabo a través de una tercera persona externa que haya } \\
\text { pasado por la misma situación y haya conseguido encontrar un trabajo, y así } \\
\text { comparta con los participantes su experiencia. No tanto a modo de conferencia } \\
\text { sino, crear un ambiente donde se pueda hablar con libertad y compartir opiniones, } \\
\text { o dudas que les ronden por la cabeza a los participantes. }\end{array}$ \\
& Finalmente se realiza una reflexión individual en el cuaderno de vida. \\
\hline Materiales & - & $\begin{array}{l}\text { Contacto con persona externa } \\
\text { Cuaderno de vida }\end{array}$ \\
& - & Observación directa \\
Evaluación & - & Autoevaluación \\
& - &
\end{tabular}

\section{Actividad 12: "Una imagen vale más que mil palabras"}

La imagen corporal a la hora de buscar trabajo es una parte importante que debemos tener en cuenta. Esta actividad debate temas, por ejemplo: ¿Podemos ir en pijama al trabajo para estar más cómodos? ¿Podemos ir con ropa sucia? Debemos tener en cuenta que es importante cuidar la higiene corporal, vestir de forma adecuada y vestir con ropa limpia.

\section{Objetivos}

Desarrollar las habilidades de comunicación verbal y no verbal necesarias para poder participar en diferentes tipos de interacción

- $\quad$ Saber controlar las propias emociones y expresarlas de forma adecuada

Desarrollar aptitudes a la hora de la búsqueda de trabajo

\begin{tabular}{lll}
\hline Competencias & - & Desarrollar una responsabilidad individual y social \\
& & \\
\hline Destinatarios & - & Menores Extranjeros No Acompañados (16 a 18) \\
& - & Jóvenes extutelados (18-25)
\end{tabular}

Temporalización - 50 minutos




Modalidad $\quad-\quad$ Grupal de 3- 4 participantes

Desarrollo $\quad$ Para comenzar se divide al aula en grupos de 3 personas. Una vez formados los grupos, deberán responder en un papel a una serie de preguntas reflejadas a continuación, con una duración de 15 minutos.

- ¿Qué es para ti el trabajo?

- ¿Por qué quieres trabajar?

- ¿ ¿Crees que estás capacitado para trabajar? ¿Por qué?

- ¿ ¿Te consideras una persona que puede hacer cualquier tipo de trabajo?

- ¿Qué tipo de trabajo consideras que estás capacitado para hacer?

A la hora de ir a trabajar, ¿Qué es importante que cuides?...

- ¿Cómo debes ir al trabajo?

- ¿Cómo podemos demostrar que somos buenos profesionales?

Mas tarde en los 15 minutos restantes, se trata de hacer una reflexión entre todos aportando cada grupo las ideas que han debatido y finalmente reflejándolo individualmente en los cuadernos de vida.

\begin{tabular}{lcl}
\hline Materiales & - & Pizarra \\
& - & Folios \\
& - & Bolígrafos \\
& - & Cuaderno de vida \\
\hline Evaluación & - & Observación directa \\
& - & Autoevaluación
\end{tabular}

\section{Actividad 13: Entrevistados}

Los seres humanos, generalmente poseen un deseo natural de actuar, además el grupo puede analizar los puntos de vista de los otros participantes, es un buen recurso para el análisis de problemas. Cuando se desea que alguien comprenda lo más íntimamente posible una conducta o situación, se le pide que "se ponga en el lugar" de quien la vivió en la realidad. Si en lugar de evocarla mentalmente, se asume el rol y se revive dramáticamente la situación, la comprensión íntima resulta mucho más que profunda y esclarecedora. Role-playing será entonces representar una situación con el objeto de que se vea como real, visible, vivida, de modo que se comprenda mejor por parte de quien o quienes deben intervenir en ella en la vida real. Este objetivo se logra no sólo por quienes representan los roles, sino por todo el grupo que actúa como observador participante del proceso.
Objetivos
Adquirir pautas de actuación ante una entrevista de trabajo
- $\quad$ Conocer las principales preguntas y dinámicas
- $\quad$ Adquirir habilidades sociales para realizar una entrevista de trabajo adecuada
- $\quad$ Ayudar a conocer a cada participante sus habilidades para ser diferente a la hora de realizar una entrevista de trabajo

\section{Competencias}

Habilidades interpersonales 


\begin{tabular}{lll}
\hline Destinatarios & - & Menores Extranjeros No Acompañados (16 a 18) \\
& - & Jóvenes extutelados (18-25)
\end{tabular}

Temporalización $\quad-\quad 50$ minutos

Modalidad $\quad$ - $\quad$ En parejas (2 participantes)

Desarrollo

Se explica el tema principal que se va abordar, en este caso el de una entrevista de trabajo. Antes de realizar la actividad se realiza durante 10 minutos una lluvia de ideas o brain storming sobre ¿Qué aspectos crees que son los más importantes a la hora de realizar una entrevista de trabajo?, para conocer los conocimientos previos que tienen al respecto de una entrevista y posteriormente se ponen en común. Se puede explicar diferentes dinámicas que se hacen en las entrevistas en grupo para ver la creatividad de los entrevistados, por ejemplo, ¿Qué te llevarías a una isla desierta? ¿Por qué?

La segunda parte de la actividad consiste en formar parejas que realizara el educador o educadora, una vez agrupados se explica que es una entrevista, para que sirve y porque debe hacerse. Debe delimitarse lo que se expondrá y para que, con toda precisión. Todos los participantes aportarán todos los datos posibles para describir y enriquecer las escenas a representar posteriormente imaginando la situación, el momento que sea, la conducta de cada personaje, etc. Creando así un contexto lo más parecido a la realidad posible. El grupo decidirá si desea dar una estructura bien definida a la escenificación o prefiere dejarla, en mayor o menor medida, a la improvisación de los intérpretes.

La tercera parte consiste en que deben hacer un pequeño role playing, con los papeles del entrevistador y el entrevistado, realizando las posibles preguntas y preparándose algunas de las respuestas que vaya hacer, dándoles nombres ficticios con la finalidad de que se posicionen en el papel y en el rol que jugara cada uno/a. Conviene ofrecer a los y las intérpretes unos minutos para colocarse en la situación mental, ponerse en el papel que les toca y lograr el clima y si lo desean, explicar someramente como proyectan actuar, tienen para esto 10 minutos lo demás deberán improvisarlo ambas partes.

Durante el desarrollo de la interpretación es importante que no se interfiera ni por parte de los educadores y educadoras ni por los demás grupos. El grupo deberá mantener una atmosfera propicia sin perder el interés por la actividad e involucrarse emocionalmente, lo importante no es el final sino el desarrollo de la acción que suele durar de 5 a 15 minutos. Para el desarrollo de esta actividad es interesante la colaboración de las experiencias personales de los educadores/educadoras que lleven a cabo la actividad, coordinando la acción y estimulando al grupo en todo momento.

Para la preparación de escenario y de acuerdo a las necesidades, conviene preparar el escenario para la acción utilizando los elementos indispensables como pueden ser un escritorio y unas sillas, lo demás puede ser imaginado con una breve descripción.

Finalmente se representará a modo de teatro, tantas entrevistas como parejas hayan realizado, y una vez finalizado se realizará un pequeño debate donde cada uno expondrá como se ha sentido y podrán realizar críticas constructivas 
a sus compañeros y compañeras. Se trata de un análisis donde pueden ofrecer sus impresiones, describir su estado de ánimo a la hora de actuar y por lo tanto lo que sintieron, y ayudándose entre otros aprendiendo de las diferentes formas de jugar en escena y pudiendo valorar la actuación de sus compañeros y compañeras.

Para concluir se hará un pequeño debate y reflexión individual apoyándose en las siguientes preguntas, y reflejándolo en el cuaderno de vida:

- $\quad$ - ¿Cómo te has sentido en la entrevista?
- De los aspectos trabajados ¿consideras que te pueden ayudar para
una futura entrevista?

- $\quad$ - ¿Cómo te has sentido en la entrevista?
- De los aspectos trabajados ¿consideras que te pueden ayudar para
una futura entrevista?

- ¿Cómo te has sentido en la entrevista?
- $\quad$ - De los aspectos trabajados ¿consideras que te pueden ayudar para
una futura entrevista?

- $\quad$ - ¿Te sientes preparado para afrontar una entrevista de trabajo?

\begin{tabular}{lll}
\hline Materiales & - & Sillas \\
& - & Escritorio \\
& - & Cuaderno de vida \\
\hline Evaluación & - & Observación directa \\
& - & Autoevaluación \\
\hline
\end{tabular}

\section{Actividad 14: Curriculum vi(d)ae}

El Curriculum Vitae es la primera impresión que das sobre tu persona durante la búsqueda de empleo, por lo tanto, es la primera oportunidad de llamar la atención con lo que tú eres y con lo que cada uno puede ofrecer a los demás. Un buen curriculum vita aumentara de forma considerable las posibilidades de conseguir una entrevista de trabajo.

\section{Objetivos}

Desarrollar la capacidad de colaborar

Fomentar el pensamiento creativo

Conocer las herramientas de búsqueda de empleo

Se capaz de elaborar un curriculum vitae

\section{Competencias}

Competencia en comunicación lingüística

\begin{tabular}{lll}
\hline Destinatarios & - & Menores Extranjeros No Acompañados (16 a 18) \\
& - & Jóvenes extutelados (18-25)
\end{tabular}

Temporalización - 50 minutos




\section{Desarrollo}

Para comenzar se aclarará el hecho de que poseer un empleo es algo determinante para adquirir papeles en el país de destino o tener acceso a una vivienda y con ello normalizar la situación en España, con todos los beneficios que esto conlleva. Para saber de dónde comenzamos se recomienda realizar unas preguntas previas como ¿Sabes que es un Curriculum Vitae? ¿Para qué sirve? ¿Has hecho alguno?

La técnica del Cuchicheo consiste en dividir a un grupo en parejas que tratan en voz baja (para no molestar a los demás) un tema o cuestión de momento. De este modo todo el grupo trabaja simultáneamente sobre un mismo asunto, en grupos mínimos de dos.

El educador o educadora explica que cada una de las personas puede dialogar con su compañero más cercano, el que esté a su lado, sin necesidad de levantarse. Este diálogo será simultáneo, de cinco minutos por cada una de las partes, se hará en voz baja intercambiando ideas para llegar a una respuesta o proposición que será luego informada al coordinador por un miembro de cada pareja, pudiéndolo apuntar en un folio para ayudarse a la hora de comentarlo.

Posibles partes a redactar con la técnica del cuchicheo:

$\begin{array}{ll}- & \text { Encabezado del CV } \\ - & \text { Datos de contacto } \\ - & \text { Experiencia laboral } \\ - & \text { Formación académica } \\ \text { - } & \text { Aptitudes y habilidades } \\ - & \text { Idiomas } \\ - & \text { Información adicional }\end{array}$

Finalmente, uno del grupo dirá en voz alta los contenidos que cree que puede tener esa parte de un curriculum vitae, ofreciendo así ideas a sus compañeros y compañeras. De las respuestas u opiniones dadas por todas las parejas se extraerá la conclusión general o se tomarán las decisiones del caso.

Para finalizar de forma individual se realizará un posible boceto de un curriculum vitae y se realizará una reflexión individual sobre la actividad en el mismo cuaderno de vida.

\begin{tabular}{lll}
\hline Materiales & - & Cuaderno de vida \\
& - & Folios \\
& - & Bolígrafos
\end{tabular}




\title{
Actividad 15: Mi trabajo ideal
}

Trabajar las expectativas representa la confianza que tienen los adolescentes en un futuro prometedor de desarrollo social, laboral y personal. La obtención de un trabajo cualificado es importante para un buen ajuste social en la vida de los jóvenes.

\section{Objetivos}

Fomentar expectativas laborales positivas

\begin{tabular}{lll}
\hline Competencias & - & Sentido de iniciativa y espíritu emprendedor \\
& - & Habilidades necesarias para el ejercicio profesional autónomo, con \\
iniciativas instrumentales (ajuste, tolerancia y respeto)
\end{tabular}

\begin{tabular}{lll}
\hline Destinatarios & - & Menores Extranjeros No Acompañados (16 a 18) \\
& - & Jóvenes extutelados (18-25)
\end{tabular}

Temporalización $\quad-\quad 50$ minutos

Modalidad $\quad-\quad$ En grupos de 4 o 5 participantes.

Desarrollo

\begin{abstract}
Esta actividad se debe llevar a cabo en grupos, los cuales ya hayan sido formados para actividades previas o que estos se conozcan entre sí. Para comenzar se recomienda realizar una reflexión sobre la importancia de conocer los propios gustos e intereses a la hora de elegir una profesión u crear una empresa, en base a esto existe la posibilidad de modificar los grupos según los intereses de cada uno. Se deberán asignar 30 minutos para que los grupos creen su empresa ideal. Ofreciendo ideas de todos los participantes y llegando a un consenso entre todos/as.
\end{abstract}

Para ello deberán pensar aspectos de una empresa, algunas de las propuestas son:

\footnotetext{
- $\quad$ - A qué se dedica

- $\quad$ - Nombre de la empresa

- $\quad$ - Mercado al que se dirige

- $\quad$ - Productos o servicios que presta
}

Finalmente, cada uno presentará su empresa a los compañeros y se debatirá en grupo como se puede llegar hasta esa idea, o que ventajas o inconvenientes encuentran los compañeros y compañeras sobre cada empresa, siempre con posibles críticas constructivas y desde el respeto.

Como en todas las actividades, por último, se dará un tiempo de reflexión final anotando en el cuaderno de vida las emociones que le han producido el imaginar crear esa empresa o las ideas que han recogido de sus compañeros y compañeras.

Materiales $\quad-\quad$ Hojas

- Bolígrafos


Cuaderno de vida

Evaluación

Observación directa

Autoevaluación

\section{Actividad 16: Limites}

Se desarrollan de esta manera habilidades y valores que ayudan a los y las participantes a entender la dinámica del conflicto y les posibilita un buen uso de la comunicación y el pensamiento creativo y poder resolver los conflictos de una manera lo más justa posible y no violenta.

\begin{tabular}{lll}
\hline Objetivos & - & Fomentar la resolución de problemas \\
& - & Fomentar la creatividad \\
- & Aprender a encontrar y elegir la solución adecuada
\end{tabular}

Competencias

La competencia en comunicación lingüística

Habilidades sociales para la resolución de conflictos

Destinatarios

Menores Extranjeros No Acompañados (16 a 18)

Jóvenes extutelados (18-25)

Temporalización $\quad-\quad 50$ minutos

Modalidad

Individual y en grupo

Desarrollo

Se entrega una hoja de papel a cada menor donde debe escribir un problema o conflicto que le pase en esos momentos o que haya experimentado anteriormente. Se doblan los folios y se meten en una caja. Una vez guardados todos se revuelven y por orden, y de uno en uno deberán ir cogiendo una hoja de la caja y leyéndola en voz alta, mientras que un compañero lo escribe en la pizarra. Mas tarde en grupos de 2 se intenta dar posibles soluciones al problema que les ha tocado, sin olvidar que es el problema de un compañero el cual deben respetar.

Una vez finalice este tiempo de buscar soluciones, se realiza un debate con posibles ventajas y desventajas de cada solución con ayuda de todos los compañeros y compañeras. Así entre todos se podrá llegar a una solución sin llegar a saber nunca quién es el compañero o compañera que ha escrito ese problema.

Finalmente, queda el tiempo de reflexión individual donde cada uno y cada una refleja en su cuaderno de vida que le ha producido la actividad y que considera que ha aprendido con ella. 


\begin{tabular}{lll}
\hline Materiales & - & Folios \\
& - & Bolígrafos \\
& - & Cuaderno de vida
\end{tabular}

\begin{tabular}{lll}
\hline Evaluación & - & Observación directa \\
& - & Autoevaluación
\end{tabular}

Actividad 17: Tecnificame

Utilizar y conocer técnicas de autocontrol permite afrontar situaciones dificiles con una mayor eficiencia ademas de mantener la calma y la claridad en el pensamiento, además beneficia las relaciones sociales y controlar el estrés ante situaciones de estrés.

\begin{tabular}{cll}
\hline Objetivos & & Proporcionar técnicas para poner en práctica sobre resolución de conflictos \\
- & Aprender a mantener el autocontrol \\
- & Aprender técnicas para la resolución de problemas \\
- & Reflexionar sobre posibles técnicas para la resolución de problemas con ejemplos de la vida \\
cotidiana
\end{tabular}

Competencias

- $\quad$ Habilidad de escuchar, respetar las ideas de otros y de dialogar

- Iniciativa para resolver problemas con responsabilidad y autonomía, tanteando posibles ventajas e inconvenientes

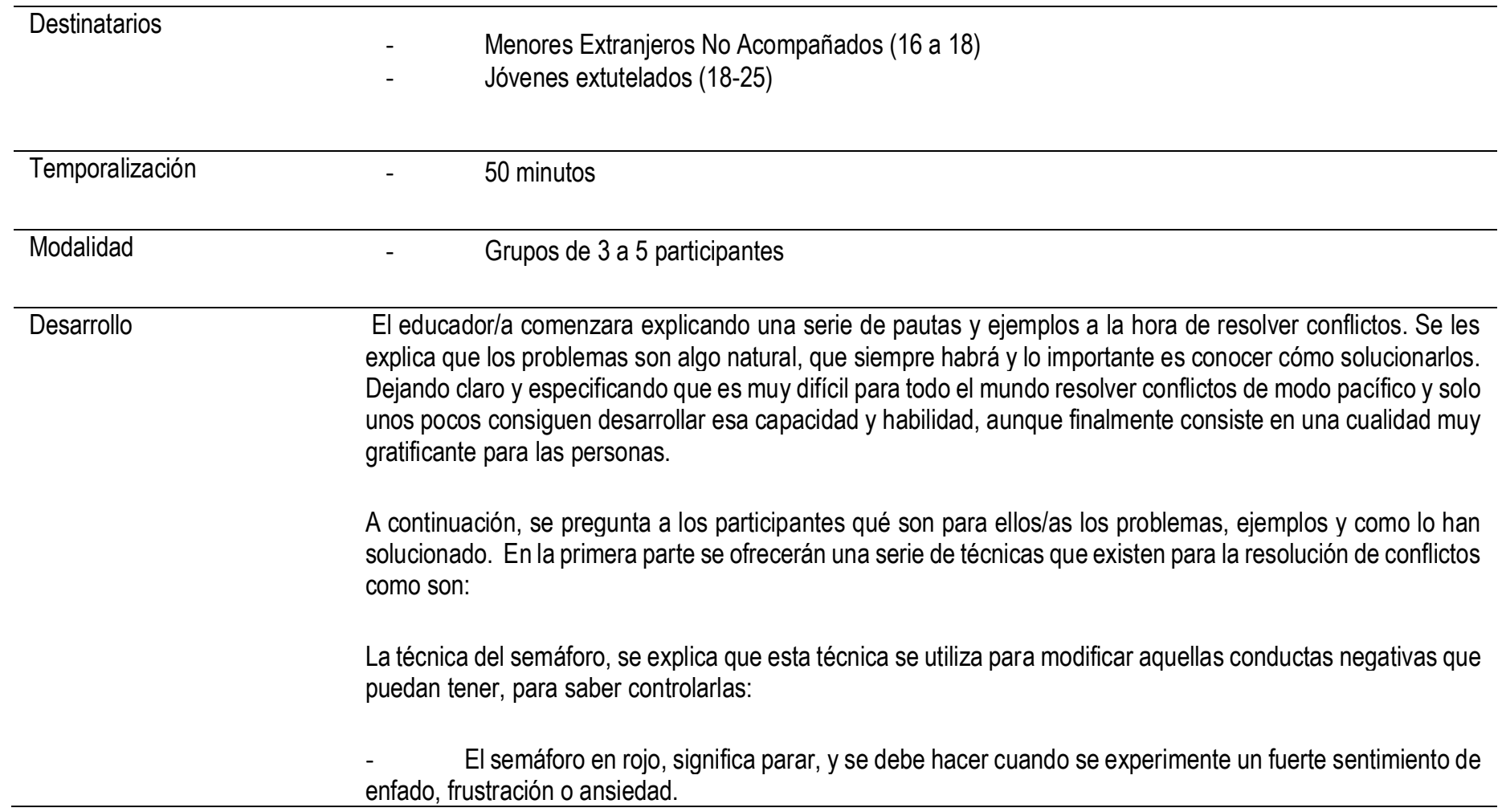


- $\quad$ El semáforo Amarillo, significa pensar, aquí es cuando se debe pensar con exactitud la situación que ha generado malestar y buscar soluciones a esa situación.

- $\quad$ El semáforo en Verde, se utiliza para seguir adelante, se debe actuar y poner en práctica la solución que has planteado anteriormente

El método PIGEP propuesto por Elizabeth Crary, un método sencillo pero eficaz que ayuda a aclarar el problema, la toma de decisiones y ayuda a canalizar el conflicto hacia la reflexión, tratándose también de una forma de autocontrol:

- $\quad$ Parar: cuando se detecta un malestar no reaccionar sino detenerse a pensar lo que se va a decir o a hacer. Se trata de no dejarse llevar por el primer impulso.

- $\quad$ Identificar: se trata de definir el problema e intentar diferenciar las necesidades de los deseos. Hablar con la otra parte escuchando su versión de los hechos y contar la propia, para ello es importante evitar etiquetas o juicios generales hacia la conversación.

- $\quad$ Generar: ofrecer ideas espontaneas, posibles soluciones distintas a las ya propuestas.

- $\quad$ Evaluar: entre las ideas propuestas anteriormente, se deben seleccionar las más viables, las que más satisfagan a las necesidades de cada una de las partes.

- $\quad$ Planificar: la puesta en marcha de las soluciones propuestas previendo los posibles obstáculos que puedan surgir para considerarla lo más realista posible, se puede elaborar un contrato para implementarla.

Mas tarde por grupos deberán inventarse una técnica para resolver posibles conflictos, o bien pueden utilizar alguna que le hayan servido alguna vez, compartiéndolo de este modo con sus compañeros, poniendo si es posible ejemplos de la vida cotidiana.

A continuación, se exponen una serie de problemas en el cuaderno de vida, las cuales se recomienda que se resuelvan en grupo.

Finalmente, se realizará un debate grupal y una reflexión individual, y se animara al grupo a poner en práctica las técnicas aprendidas cuando se enfrenten a algún problema, reflejándolo si es posible en el cuaderno de vida para transmitirlo al educador/a en las siguientes sesiones. Las reflexiones individuales sobre la sesión quedarán reflejadas en el cuaderno de vida.

\begin{tabular}{lll}
\hline Materiales & - & Folios \\
& - & Bolígrafos \\
& - & Cuaderno de vida \\
\hline Evaluación & - & Observación directa \\
& - & Autoevaluación \\
\hline
\end{tabular}

Actividad 18: Gestión del tiempo libre

Saber planificar nuestro ocio sano y pleno, hacer lo que nos gusta y formar parte de un espacio y un tiempo en el que ser nosotros y nosotras de forma plena es esencial. Por lo que gestionar un ocio de calidad es imprescindible.

\begin{tabular}{lll}
\hline Objetivos & - & Planificar actividades que hagan sentirse bien personalmente \\
& - & Gestionar su ocio y tiempo libre \\
\hline Competencias & - & Habilidad para generar, diseñar e implementar conocimiento aplicado e instrumental que se ajuste \\
& & a las necesidades de los casos y del mundo real \\
\hline Destinatarios & - & Menores Extranjeros No Acompañados (16 a 18) \\
& - & Jóvenes extutelados (18-25) \\
\hline Temporalización & - & 50 minutos \\
\hline Modalidad & - & Individual y grupal \\
\hline Desarrollo & La presente actividad se comenzará por una lluvia de ideas "brain storming" donde cada participante \\
& deberá decir al menos 3 ideas sobre qué hacer cuando tenemos tiempo libre y que es para nosotros el \\
& ocio. \\
& Una vez finalizado esto, se les dividirá en grupos de 3 y cada grupo realizará una tabla de las posibles \\
& actividades en las que se puede investir el tiempo de ocio, especificando cuales les motiva a cada uno. \\
\hline
\end{tabular}


Todos y todas las participantes deben llegar a un acuerdo sobre cuáles son las actividades que se pueden hacer en el tiempo libre. Algunas actividades que se pueden proponer son: senderismo, escalada, cine, escape rooms

Una vez realizado el cuadrante, cada uno y con ayuda del grupo deberá escribir la información que tenga sobre esa actividad, jugadores, dinero que ganan, experiencias personales, beneficios, jtodo vale! Mas tarde cada grupo expondrá su cuadrante y cada uno de forma individual contará a sus compañeros y compañeras todo lo que sabe sobre esa actividad, pudiendo intervenir los demás grupos para enriquecer la información.

Finalmente se realizará una reflexión individual, anotando como se ha sentido en el cuaderno de vida, y que actividad le gustaría comenzar, cuáles son las inquietudes de los participantes, poniendo los pros y los contras para poder valorarlo personalmente.

\begin{tabular}{lll}
\hline Materiales & - & Cuaderno de vida \\
& - & Bolígrafos \\
\hline Evaluación & - & Observación directa \\
& - & Autoevaluación \\
\hline
\end{tabular}

\section{Actividad 19: ¡Te necesito!}

Crear un ambiente donde el trabajo en equipo sea primordial y donde se considere que cada uno puede aportar al grupo diferentes aspectos que resultarían útiles, todos y todas somos importantes y hay que ser conscientes de la importancia que tiene este aspecto en el mundo laboral.
Objetivos
- Ayudar a que cada integrante reconozca sus cualidades y capacidades

- Brindar la oportunidad de que las personas puedan reconocer los valores con que se vinculan

- Promover que los participantes identifiquen en los demás los aspectos positivos

\begin{tabular}{lll}
\hline Competencias & $\bullet$ & $\begin{array}{l}\text { Habilidades necesarias para el ejercicio profesional autónomo, con iniciativas } \\
\text { instrumentales (ajuste, tolerancia, respeto) }\end{array}$ \\
\hline Destinatarios & $\bullet$ & Menores Extranjeros No Acompañados (16 a 18) \\
& $\bullet$ & Jóvenes extutelados (18-25) \\
\hline Temporalización & $\bullet$ & 50 minutos \\
\hline Modalidad & $\bullet$ & Individual y grupal
\end{tabular}

Desarrollo La o el educador deberá comentar a los grupos que cada integrante de este debe de imaginarse que durante 7 meses se irán a un viaje de negocios en otro país y deben seleccionar cuales serían las personas que los acompañarían y formar así una comitiva.

Cada integrante podrá elegir a 5 compañeros y compañeras para irse al viaje de negocios. En la elección deben remarcar porque eligen a cada uno y que capacidades o cualidades ve en el que le puedan resultar interesante para realizar ese trabajo.

Se les asignara 30 minutos para que cada participante reflexione acerca de su comisión y de las cualidades que resultarían más interesantes para ese trabajo.

Mas tarde y una vez finalizada la primera parte se otorgan 15 minutos para que de forma individual se acerque a cada compañero y cuenten porque le han elegido, sin llegar a ponerlo en común. Para finalizar, se otorgarán 10 minutos de reflexión y debate grupal donde se ofrecen unas posibles preguntas guía:

- ¿Cómo me he sentido con los comentarios de mis compañeros?

- ¿ ¿Soy consciente de cómo y por qué puedo influir en otra persona?

- ¿ ¿Era consciente que contaba con esas capacidades y/o cualidades que otros han valorado?

- ¿Cómo me siento al saber que puedo resultar útil para otras personas que me necesitan?

A partir de estas preguntas se realizará un debate grupal sobre la actividad, y se dejaran unos minutos para rellenar la reflexión individual en el cuaderno de vida. Finalmente, para concluir la propuesta, se pasará a forma de pos-test la evaluación de la propuesta para que se rellene por cada participante de forma individual.

\begin{tabular}{lll}
\hline Materiales & - & Folios \\
& - & Bolígrafos \\
& - & Cuaderno de vida
\end{tabular}

Evaluación $\quad-\quad$ Observación directa


Evaluación de la propuesta

\section{RECURSOS}

Para llevar a cabo la propuesta de intervención es necesario:

Recursos materiales:

- La impresión del "Cuaderno de vida".

- Una sala amplia con mesas y sillas.

- Material fungible: Cartulinas, folios, bolígrafos, rotuladores, ovillos de lana, cajas de zapatos, espejo grande, colchonetas, tizas, folios de colores, sobres, revistas.

Recursos humanos:

- Trabajador/a social y /o Educador/a social del centro de menores o piso tutelado

- Persona externa que haya sido menor extranjero no acompañado y que acceda a contar su experiencia.

\section{EVALUACIÓN}

En este apartado se desarrolla la metodología planificada para la evaluación de la propuesta de intervención con el fin de orientar y permitir efectuar juicios de valor necesarios para la toma de decisiones. La evaluación se trata del proceso de análisis que utilizaran los profesionales que trabajen dicha propuesta para comprobar que el cumplimiento de los objetivos se va desarrollando correctamente, para la permanente y progresiva adecuación de los objetivos, estrategias, estilos, medios y recursos materiales a las necesidades, características y perfiles de los participantes a los que va dirigida.

En este sentido, se evaluarán a través de diferentes herramientas, la evaluación de los objetivos y logros con la Autoevaluación, en segundo lugar la evaluación del proceso, valorando la calidad de la propuesta, esta evaluación permitirá detectar mejoras o necesidades que deban incluirse en la propia puesta en marcha de la propuesta, suponiendo así una mejora continua, por último la evaluación de los resultados, donde se pretende evaluar el impacto que ha tenido la propuesta en la vida de los jóvenes.

Se trata de un proceso de evaluación sistemática y flexible, además se trata de una evaluación continua con la que se podrán corroborar si se está llegado o no a los objetivos planteados previamente, para poder si es necesario realizar las modificaciones pertinentes a lo largo del transcurso de la propuesta, por lo que se irán supervisando los procesos a la vez que se va produciendo una continua retroalimentación. Tiene un carácter formativo, la riqueza y características de la propuesta ha obligado a que se plantee una evaluación cualitativa a través de preguntas cortas y cuantitativa con ítems a valorar con una escala Likert del 1 al 5.

Se considera importante establecer unos criterios de evaluación relacionados con los objetivos de la propuesta y de las actividades a partir de unas normas preestablecidas que servirán como referencia para establecer la buena marcha o no del proceso. Se utilizarán para ello criterios de pertinencia para conocer el grado de adecuación de la propuesta con el contexto, criterios de actualización para averiguar la adecuación de los objetivos del programa y las necesidades reales y criterios de eficacia para medir el nivel de logro de los objetivos. 
Para la planificación de la evaluación se ha tenido en cuenta la delimitación del objeto de evaluación, adaptándose, teniendo en cuenta el contexto y los destinatarios. Herramientas de evaluación a corto plazo de la propuesta de intervención:

- Observación directa por parte de los educadores, que se reflejará en el Registro de las sesiones y que se deberá ir completando de forma individualizada para todos los participantes de la intervención, valorando el grado de compromiso de cada uno/a.

- Autoevaluaciones que se desarrollan en cada una de las actividades para conocer la perspectiva de los participantes.

Con el fin de conocer los resultados globales y por lo tanto a medio/largo plazo de la propuesta de intervención, la evaluación de la propuesta de intervención esta ajustada con los objetivos que se pretenden conseguir con la puesta en marcha de la propuesta:

- Test de evaluación, el cual se realizada según el cronograma la primera y la última sesión de la intervención, comparando los resultados de este, consta de una serie de indicadores y criterios a valorar del 1 al 5 y unas preguntas cortas.

- Rúbrica para la evaluación del programa, realizada de forma conjunta por los educadores/as que lleven a cabo el programa, con el fin de obtener información desde los diferentes profesionales que lleven a cabo el proceso de intervención.

Finalmente se elaborará un informe evaluativo con los resultados de estas evaluaciones. Proporcionando una visión clara y estructura de todo el proceso. Esta evaluación ha de plantearse, en todo caso, con una finalidad esencialmente formativa, lo que implica que ha de llevarse a cabo con el propósito firme de utilizarla para mejorar los resultados, para optimizar el proceso de ejecución y, si fuera preciso, para reconsiderar los objetivos propuestos.

\section{DISCUSIÓN Y CONCLUSIONES}

La propuesta de intervención presentada en este estudio favorecerá el autoconcepto positivo de los participantes, además de la autonomía y la emancipación de estos mejorando su inserción laboral y preparando a los jóvenes para que adquieran habilidades y capacidades necesarias para la vida independiente.Sobre los posibles resultados al poner en marcha el programa y al tratarse de una propuesta de intervención flexible y evaluada se puede adaptar a las necesidades individuales de los participantes.

Es imprescindible fomentar el autoconcepto positivo a la hora de trabajar la transición a la etapa adulta, con actividades que fomenten el trabajo en grupo ya que se coincide por lo tanto en la idea de González (2010) sobre que el mayor riesgo es una valoración social en el grupo y sobre el grupo sea negativa, lo que atendiendo al autoconcepto conlleva a una identidad social negativa o amenazada. Se afirma la idea por lo tanto de que hay parte del autoconcepto de las personas que proviene de percibirse como miembro dentro de diferentes categorías sociales concretas, este tiene un alto componente valorativo y emocional y genera comportamientos intergrupales coincidiendo así con la Teoría de la Identidad Social (Botella y Mas, 2004, citado por González, 2010).

Se coincide con la necesidad de trabajar sus expectativas ya que muchas veces se muestran frustrados por la imposibilidad de cumplir las expectativas que han depositado en ellos/ ellas por parte de sus familias, lo que conduce a la baja autoestima, autopercepción negativa y desmotivación (APDHA, 2009; Blancas y Jurado, 2010; Martínez, Sahanuja, Santoja, 2007). 
En dicho estudio se asume una relación lineal entre el autoconcepto y el comportamiento antisocial y delictivo, coincidiendo con estudios que advierten que los adolescentes con bajo autoconcepto manifiestan más conductas amenazantes o intimidatorias sobre los demás (e.g., Rugby y Slee, 1993, citado en Vázquez, Mohamed-Mohand y Vilariño, 2008), y mantienen mayores niveles de conducta delictiva (e.g., Weist, Paskewitz, Jackson y Jones, 1998, Vázquez, Mohamed-Mohand y Vilariño, 2008). Así es que poseer una percepción positiva de uno mismo a través de diferentes propuestas es un indicador de protección frente a la implicación de conductas desviadas coincidiendo con Ruiz, Lozano y Polaino (1994, citado en Vázquez, Mohamed-Mohand y Vilariño, 2008).

En base a esta propuesta de intervención y la puesta en marcha de ambos módulos se conseguirá evitar ciertas conductas negativas ante la sociedad, coincidiendo con algunos estudios que citan que los adolescentes con un alto autoconcepto tienen una buena adaptación social y tienen conductas prosociales de ayuda y de respeto social (e.g., Calvo, González y Martorell, 2001; Garaigordobil, Cruz, y Pérez, 2003; Gutiérrez y Clemente, 1993; Rugby y Slee, 1993, citado en Vázquez, Vázquez, Mohamed-Mohand y Vilariño, 2008), así es que un elevado autoconcepto puede modular el impacto negativo de problemas psicológicos y de conducta (Garaigordobil, Durá, y Pérez, 2005, citado en Vázquez, Mohamed-Mohand y Vilariño, 2008).

Se concluye con que existen diversos programas y proyectos de intervención con respecto a la emancipación y al ámbito laboral como el programa Umbrella (Bravo y Del Valle, 2009) que avalan y coinciden con este estudio en la importancia de trabajar la autonomía con menores extranjeros no acompañados. En esta línea y coincidiendo con la idea de FEPA (2014), al trabajar el proceso de la emancipación se hacen visibles tanto las propias fortalezas como las debilidades por lo que se confirma en este estudio que es preciso planificar un plan progresivo de acción para acompañar al sujeto hacia su vida autónoma teniendo presente sus circunstancias, intereses y necesidades personales.

El papel del psicopedagogo en este contexto tendría el objetivo de fomentar un contexto en el que cada menor pueda ser evaluado teniendo en cuenta sus características como grupo e individuales, para otorgarles itinerarios personalizados a sus objetivos personales y a sus necesidades coincidiendo con la línea de Arnau y Gilligan (2015) de que los procesos de inserción laboral son fruto de una serie de procesos complejos propios de cada caso, no existiendo casos idénticos.

Afirmando en el presente estudio que aquellos jóvenes que han tenido una infancia marcada por problemas familiares, sociales o con carencias en sus necesidades básicas pueden ver afectado su autoconcepto e identidad personal, lo que puede condicionar las propuestas de intervención dirigidas a la formación para su autonomía.

Finalmente, se concluye con que para todos los jóvenes la transición a la vida adulta es un proceso con múltiples dificultades, pero en el caso de los Menores Extranjeros No Acompañados aún lo, es más, derivando en muchas ocasiones en conductas antisociales, por lo que trabajar a través de propuestas de intervención es imprescindible favorecer progresivamente un autoconcepto positivo para mejorar los conocimientos y habilidades necesarias para enfrentarse a la vida independiente. A través de propuestas dirigidas a mejorar el autoconcepto positivo en adolescentes y actividades centradas en las características personales positivas se puede facilitar la intervención de otros problemas como es en este caso la preparación para la vida independiente y su integración en un entorno sociolaboral. Se confirma que existe gran cantidad de literatura en base a los Menores Extranjeros No Acompañados y extutelados, por lo que es necesario aprovechar ese 
conocimiento que aporta la investigación en la elaboración de respuestas efectivas como propuestas de intervención.

\section{LIMITACIONES}

El programa no se ha podido llevar a cabo de forma presencial debido a la situación de pandemia actual. Esta se convierte en una de las mayores flaquezas de la presente investigación, ya que la presencialidad y puesta en práctica de la propuesta hubiese resultado beneficiosa para los resultados del estudio. La otra limitación con la que se puede encontrar la propuesta es debido a las diferencias culturales y diferencias idiomáticas de los jóvenes, debido en muchos casos al ingreso en los centros con edades próximas a la mayoría de edad.

\section{FUTURAS LINEAS DE INVESTIGACIÓN}

El estudio abre nuevas vías de investigación, la primera se trata de seguir trabajando en esta línea investigando acerca de las necesidades y posibilidades de intervención una vez se hayan emancipado, la segunda posible línea de investigación, seria analizar la calidad de las intervenciones que se están desarrollando, así como incentivar el desarrollo y análisis de las necesidades individuales y colectivas para poder dar una respuesta adaptada, lo cual resultaría interesante y necesario para la administración.

\section{REFERENCIAS}

Aguaded- Ramírez, E. y Angelidou, A. (2017). Menores extranjeros no Acompañados. Un fenómeno relevante en la sociedad española. La perspectiva de los trabajadores en los centros de acogida. Revista de Educación de la Universidad de Granada, 24, 47-63.

Alarcón, A. (2012). Estilos parentales de socialización y ajuste psicosocial de los adolescentes: un análisis de las influencias contextuales en el proceso de socialización. [Tesis doctoral, Universidad de Valencia]. Repositorio de Contingut Lliure.

Alto Comisionado de las Naciones Unidas para los Refugiados -ACNUR. (2004). Declaración de Buenas Prácticas. Alianza Internacional Save the Children y ACNUR.

Arnau, L. y Gilligan, R. (2015). What helps young care leavers to enter the world of work? Possible lessons learned from an exploratory study in Ireland and Catalonia. Children and Youth Services Review, 53, 185191.

Asociación Pro-Derechos Humanos de Andalucía (2009). Informe "Jóvenes de origen inmigrante extutelados en la ciudad de Córdoba". Observatorio de la Infancia en Andalucía.

Azorín, C. (2019). Diseño y evaluación de un plan para la atención del alumnado inmigrante con desconocimiento del español. Contextos educativos,23, 179-197.

Belattar, A. (2014). Menores migrantes no acompañados: Victimas 0 Infractores. Revista sobre la infancia y la adolescencia,7,25-39.

Bendit, R. y Hahn-Bleibtreu, M. (2008). Youth transitions: processes of social inclusión and patterns of vulnerability in a globalized Word. Budrich: Leverkusen-Opladen

Bhabha, J. (2011). Children without a state: A global human rights challenge. Cambridge: MIT Press.
Bicochi, L. y Levoy, M. (2008). Los niños indocumentados en Europa: victimas invisibles de las restricciones a la inmigración, Bruselas, Platform for International Cooperation on Undocumented Migrants.

Blancas, R. y Jurado, G. (2010). Estrategias de intervención social con jóvenes inmigrantes ex tutelados por el Servicio de Protección de Menores. Revista de Trabajo Social y Acción Social,47, 134-142.

Bravo, A. y Del Valle, J. (2009). Crisis y revisión del acogimiento residencial. Su papel en la protección infantil. Papeles del Psicólogo, $30(1), 42-52$.

Bravo, A. y Santos- González, I. (2017). Menores extranjeros no acompañados en España: necesidades y modelos de intervención. Psychosocial Intervention,26, 55-62.

Bravo, A., Santos, I. y Del Valle, J. (2010). Revisión de actuaciones llevadas a cabo con menores extranjeros no acompañados en el Estado Español. Observatorio de la infancia de Asturias.

Buendia, L; Colás, Ma P. y Hernández, F. (1998). Métodos de Investigación en Psicopedagogía. McGraw-Hill.

Burns, R. (1990). El autoconcepto. Bilbao: EGA.

Cazalla-Luna, N. y Molero, D. (2013). Revisión teórica sobre el autoconcepto y su importancia en la adolescencia. Revista Electrónica de Investigación y Docencia,10, 43-64. Doi: $10.17561 /$ reid

Centro Nacional de Desaparecidos (2020). Informe de personas desaparecidas, 2020. Ministerio del Interior, Gobierno de España.

Coelho, V. A., Marchante, M. y Jimerson, S. R. (2017). Promoting a Positive Middle School Transition: A Randomized-Controlled Treatment Study Examining Self- Concept and Self-Esteem. Journal of Youth and Adolescence, 46(3), 558-569. 
Colás, Ma.P. (1998). Métodos y técnicas cualitativas de investigación en psicopedagogía. Métodos de investigación en psicopedagogía, 251286. Madrid: McGraw-Hill.

Crary, E. (1994). Crecer sin peleas. Cómo enseñar a los niños a resolver conflictos con inteligencia emocional. Ed. Integral, Barcelona, 192.

D'Ágata, E. (2011). Calidad de vida en los adolescentes con escoliosis idiopática: una comparación transcultural entre métodos de intervención. [Tesis doctoral. Facultad de Psicologia, Ciencias de la Educación y del Deporte, Blanquernal Tesis Doctorals en Xarxa.

Díaz, M. (2017). Menores refugiados: impacto psicológico y salud mental. Apuntes de Psicología, 35(2), 83-91.

Esnaola, I., Goñi, A. y Madariaga, JM. (2008). El autoconcepto: perspectivas de investigación. Revista de psicodidactica, 13(1), 69-96.

Europa Press (2020, 15 de febrero)2018 cierra con al menos 12.500 menores extranjeros solos, mientras el Gobierno negocia con Marruecos su retorno. Europa Press.

FEPA. (2014). Jóvenes Extutelados: el reto de emanciparse hoy. Dossiers del Tercer Sector, 33.

FEPA. (2015). Jóvenes Extutelados: el reto de emanciparse hoy en día. Dossiers del Tercer Sector, 41.

Fernández, L. (2014). Relaciones entre las prácticas parentales y los estilos de socialización familiar en la cultura española: El modelo bidimensional parental y el ajuste de los hijos. [Tesis doctoral. Facultad de Psicología. Universidad de Valencia]. Repositori de contingut lliure.

Fernández, R. (2021a, 12 de abril). Distribución porcentual de los menores extranjeros no acompañados registrados en España en 2019, por país de origen. [Grafica]. Statista.

Fernández, R. (2021b, 12 de abril). Menores extranjeros no acompañados acogidos en España en 2019 por género y tipo de acogida. [Grafica]. Statista.

Fernández, R. (2021c, 12 de abril). Menores migrantes inscritos en el Registro de Menores Extranjeros no Acompañados (MENA) de España en diciembre de 2019, por comunidad autónoma. [Grafica]. Statista.

Fernández, R. (2021d, 12 de abril). Número de menores extranjeros no acompañados fugados de centros de acogida en España entre 2015 y 2019. [Grafica] Statista.

Fernández-Lasarte, O., Goñi, E., Camino, I. y Zubeldia, M. (2018). Ajuste escolar y autoconcepto académico en la Educación Secundaria. Revista de Investigación Educativa, 37(1).

Fiscalía General del Estado (2019). Memoria de la Fiscalía 2019. Ministerio de Justicia. Gobierno de España, Imprenta Nacional de la Agencia Estatal Boletín Oficial del Estado.

Fuentes, R. (2014). Menores extranjeros no acompañados (MENA). Azarbe. Revista Internacional de Trabajo Social y Bienestar,3, 105-111.

Galindo-Domínguez, H. (2019). Estandarización por curso y género de la escala de autoconcepto AF-5 en educación primaria. Psicología Educativa,25(2), 117-125.
Garaigordobil, M., Durá, A. y Pérez, J. I. (2005). Síntomas psicopatológicos, problemas de conducta y autoconcepto-autoestima: Un estudio con adolescentes de 14 a 17 años. Anuario de Psicología Clínica y de la Salud, 1, 53-63.

García, F. y Musitu, G. (2001). Autoconcepto Forma 5. Madrid. Ediciones TEA.

Garcia, F. y Musitu, G. (2014). Autoconcepto Forma 5. Madrid. Ediciones TEA.

Giménez, C. y Suárez, L. (2000). Menores no acompañados que han entrado en territorio español sin representación legal. Programa "Migración y Multiculturalidad" UAM.

González, A. (2010). Evolución del papel de las entidades de acción social y del educador social en la atención de los Menores Migrantes no Acompañados. Educación social. Revista de intervención socioeducativa, $45,166-183$

González, O. (2005). Estructura multidimensional de autoconcepto físico. Revista de Psicodidáctica,10, 121-130.

Harter, S. (1990). Problemas en la evaluación del autoconcepto de los niños y adolescentes. Cognitive Therapy and Research,14(2), 113-142.

Ibabe, I. (2016). Academic failure and child-to-parent violence: family protective factors. Frontiers in Psychology, 7, 1-11.

Íniguez Ma.S. (2016). Influencia de la familia en el autoconcepto y la empatía en los adolescentes. [Tesis doctoral. Desarrollo personal y participación social. Universidad de Valencia]. Repositorio de Contingut Lliure.

Lázaro, I y Morroy, B. (2010). Los menores extranjeros no acompañados. Madrid: TECNOS

López, M., Santos, I., Bravo, A. y del Valle, J.F. (2013). El proceso de transición a la vida adulta de jóvenes acogidos en el sistema de protección infantil. Anales de psicología, 29(1), 187-196.

Martínez, A. (2011). Menores marroquíes no acompañados: análisis de la situación socio legislativa del sistema de protección andaluz. Actas del I Congreso Internacional sobre Migraciones en Andalucía, Granada: Instituto de Migraciones, 934-942.

Martínez, A., Sanahuja, A. y Santonja, V. (2007). Manual para la intervención psicosocial con menores migrantes. Cuadernos de investigación, 1. Valencia: CeiMigra.

Melendro, M. (2015). Los estudios sobre el tránsito a la vida adulta de jóvenes vulnerables y estrategias para su inclusión social. Revista de estudios de juventud, 110, 201-215.

Mendoza-Pérez, K. \& Morgade-Salgado, M. (2019). "Unaccompanied" Minors? Accompanied Foreign Minors, Families and New Technologies. Int. Migration \& Integration, 20, 121-1236.

Monterde, C. (2013). Expectativas de acogida en el imaginario de los menores que migran solos. Revista electrónica de Investigación y Docencia (REID), 9, 142-158.

Montserrat, C Casas, F. Malo, S y Bertran, I. (2011). Itinerarios educativos de los jóvenes extutelados. Informes, estudios e investigación. Madrid: Ministerio de Sanidad, Política Social e Igualdad. 
Observatorio Argos (2021). Informe de contratación de personas extranjeras. Servicio Andaluz de empleo, Junta de Andalucía.

Observatorio de Emancipación (2020). Balance general, $2^{\circ}$ trimestre de 2019. Consejo de la juventud de España.

Observatorio de la Infancia en Andalucía Junta de Andalucía. (2012) Inmigración. Estado de la Infancia y adolescencia en Andalucía, Cuaderno 2. Consejería para la Igualdad y Bienestar Social. Junta de Andalucía.

OCDE (2017). International Migration Outlook 2017. Paris: OECD Publishing.

Ortega, J. (2019). Menores migrantes: Necesidades educativas y laborales detectadas a través de un estudio cualitativo. Revista de Estudios Socioeducativos, 7, 55-70.

Ospina, G (2015), La inmigración desde el Magreb. Un reto para la Unión Europea. Revista UNISCI,39,151-173

Palacios-Garay, J. y Coveñas-Lalupú, J. (2019). Predominancia del autoconcepto en estudiantes con conductas antisociales del Callao. Revista de Psicología Educativa, 7(2), 325-352.

Pardilla, V. (2017). Análisis crítico del sistema español de protección de los menores extranjeros no acompañados. [Trabajo Fin de Grado, Universidad Miguel Hernández de Elche.] RediUMH.

Parra, A., Oliva, A. y Sánchez-Queija, I. (2004). Evolución y determinantes de la autoestima durante los años adolescentes. Anuario de Psicologia, 35(3), 331-346.

Parrilla, A., Gallego, C. y Moriña, A. (2010). El complicado tránsito a la vida activa de jóvenes en riesgo de exclusión: una perspectiva biográfica. Revista de Educación, 351, 211-233.

Rabazo M. J. (1999). Interacción familiar, competencia socio-escolar y comportamiento disocial entre adolescentes. [Tesis Doctoral, Universidad de Extremadura, Facultad de Educación, Departamento de Psicología y Sociología de la Educación]. Roderic.

Rodríguez, R. (2006). La integración social y laboral de jóvenes que han estado tutelados y tuteladas por la Junta de Andalucía y han cumplido la mayoría de edad. Revista de Estudios de Juventud Jóvenes y educación no formal, 74, 252- 277

Rodríguez, S. (2010). El autoconcepto académico como posibilitador del rendimiento escolar. Revista Psicología Científica 12(17)

Rosenberg, M. (1979). Conceiving The Self . New York, Basic Books

Ruiz, A.C., Palma, M.O. y Vives, L.C (2019). Jóvenes inmigrantes extutelados. El tránsito a la vida adulta de los menores extranjeros no acompañados en el caso español. Ehquidad International Welfare Policies and Social Work Journal, 12, 31-52.

Santana, L., Alonso, E. y García, L.F. (2016). La inserción sociolaboral de jóvenes en riesgo de exclusión social. Revista Española de Orientación y Psicopedagogía, 27(3), 61-75.

Santana, L., Alonso, E. y García, L.F. (2018). Trayectorias laborales y competencias de empleabilidad de jóvenes nacionales e inmigrantes en riesgo de exclusión social. Revista Complutense de Educación, 29 (2), 355-369.
Santana, L., González, O. y García, L.F. (2016). Percepción del empresariado de las competencias y características relevantes para el empleo. Revista Española de Orientación y Psicopedagogía, 27(1), 2946.

Santos- González (2015). Las necesidades psicológicas en los menores extranjeros no acompañados acogidos en España. [Tesis doctoral. Universidad de Oviedo]. Repositorio Institucional de la Universidad de Oviedo.

Save the Children (2016). Infancias invisibles. Informe sobre Menores extranjeros no acompañados, víctima de trata y refugiados en España. Save the Children España.

Save the Children (2018). Los más solos. Los fallos en el sistema de acogida, protección e integración de los menores migrantes no acompañados que llegan a España. Save the Children España.

Save the Children (2021). Crecer sin papeles en España. Save the Children España.

Schmidt, A. (2010). Autoconcepto y Motivaciones Vocacionales en estudiantes de primer año de carreras de Humanidades y Ciencias Exactas $\{$ Tesis doctoral Pontificia Universidad Católica Argentina, Paraná]. UCA.

Senovilla, D (2007). Situación y tratamiento de los menores extranjeros no acompañados en Europa. Observatorio Internacional de Justicia Juvenil.

Shavelson, R., Hubner, J. \& Stanton, G. (1976). Self-concept: Validation of construct interpretations. Review of Educational Research, 46(3), 407441.

Sosa, D. M., Sánchez, S. y Guerrero, E. (2016). Autoconcepto Académico: Modalidades de escolarización, repeticiones de curso y sexo. Revista De Educación, 35(2), 69-82.

Stein, M. (2006). Research review: Young people leaving care. Child and Family Social Work, 11(3), 273-279.

Tassinari, F. (2019). La identificación de los MENAs y el tutor voluntario en Italia: jun modelo a asumir por la UE?. Cuadernos de derecho Transnacional 11(1), 545-570

Tezanos, E. (2009). Juventud y exclusión social. Decimo foro sobre tendencias sociales. Revista de ciencias sociales,212, 138-142.

Uceda, A (2019). La transición a la adultez de los menores extranjeros no acompañados (MENA): cuestión de días. [Trabajo Fin de Grado, Universidad de Almería]. Repositorio UAL.

Unicef (2010). Informe sobre menores no acompañados/as en España. Sueños de Bolsillo. Grupo de investigación IFAM. Madrid: Unicef y Banesto

Unicef (2019). Los derechos de los niños y niñas migrantes no acompañados en la frontera sur española. Madrid: UNICEF Comité Español.

Unicef y CGAE (2009). Ni ilegales ni invisibles. Realidad jurídica y social de los Menores Extranjeros en España. Informe 2009.Madrid. UNICEF.

Vargas, J. (20 de febrero de 2019). Menores migrantes: los hijos e hijas de nadie. Público. 
Vázquez, M.J., Mohamed-Mohand, L y Vilariño, M. (2008). Autoconcepto y comportamiento antisocial: Menores infractores vs. Menores normativos. Revista Galega de Cooperación Científica Iberoamericana, 16, 25-30.

Vera, B., Rosselló, J. y Toro-Alfonso, J. (2010). Autoestima y juventud puertorriqueñas: eficacia de un modelo de intervención para mejorar la autoestima y disminuir los síntomas de depresión. Revista Puertorriqueña de Psicología, 21, 35-61.

\section{REFERENCIAS BIBLIOGRAFICAS LEGISLATIVAS}

Constitución Española de 29 de diciembre de 1978. Publicado en BOE número 311. Referencia: BOE-A-1978-31229.

Convención sobre los Derechos del Niño, (1990). Instrumento de Ratificación de la Convención sobre los Derechos del Niño. adoptada por la Asamblea General de las Naciones Unidas el 20 de noviembre de 1989. Publicado en BOE núm. 313

Decreto 124/2014, de 2 de septiembre, por el que se aprueba el III Plan Integral de Inmigración en Andalucía Horizonte de 2016. Publicado en BOJAN, núm. 172 de 4 septiembre de 2014.

Decreto 355/2003, de 16 de diciembre, del Acogimiento Residencial de Menores. Publicado en BOJA Boletín número 245 de 22 de diciembre de 2003.

Ley 1/1998 de 22 de abril de los Derechos y Atención al menor. Publicado en BOJAN núm. 53 de 12 de mayo de 1998.

Ley $1 / 1998$ de 20 de abril, de los Derechos y la Atención al Menor, «BOE» núm. 150, de 24 de junio de 1998, páginas 20689 a 20702, ha tenido su desarrollo reglamentario a través del Decreto 42/2002 (Régimen de desamparo, tutela y guarda administrativa en Andalucía) y del Decreto 353/2003 (Acogimiento Residencial en Andalucía).

Ley 26/2015, de 28 de julio, de modificación del sistema de protección a la infancia y a la adolescencia. Publicado en BOE número 180 de 29 de julio de 2011
Vidal, M. y Rivera, N. (2007). Investigación-acción. Escuela Nacional de Salud Pública; 21(4).

Wade, J. \& Dixon, J. (2006). Making a home, finding a job: Investigating the early housing and employment outcomes for young people leaving care. Child and Family Social Work, 11(3), 199-208.

Ley Orgánica 1/1996, de 15 de enero, de Protección Jurídica del Menor, de modificación parcial de Código Civil y de la ley de Enjuiciamiento Civil.

«BOE» núm. 15, de 17/01/1996.

Publicado

en

Ley Orgánica 2/2007, de 19 de marzo, de reforma del Estatuto de Autonomía para Andalucía. Publicado en BOE núm. 68 de 19 de marzo de 2007.

Ley Orgánica 4/2000 del 11 de enero, sobre derechos y libertades de los extranjeros en España y su integración social. Publicado en BOE, núm. 10 de 12 de enero de 2000.

Ley Orgánica 8/2013, de 9 de diciembre, para la mejora de la calidad educativa. Publicado en «BOE» núm. 295, de 10 de diciembre de 2013.

Orden de 13 de julio de 2005, por la que se aprueba el Proyecto Educativo Marco para los centros de protección de menores en el ámbito de la Comunidad Autónoma de Andalucía. Publicado en BOJA no 150 de 03 de agosto de 2005.

Ratificación de la Convención sobre los Derechos del Niño, adoptada por la Asamblea General de las Naciones Unidas el 20 de noviembre de 1989. Publicado en BOE núm. 313, de 31 de diciembre de 1990.

Real Decreto 557/2011, de 20 de abril, por el que se aprueba el Reglamento de la Ley Orgánica 4/2000, sobre derechos y libertades de los extranjeros en España y su integración social. Publicado en BOE, núm. 103, de 30 de abril de 2011.

Resolución 97/C 221/03 del Consejo de Europa de 26 de junio de 1997, relativa a los menores no acompañados nacionales de países terceros. Publicado en Diario Oficial de las Comunidades Europeas núm. C 221/23 de 19 de julio de 1997. 